\title{
Guidelines for Pollution Control Equipment Components
}

by

Jearldine I. Northrup

Aaron J. Averbuch

Joyce C. Baird

Mark D. Ginsberg

James $\mathrm{H}$. Johnson

Hannon T. Maase

Veda D. Scarpetta

Pollution control at Army installations has become a key element in the management process as changing policies stringently dictate the treatment and storage or disposal of wastes harmful to public health and the environment. It is the responsibility of installation personnel to ensure that manufacturing wastes emitted to the environment are minimized. One of the means of controlling manufacturing wastes is to use pollution control equipment (PCE) that is an integral part of the manufacturing process. A team of researchers at the U.S. Army Construction Engineering Research Laboratories (USACERL) researched commercially available PCE and identified critical PCE components. Research results were incorporated into a guideline report for installation personnel responsible for designing and purchasing PCE, so that they can procure the most efficient and cost-effective equipment. 


\section{Foreword}

This study was conducted for HQ Industrial Operations Command under Project 4A162720D048, "Industrial Operations Pollution Control Technology"; Work Unit UL-U47, "Enhanced D\&M Pollution Control Equipment." The technical monitor was Rickey Peer, SM CPB-EM.

The work was performed by the Industrial Operations Division (UL-I) of the Utilities and Industrial Operations Laboratory (UL), U.S. Army Construction Engineering Research Laboratories (USACERL). The USACERL principal investigator was J earldine I. Northrup. Walter J . Mikucki was Chief, CECERUL-I; J ohn T. Bandy was Operations Chief, CECER-UL; and Gary Schanche, CECER-UL, was the responsible Technical Director. The USACERL technical editor was William J . Wolfe, Technical Resources.

Dr. Michael J . O'Connor is Director of USACERL. 


\section{Contents}

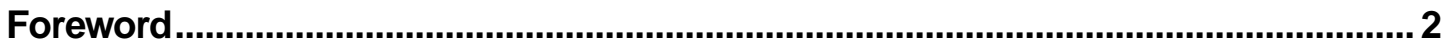

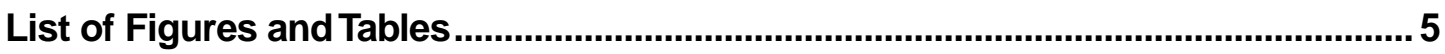

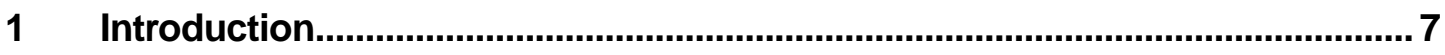

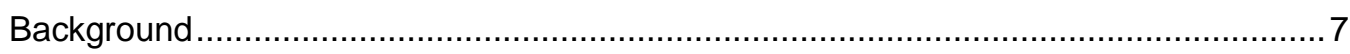

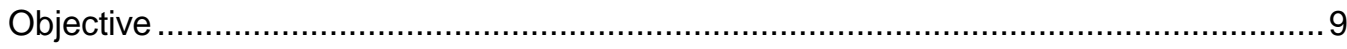

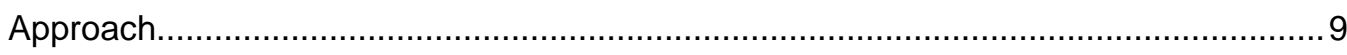

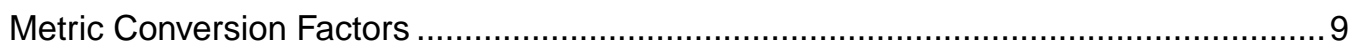

2 Filters - Critical Components of PCE ........................................................10

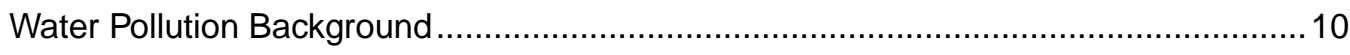

Controlling Water/Liquid Pollution with Filters .................................................... 11

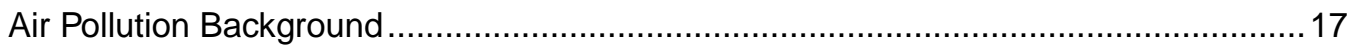

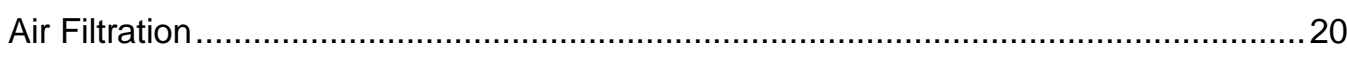

3 Controls-Critical Components of PCE ......................................................... 30

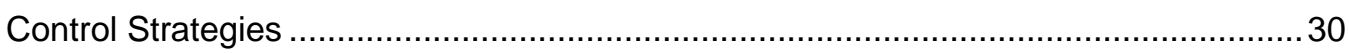

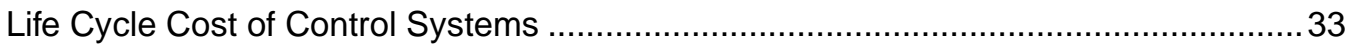

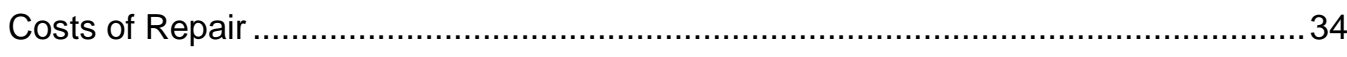

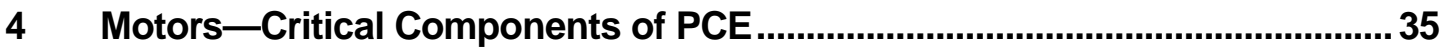

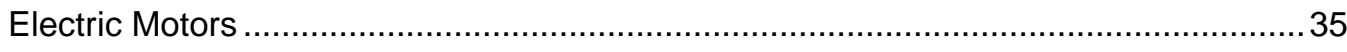

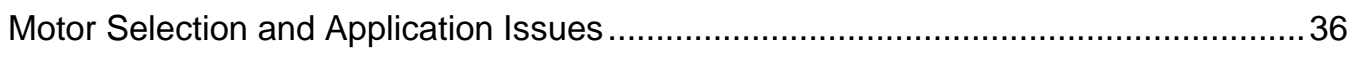

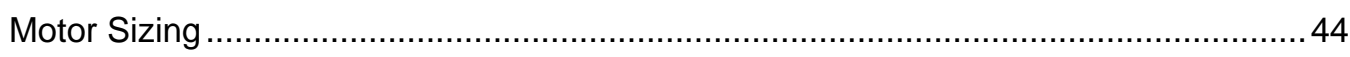

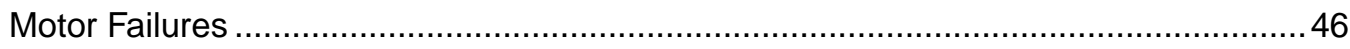

$5 \quad$ Sensors - Critical Components of PCE....................................................... 53

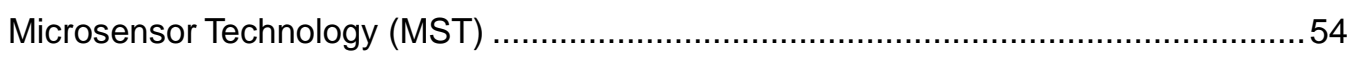

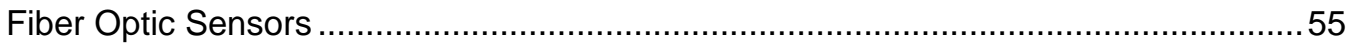

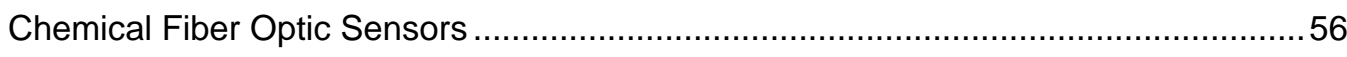

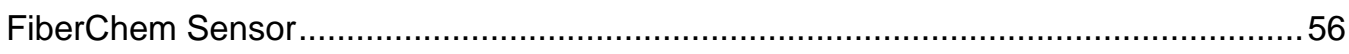

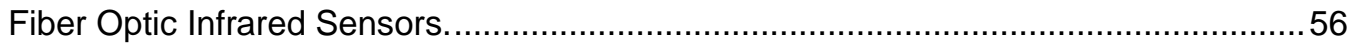

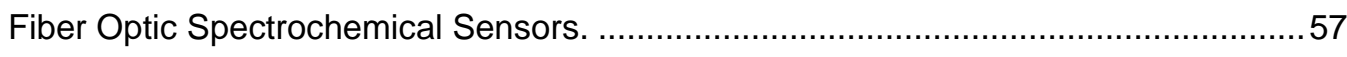

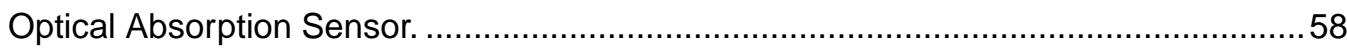




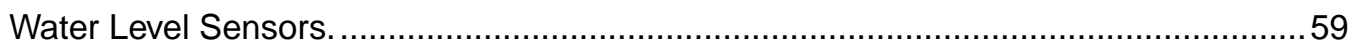

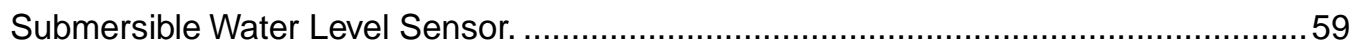

Gas Bubbler Pressure Transmitter/Sensor.........................................................6 60

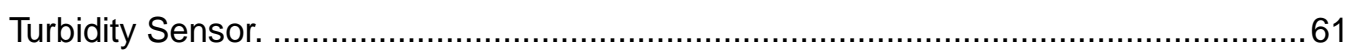

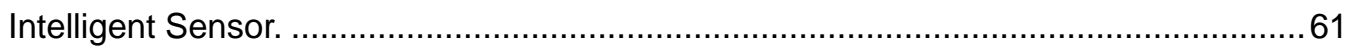

Site Characterization and Analysis Penetrometer System (SCAPS) ............................62

Gas Sensor Array for the Detection of Hazardous Compounds. .................................62

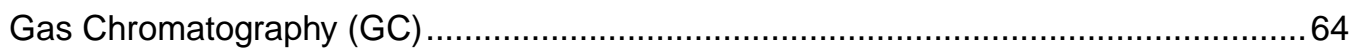

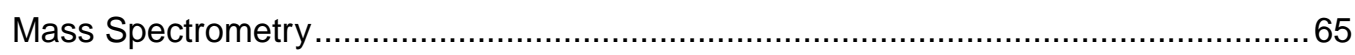

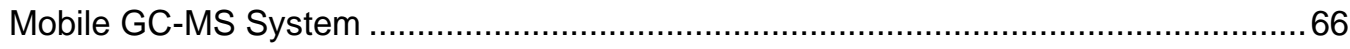

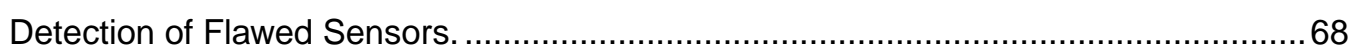

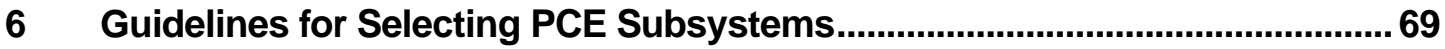

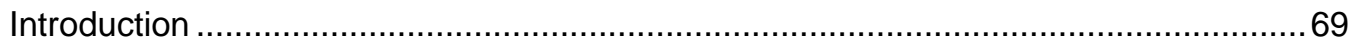

Selecting PCE to Meet Future Requirements .......................................................69

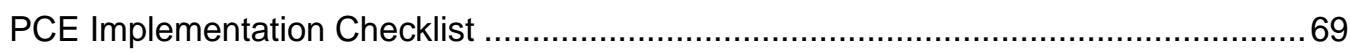

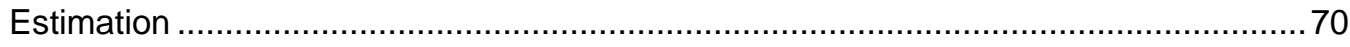

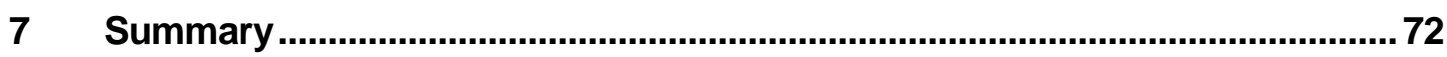

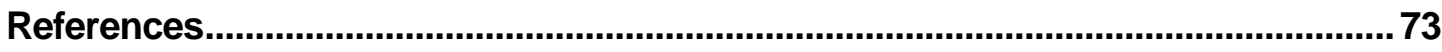

Appendix A: Review of Pollution Control Equipment (PCE) .................................76

Appendix B: Guidelines for Designing PCE

\section{Distribution}




\section{List of Figures and Tables}

\section{Figures}

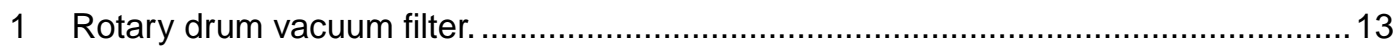

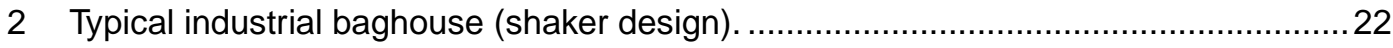

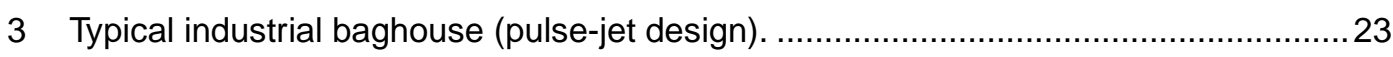

4 Torque-speed characteristics for a standard and energy motor showing the effect of increased speed on power output. ......................................................... 39

5 Motor derating factors due to unbalanced supply voltage........................................ 44

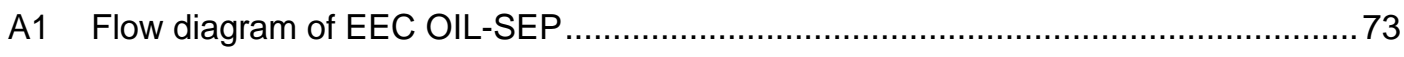

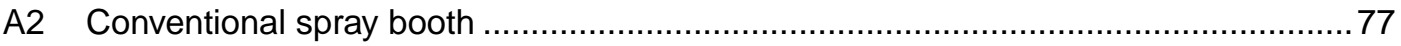

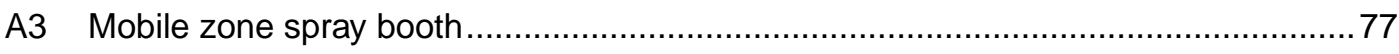

\section{Tables}

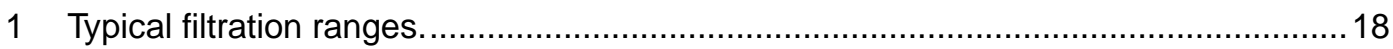

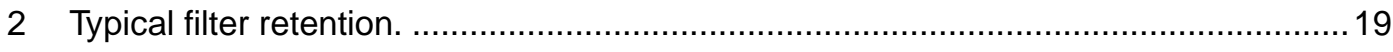

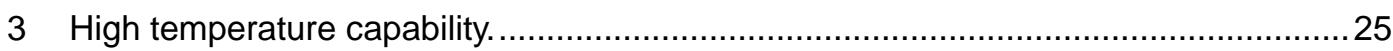

4 General summary of air-to-cloth ratios in various industrial categories. .....................26

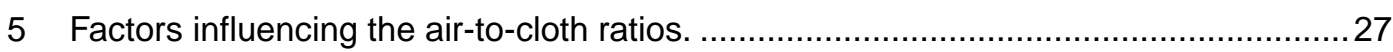

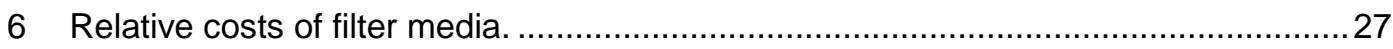

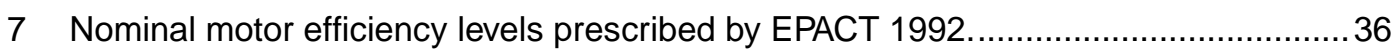

8 NEMA temperature rise requirements for the different insulation classes (fan-

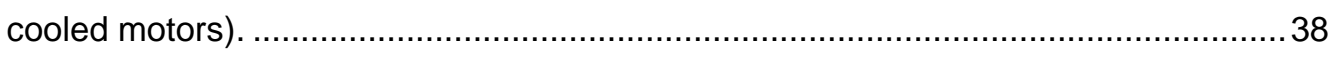

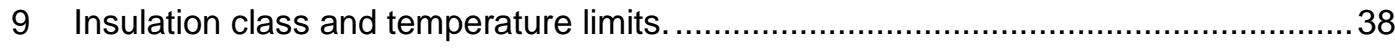

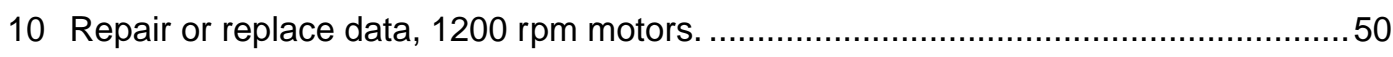

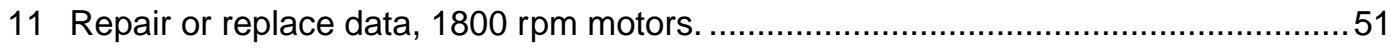

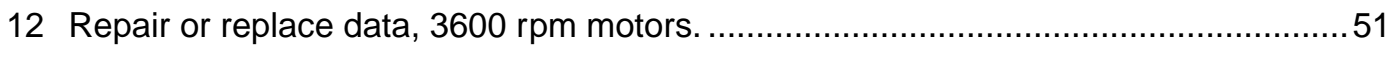

13 Fiber optic infrared sensors by Omega Engineering, Inc........................................58 
14 Research and development on new measuring methods. 63

A1 Army-wide totals for treating and disposing of installation waste (Red Book)..............76

A2 Army Materiel Command (AMC) totals for treating and disposing of installation waste (Red Book). .77

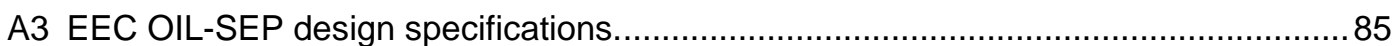

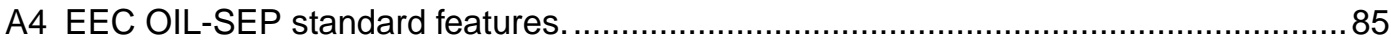

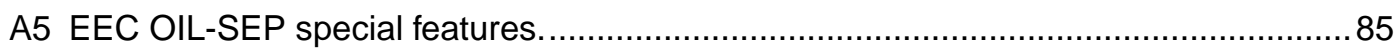

A6 Estimates of savings by installing a recirculating system........................................ 89 


\section{Introduction}

\section{Background}

Many U.S. Army installations perform industrial processes that are subject to the same laws and regulations governing pollutant emissions as commercial, industrial operations. For example, the Pollution Prevention Act of 1990 makes it clear that it is national policy to reduce waste at its source when this is possible. U.S. policy as declared by Congress in 1984 and included in the amended Resource Conservation and Recovery Act (RCRA) states that any waste generated must be treated, stored, or disposed of in a way that minimizes present and future harmful threats to public health and the environment. Such treatment, storage, or disposal of waste are subject to regulations and permit conditions under the Clean Air Act, Clean Water Act, or solid waste regulations.

Such laws and regulations reflect an increasing awareness over the past 20 years of the harmful effects of pollution on human beings and their environment. During this period, engineering and other professions have developed technologies to reduce and/or eliminate pollutant emissions. Certainly, the best way to prevent pollution is to reduce or eliminate waste at its source, and one of the most profitable methods of achieving this is though process change. Efforts to reduce waste at its source can include: (1) the elimination of an operation entirely or in part, (2) modification of the operation, (3) relocation of the operation, (4) application of appropriate pollution control equipment (PCE) technology, or (5) some combination of the preceding four methods.

A common element in most efforts to reduce or eliminate pollution is the fourth item, the use of PCE technologies to verify that pollution is kept at or below target levels. It is essential to maintain PCE in superior order for it to perform the job for which it is designed - controlling waste at its source. Malfunctions in PCE that subsequently produce incorrect readings for emissions can cost an installation up to $\$ 25,000$ per day in fines. 
Army installations possess a variety of PCE. For a number of reasons, these systems are commonly composed of devices that are procured and installed separately. Consider the following typical situations:

- An installation purchases chlorine pumps to treat wastewater, but then finds that it must adjust the flow manually until it can acquire (and install) an automatic chlorine residual analyzer.

- An installation purchases PCE that includes an alarm system, which in turn requires an operator to be present at the location of the alarm. A radio link between the office and the plant must later be installed to remedy the situation.

- An installation uses wet scrubbers to remove particulates. However, the device to monitor the stack gases to see if the scrubbers are working uses an ionization technique. The moisture present in the stack gases causes the device to read high and as a result, the installation will not trust the device. The installation must try to obtain an alternative procedure using differential pressure that would have to be monitored by installation personnel.

Such "real world" situations illustrate common problems arising from the use of PCE. These problems typically involve:

- the incompatibility of add-on parts

- innovative uses of PCE for functions other than the design purpose

- a deficiency of operations and maintenance (O\&M) instructions for PCE

- manual rather than automated controls in PCE

- a lack of understanding of the intricacies of this sophisticated equipment.

These problems have less to do with the capabilities of the equipment or its operation than with the way planners integrate the purchase, installation, maintenance, and continued use of the PCE system. Such problems start-and should be resolved-at the drawing table. Equipment design, written specifications, and scope of work for contractors are all elements that should be foremost in the buyer's mind during pre-purchase planning stages. The design will dictate whether the PCE system will be appropriate for a specific job, whether it can be easily maintained, and ultimately whether it will enable the installations to keep up with pollution control regulations and avoid penalties for violating regulation requirements. While no one can be expected to know all areas of engineering related to the system design of pollution control equipment, a set of general guidelines can help installation planners reduce the common mishaps by ensuring that the appropriate system for a specific job is selected. 


\section{Objective}

The objective of this study was to provide Department of Defense (DOD) installations with implementation guidelines for PCE technologies.

\section{Approach}

1. A literature search was conducted to obtain lists of commercially available PCE and to investigate PCE that may help to curb known pollution emission problems at DOD installations (Appendix A).

2. A study was done to identify critical components of PCE. Researchers with expertise in the identified critical components (sensors, controls, motors, and filters) independently studied these PCE components.

3. Research results were incorporated into an implementation guideline report for DOD installations to help installation personnel select the most cost effective PCE to adequately deal with the pollution emanating from Army manufacturing processes.

\section{Metric Conversion Factors}

The following metric conversion factors are provided for standard units of measure used throughout this report:

\begin{tabular}{|lll|}
\hline $1 \mathrm{in}$. & $=$ & $25.4 \mathrm{~mm}$ \\
$1 \mathrm{ft}$ & $=$ & $0.305 \mathrm{~m}$ \\
$1 \mathrm{mile}$ & $=$ & $1.61 \mathrm{~km}$ \\
$1 \mathrm{sq} \mathrm{ft}$ & $=$ & $0.093 \mathrm{~m}^{2}$ \\
$1 \mathrm{cu} \mathrm{ft}$ & $=$ & $0.028 \mathrm{~m}^{3}$ \\
$1 \mathrm{lb}$ & $=$ & $0.453 \mathrm{~kg}$ \\
$1 \mathrm{gal}$ & $=$ & $3.78 \mathrm{~L}$ \\
$1 \mathrm{psi}$ & $=$ & $6.895 \mathrm{kPa}$ \\
$1 \mathrm{ton}$ & $=0.907 \mathrm{metric}$ ton \\
$\mathrm{lb} / \mathrm{sq} \mathrm{ft}$ & $=4.882 \mathrm{~kg} / \mathrm{m} 2$ \\
${ }^{\circ} \mathrm{F}$ & $=$ & $\left({ }^{\circ} \mathrm{C} \times 1.8\right)+32$
\end{tabular}




\section{Filters-Critical Components of PCE}

\section{Water Pollution Background}

The first instance of using filtration as a means of treating water is attributed to J ohn Gibb, who designed and built an experimental slow sand filter for his bleachery in 1804. Gibb, whose manufacturing plant was in Paisley, Scotland, sold the surplus treated water to the community for a halfpenny per gallon. With the help of others, Gibb improved on the filtration process, and in 1829 the Chelsea Water Company in London with James Simpson adopted the methodology as the water treatment plant constructor. At this time, Simpson had no idea of the complexity of the purification processes of a sand filter. He viewed the sand medium simply as a very effective strainer that mechanically held large particles in the interstices between the sand grains.

The practice of water filtration continued in popularity, and in 1852 the Metropolis Water Act was passed that required all water obtained from the River Thames within 5 miles of St. Paul's Cathedral to be filtered before distribution to the public.

In 1858 in London, the first regular testing of water supplies began, including chemical analyses. This was in response to the discoveries of J ohn Snow, who concluded that cholera was transmitted by water. Filtration and drawing water upstream from the point of any sewer discharge were methods used to avoid transmitting the disease. However, the most conclusive evidence of the effectiveness of water filtration came in 1892 from neighboring towns, Hamburg and Altona, Germany, that both relied on the River Elbe for their respective drinking water supplies. Hamburg used unfiltered water, but Altona filtered its water before use. Subsequently, the water became infected due to a cholera epidemic that caused 7,500 deaths (one death in 30) in Hamburg, while Altona escaped the scourge al most untouched.

In 1885, the first mechanical filters were installed in the United States. Automatic pressure filters were first patented in England in 1899. Since then, many modifications and improvements have been introduced, mainly relating to 
constructional details. Even today biological slow sand filters produce water that is of unsurpassed high quality.

\section{Controlling Water/Liquid Pollution with Filters}

Filters to extract waste from liquids are divided into two general types: pressure and gravity.

\section{Pressure Filters}

Pressure filters consist of closed vessels that contain beds of sand or some other granular material through which water under pressure is forced. These filters have been installed in many public water supplies and are used in certain industrial activities. Although their initial cost is high, they are especially useful in highly automated plants, in remotely located treatment plants that operate with infrequent attendance, and in systems that operate with only a single pumping stage between the inlet and the distribution system.

\section{Gravity Filters}

In general, gravity filters consist of an open-topped box, drained at the bottom and partly filled with a filtering medium, usually clean sand. Raw water enters the space above the sand and flows downward under the action of gravity. During the downward passage of the water, purification takes place and the treated water is discharged through the under-drains. Gravity filters are further divided into slow and rapid categories. Rapid filters operate 20 to 50 times faster than slow gravity filters.

Rapid Filtration. In theory, the rapid filters need only 2 to 5 percent of the area required by the slow filters. In practice however, the reduction in space requirements is partially offset by the pretreatment requirements of the rapid filtration method. The reduction in area is closer to 20 percent.

Slow Filtration. A fine sand is used in slow filtration and the designed rate of downward flow of the water under treatment lies in the range 0.1 to $0.4 \mathrm{~m} / \mathrm{h} / \mathrm{m}^{2}$ of surface. Except in the case of extremely turbid water, a slow filter may run for weeks or even months without cleaning. The suspended solids and colloidal material are deposited at the top of the bed. Operators use hand tools or mechanical equipment to remove the deposited material by scraping off the surface layer to a depth of 1 to $2 \mathrm{~cm}$. Raw water lies in the space above the 
medium for several hours. During this time, the larger particles separate and settle. The water then percolates through the medium for at least 2 hours, during which it undergoes purification.

Rapid filtration uses a coarser medium with grain size of 0.6 to $2.0 \mathrm{~mm}$. Because the spaces between the grains are quite large, there is less resistance to the downward flow, which permits higher velocities within the range 5 to 15 $\mathrm{m}^{3} / \mathrm{m}^{2} / \mathrm{h}$. The impurities are removed more quickly, but they are deposited more deeply into the medium. Some catalytic action occurs, encouraging deposition of iron and manganese in the medium. Since rapid filtration is so fast, it must be used in conjunction with chemical treatment, flocculation, and sedimentation in the early stages to effect bacterial and chemical purification. Frequent cleaning (every 1 or 2 days) is required. To restore both the filter's capacity and the quality of the effluent, the medium should be cleaned throughout its depth. The filter is cleaned by "backwashing," by forcing high-pressure water upward through the bed. Application of compressed air or mechanical agitation can help to scrub the grains and wash away accumulated impurities.

Although mechanical straining is a property of sand filters, a more important attribute is adsorption, which results from electrical forces, chemical bonding, and mass interaction. Adsorption occurs at every surface on which water comes into contact with a sand grain. The aggregate area of these surfaces in $1 \mathrm{~m}^{3}$ of filter amounts to about $15,000 \mathrm{~m}^{2}$. The water passes in a laminar flow that constantly changes direction as it moves from one grain to another. At each change of direction, gravity and centrifugal forces act on the particles of material carried by the water. Every particle, bacterium, and virus in the water is brought into contact with the surfaces of the sand grains to which they become attached by mass attraction or by electrical forces.

\section{Types of Filters for Waste Liquids}

Rotary Drum Filters. These filters constitute the countercurrent-mode type and are of two types: (1) vacuum operated (the majority), or (2) pressure operated (rarely subjected to excessive pumping pressures). The main advantage of these filters is their ability to operate continuously, although total filtration cycles are limited to restricted time intervals. Due to this, it is necessary to maintain almost constant slurry properties. If slurry properties are changing, the required times for completing individual operations of the filtration process may vary widely. 
These filters are usually specified at a submergence rate of 50 percent for separating low-concentration, stratified suspensions. These slurries require only gentle mixing to prevent particle settling. Rotary drum filters are not so useful in handling polydispersions that contain particles with wide size ranges because of fouling by small solids.

Drum Vacuum Filters with External Filtering Surfaces. These filters are characterized by the rate of immersion of the drum into the suspension. The apparatus (Figure 1) consists of a hollow drum (1) with a slotted face and whose exterior contains shallow tray-shaped compartment (2). Over these compartments is placed the filter cloth supported by a grid or heavy screen. The drum rotates on a shaft, one end of which is connected to a drive (3) and the other to a hollow trunion (4) that adjoins an automatic valve (5). The drum is partly immersed in a tank (6) containing the suspension. The cake formed on the outer surface of the drum is removed by means of a scalper (7) as the drum rotates (Cheremisinoff, 18).

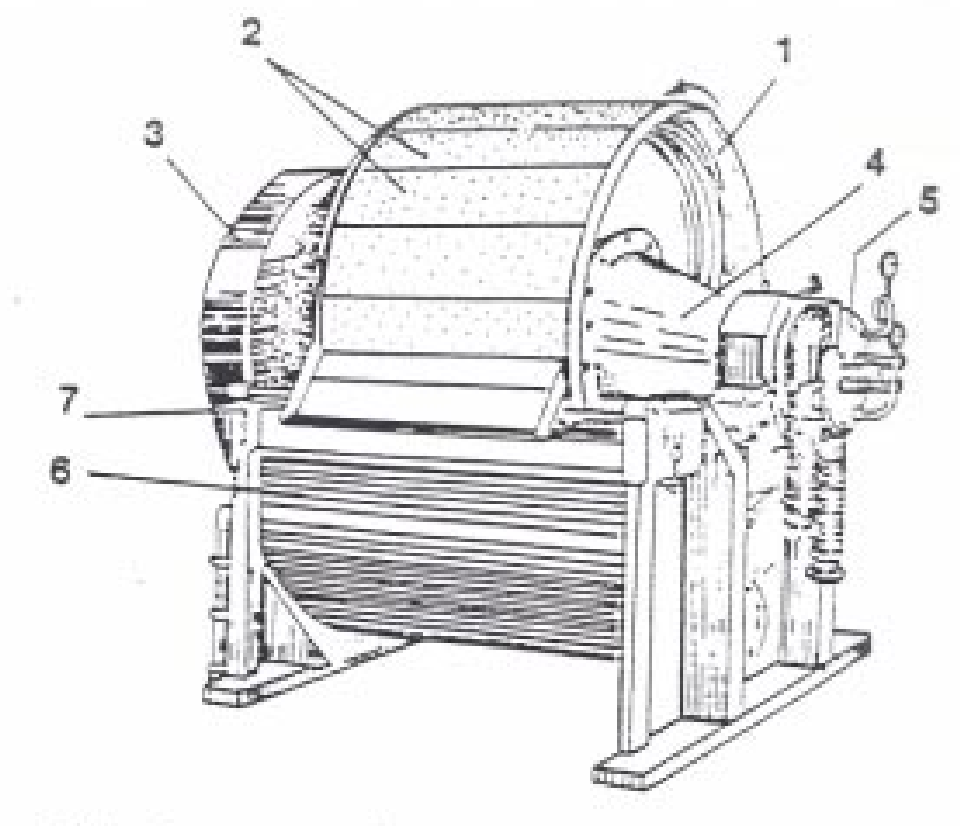

Rotary-dram vacuum filter with extemal fitration sutiaca. 1 = hollow drum; 2 - Eitzation compartments; 3 - drive; 4 = hollow munion, 5 automatic valve; $6=\operatorname{tank}$ for suspension; $7=$ knife for cake scraping.

Cheremisinoff/Cheremisinoff, FILTRATION EQUIPMENTFOR WASTEWATER TREATMENT, (C1993, p. 18. Reprinted by permission of Prentice Hall, Upper Saddle river, New Jersey.

Figure 1. Rotary drum vacuum filter. 
As the drum rotates in a clockwise direction, each compartment goes through the following operations: (1) filtration, (2) first dewatering, (3) washing, (4) second dewatering, (5) cake removal, and (6) cloth regeneration. In the filtration zone, the compartment comes into contact with the suspension. The filtrate is discharged through a pipe connected to a vacuum source and the cake forms on the compartment's surface. In the first dewatering zone, the cake comes into contact with the atmosphere. Because of the vacuum, air is drawn through the cake. To complete filtrate recovery, the compartment remains connected to a collection port on the automatic valve. Nozzles wash the cake during the washing phase, and the wash liquor removed in a collector. In the second dewatering zone, the cake is in contact with the atmosphere and the washing liquid is displaced and delivered to the collector. In the discharge zone, the compartment is connected to a port that is supplied with a compressed air source. This reversal of pressure loosens the cake from the filter medium and the scraper (knife) removes it. In the regeneration zone, compressed air is sent through the cloth, and air enters the compartment through a port. The automatic valve promotes the activation of the filtering, washing, and cake discharge functions of the filter section and provides separate outlets for the filtrate and wash liquid as well as a connection by which compressed air blowback is applied.

Cocurrent Filters. These are top-feed filters that use flat and cylindrical filtering media. This class of filter includes sophisticated internal rotary drum filters, Nutsch filters, horizontal rotary filters, and belt filters. Also, in these filters, the gravity force action and filtrate flow coincides.

- Internal rotary drum filters are suitable for use with rapid settling slurries that do not require a high degree of washing. These filters are also capable of handling heavy, quick-settling materials.

- Nutsch filters have the capability of providing frequent and uniform washings and are of one design type with a flat filtering plate. This design incorporates a large false-bottomed tank and loose filter medium. The false-bottomed tank is of the same design whether used as a vessel for gravity or vacuum filtration. However, greater strength and more refined construction are needed to resist the higher pressure differentials of vacuum over gravity.

- Horizontal rotary filters are designed for filtering quick-draining crystalline solids. Its horizontal surface prevents solids from falling off or being washed away by the wash water, thus allowing a heavy layer of solids to be treated. The apparatus is designed such that a circular horizontal table rotates about a 
central axis. The table is divided into pie-shaped segments that have perforated or woven metal tops and is covered with a filter medium. Each segment is connected to a central valve mechanism that is responsible for timing the removal of filtrate and wash liquids and the dewatering the cake during a revolution. The cake is scraped off the surface by a discharge scroll.

- Belt filters consist of a series of Nutsch filters that move along a dosed path. The advantages of the belt filters are their comparatively simple design and the ability to provide countercurrent cake washing and removal of thin layers of cake. Disadvantages include large area requirements, inefficient use of the total filter area, and poor quality washing at the belt edges.

Cross-Mode Filters. This group includes a vertical flat or cylindrical filtering partition, which makes the filters useful as thickeners because it is convenient to remove cake by reverse filtrate flow.

Filter Presses. The most common filter press is the plate-and-frame design that consists of a metal frame with two end supports held together by two horizontal steel bars. A collection of flat plates with cloth filter media is situated on the bars. The plates are clamped together to form a series of hollow chambers and the plates covered with cloth form the filtering surface. When the press is erected, holes in the fabric are concurrent with holes in the plates and frames to form a continuous channel along the length of the press. As the filterable slurry is pumped through the channel, it fills all of the frames and the filtrate passes through the fabric and out through a discharge cock. In this feed line, the plates consisting of washing and nonwashing types are placed alternately. Initial investment and floor area requirements for the plate-and-frame filters are inexpensive when contrasted with other filter types. However, the labor costs for removing the cakes and the fixed downtime charges may constitute a large percent of the total operating cost per cycle.

Leaf Filters. In leaf filters, the cake is deposited on each side of the leaf, allowing the filtrate to flow to the outlet in channels that run between the cakes. When filtering and when washing, the leaves are immersed in the sludge and wash liquid, respectively. In vacuum filtration, the leaf assembly is immersed in the sludge in open tanks, and in pressure filtration, the leaf assembly may be contained in a shell.

Disk Filters. These filters include a series of concentric disks mounted on a horizontal rotary shaft, and the operation is similar to that of the rotary drum vacuum filters. Compared to the drum vacuum filter, the disk filter occupies considerably less floor space. However, due to the vertical filtering surfaces, the 
disk filter is not as efficient in washing the cakes as is the drum filter. The disk filter is a good choice when the cake is not washed and floor space is not plentiful.

Strainer and Filter Baskets. Strainer and filter baskets are used as prefiltering or prestraining devices to stop the larger contaminated particles and extend the life of the system. Single-stage strainers and bag filters differ only in the design of the basket. Strainer baskets possess solid flat bottoms, whereas baskets for filter bags have perforated bottoms. Fabric bag filters provide removal ratings from 20 mesh to nominal $1 \mu \mathrm{m}$, for both Newtonian and viscous liquids. Strainers should be selected such that the resulting pressure drop does not exceed a determined limit with a clean basket strainer, usually 2 psi.

Diaphragm Filters. The diaphragm filter is a special design of filter presses. These filters can reduce sludge dewatering costs by incorporating a squeezing cycle using a diaphragm. The filter combines an initial pumping and subsequent squeezing cycle that can reduce the process cycle time up to 80 percent. On completion of the pumping and squeeze cycles, the chambers into which the sludge is sent automatically open and the cakes are discharged. After a number of cycles, the filter cloth will need cleaning.

\section{Ultrafiltration (UF)}

Ultrafiltration removes particles in the range from 0.002 to 0.2 microns. To operate UF, pressure drops of 20 to $40 \mathrm{psi}$ or greater are required at flux rates of 300 to $400 \mathrm{gal} / \mathrm{sq} \mathrm{ft}$. Flow is parallel with the filtration membrane (cross flow), and water and low molecular weight (less than 1000) contaminants pass through the membrane. Although UF is a very effective means of filtration, its high capital and operating costs may be deterrents.

\section{Hyperfiltration (Reverse Osmosis or RO)}

Hyperfiltration removes the finest particles including ions ranging in size from 1 to 20 Angstroms ( 0.0001 to 0.002 microns) using semipermeable membranes at high pressure. The important operating parameters of RO are (1) recovery (percent feed converted to permeate); (2) reflux (recycling of the concentrate of dissolved salts for another pass through the RO unit); and (3) rejection (ability to separate dissolved salts from the permeate). The flow is parallel to the membrane in RO units. 


\section{Hints for Filter Media Selection}

Table 1 lists the typical filtration ranges encountered by certain industries including chemical, petroleum, and all industries. Careful media selection is essential. If the media are too coarse, they will not provide the required protection. However, specifying finer media than are needed can substantially increase equipment and operating costs. Some factors that need consideration in media selection are: (1) solids content, (2) type of contaminant to be removed, (3) particle size and shape, (4) viscosity, (5) corrosiveness, (6) abrasiveness, (7) adhesive qualities, (8) liquid temperature, and (9) required flow rate.

Examples of media are wire mesh (typically 10 to 700 mesh), fabric (30 mesh to $1 \mu \mathrm{m}$ ), slotted screens (10 mesh to $25 \mu \mathrm{m}$ ), and perforated stainless steel screens (10 to 30 mesh). Table 2 lists typical particle retention sizes for varying media.

\section{Air Pollution Background}

Concerns about air pollution control extend back at least as far as the thirteenth century. As early as $A D$ 1285, the smoke from the burning of sea coal in limekilns in London created serious problems. In response to the pollution problem, King Edward I in 1307 banned the burning of sea coal in limekilns. This abated the problem, but it reappeared again by the middle of the sixteenth century. Periods of peak air pollution problems in pre-industrial London corresponded to periods of population expansion and "fuel" crises, that is, when sea coal was burned because wood was in short supply or at too high a price.

Unlike water pollution, evidence of the effects of air pollution on health is much less dramatic. In fact, during the 1930s and 1940s, a factory smokestack issuing a thick plume of smoke was considered a status symbol that signified prosperity. Air pollution is unlike water pollution in this respect, since little was done to control air pollution until 1945. The air pollution process involves a source that emits pollutants to the atmosphere. The pollutants are transported, diluted, and modified chemically or physically in the atmosphere, and some finally reach a receptor where they incur damage on health, property, or other parts of the environment.

Between 1945 and 1969, a new awareness of air pollution became apparent and some local efforts to combat it were instated in a few cities including Pittsburgh, Los Angeles, and St. Louis. The Federal government began coordinating these activities between 1963 and 1967, resulting in the Environmental Policy Act and Clean Air Act of 1970. 
Table 1. Typical filtration ranges.

\begin{tabular}{|c|c|c|c|c|c|}
\hline \multicolumn{2}{|c|}{ Chemical Industry } & \multicolumn{2}{|c|}{ Petroleum Industry } & \multicolumn{2}{|c|}{ All Industries } \\
\hline Alum & 60 mesh-60 $\mu \mathrm{m}$ & $\begin{array}{l}\text { Atmospheric } \\
\text { Reduced Crude }\end{array}$ & $25-75 \mu \mathrm{m}$ & Adhesives & 30-150 mesh \\
\hline Brine & $100-400$ mesh & $\begin{array}{l}\text { Completion } \\
\text { Fluids }\end{array}$ & $\begin{array}{l}200 \text { mesh to } 1- \\
3 \mu \mathrm{m}\end{array}$ & $\begin{array}{l}\text { Boiler Feed } \\
\text { Water }\end{array}$ & $5-10 \mu \mathrm{m}$ \\
\hline $\begin{array}{l}\text { Ethyl } \\
\text { Alcohol }\end{array}$ & $5-10 \mu \mathrm{m}$ & DEA & $\begin{array}{l}250 \text { mesh to } 5- \\
10 \mu \mathrm{m}\end{array}$ & Caustic Soda & 250 mesh \\
\hline $\begin{array}{l}\text { Ferric } \\
\text { Chloride } \\
\end{array}$ & 30-250 mesh & $\begin{array}{l}\text { Deasphalted } \\
\text { Oil }\end{array}$ & 200 mesh & Chiller Water & 200 mesh \\
\hline $\begin{array}{l}\text { Herbicide } \\
\text { Pesticide }\end{array}$ & $100-700$ mesh & Decant Oil & 60 mesh & City Water & 500 mesh to $1-3 \mu \mathrm{m}$ \\
\hline $\begin{array}{l}\text { Hydrochl } \\
\text { Acid }\end{array}$ & $\begin{array}{l}100 \text { mesh to } 5- \\
10 \mu \mathrm{m}\end{array}$ & Diesel Oil & 100 mesh & $\begin{array}{l}\text { Clay Slip } \\
\text { (ceramic \& } \\
\text { china) }\end{array}$ & 20-700 mesh \\
\hline $\begin{array}{l}\text { Mineral } \\
\text { Oil }\end{array}$ & 400 mesh & Gas Oil & $25-75 \mu \mathrm{m}$ & $\begin{array}{l}\text { Coal-Based } \\
\text { Synfuel }\end{array}$ & 60 mesh \\
\hline $\begin{array}{l}\text { Nitric } \\
\text { Acid }\end{array}$ & $\begin{array}{l}40 \text { mesh to 5- } \\
10 \mu \mathrm{m}\end{array}$ & Gasoline & $1-3 \mu \mathrm{m}$ & Condensate & 200 mesh to $5-10 \mu \mathrm{m}$ \\
\hline $\begin{array}{l}\text { Phosphor } \\
\text { Acid }\end{array}$ & $\begin{array}{l}100 \text { mesh to } 5- \\
10 \mu \mathrm{m}\end{array}$ & $\begin{array}{l}\text { Hydrocarbon } \\
\text { Wax }\end{array}$ & $25-30 \mu \mathrm{m}$ & Coolant Water & 500 mesh \\
\hline $\begin{array}{l}\text { Sodium } \\
\text { Hydroxid }\end{array}$ & $1-3$ to $5-10 \mu \mathrm{m}$ & Isobutane & 250 mesh & $\begin{array}{l}\text { Cooling-Tower } \\
\text { Water }\end{array}$ & $150-250$ mesh \\
\hline \multirow{2}{*}{$\begin{array}{l}\text { SodiumH } \\
\text { ypo- } \\
\text { chlorite }\end{array}$} & $1-3$ to $5-10 \mu \mathrm{m}$ & MEA & $\begin{array}{l}200 \text { mesh to } 5- \\
10 \mu \mathrm{m}\end{array}$ & $\begin{array}{l}\text { Deionized } \\
\text { Water }\end{array}$ & $100-250$ mesh \\
\hline & & Naphtha & $25-30 \mu \mathrm{m}$ & Ethylene Glycol & 100 mesh to $1-3 \mu \mathrm{m}$ \\
\hline $\begin{array}{l}\text { Sodium } \\
\text { Sulfate }\end{array}$ & 5-10 $\mu \mathrm{m}$ & $\begin{array}{l}\text { Produced } \\
\text { Water for } \\
\text { Injection }\end{array}$ & $1-3$ to $15-20 \mu \mathrm{m}$ & Floor Polish & 250 mesh \\
\hline $\begin{array}{l}\text { Sulfuric } \\
\text { Acid }\end{array}$ & $\begin{array}{l}250 \text { mesh to } 1- \\
3 \mu \mathrm{m}\end{array}$ & Residual Oil & $25-50 \mu \mathrm{m}$ & Glycerine & $5-10 \mu \mathrm{m}$ \\
\hline \multirow{12}{*}{$\begin{array}{l}\text { Synthetic } \\
\text { Oils }\end{array}$} & $25-30 \mu \mathrm{m}$ & Seawater & $5-10 \mu \mathrm{m}$ & Inks & 40-150 mesh \\
\hline & & Steam Injection & $5-10 \mu \mathrm{m}$ & $\begin{array}{l}\text { Liquid } \\
\text { Detergent }\end{array}$ & 40 mesh \\
\hline & & $\begin{array}{l}\text { Vacuum Gas } \\
\text { Oil }\end{array}$ & $25-75 \mu \mathrm{m}$ & Machine Oil & 150 mesh \\
\hline & & & & Pelletizer Water & 250 mesh \\
\hline & & & & $\begin{array}{l}\text { Phenolic Resin } \\
\text { Binder }\end{array}$ & 60 mesh \\
\hline & & & & $\begin{array}{l}\text { Photographic } \\
\text { Chemicals }\end{array}$ & $25-30 \mu \mathrm{m}$ \\
\hline & & & & $\begin{array}{l}\text { Pump Seal } \\
\text { Water }\end{array}$ & 200 mesh to $5-10 \mu \mathrm{m}$ \\
\hline & & & & Quench Water & 250 mesh \\
\hline & & & & Resins & 30-150 mesh \\
\hline & & & & Scrubber Water & 40-100 mesh \\
\hline & & & & Wax & 20-200 mesh \\
\hline & & & & Well Water & 60 mesh to $1-3 \mu \mathrm{m}$ \\
\hline
\end{tabular}


Table 2. Typical filter retention.

\begin{tabular}{|c|c|c|c|c|}
\hline \multirow{2}{*}{$\begin{array}{l}\text { Mesh } \\
\text { Medium } \\
\text { Wire Mesh } \\
\end{array}$} & \multirow{2}{*}{$\begin{array}{c}\text { Mesh or mesh } \\
\text { equivalent }\end{array}$} & \multicolumn{2}{|c|}{$\begin{array}{l}\text { Nominal particle } \\
\text { retention(in.) }(\mu \mathrm{g})\end{array}$} & \multirow{2}{*}{$\begin{array}{c}\begin{array}{c}\text { Percentage of } \\
\text { open area }\end{array} \\
56 \\
\end{array}$} \\
\hline & & 0.065 & 1,650 & \\
\hline & 20 & 0.035 & 890 & 46 \\
\hline & 30 & 0.023 & 585 & 41 \\
\hline & 40 & 0.015 & 380 & 36 \\
\hline & 60 & 0.009 & 230 & 27 \\
\hline & 80 & 0.007 & 180 & 32 \\
\hline & 100 & 0.0055 & 140 & 30 \\
\hline & 150 & 0.0046 & 115 & 37 \\
\hline & 200 & 0.0033 & 84 & 33 \\
\hline & 250 & 0.0024 & 60 & 36 \\
\hline & 400 & 0.0018 & 45 & 36 \\
\hline & 700 & 0.0012 & 30 & 25 \\
\hline \multirow[t]{3}{*}{ Perforated } & 10 & 0.063 & 1,575 & 15 \\
\hline & 20 & 0.045 & 1,125 & 18 \\
\hline & 30 & 0.024 & 600 & 12 \\
\hline \multirow[t]{13}{*}{ Slotted } & 10 & 0.063 & 1,600 & 50 \\
\hline & 15 & 0.045 & 1,140 & 43 \\
\hline & 20 & 0.035 & 890 & 36 \\
\hline & 30 & 0.024 & 610 & 30 \\
\hline & 40 & 0.015 & 380 & 20 \\
\hline & 60 & 0.009 & 230 & 18 \\
\hline & 80 & 0.007 & 180 & 25 \\
\hline & 100 & 0.006 & 150 & 13 \\
\hline & 120 & 0.005 & 125 & 11 \\
\hline & 150 & 0.004 & 75 & 9 \\
\hline & 200 & 0.003 & 50 & 7 \\
\hline & 325 & 0.002 & 25 & 5 \\
\hline & & 0.001 & & 3 \\
\hline \multirow[t]{10}{*}{ Fabric } & 60 & 0.009 & 230 & $\mathrm{NA}^{\mathrm{a}}$ \\
\hline & 80 & 0.007 & 180 & NA \\
\hline & 100 & 0.0055 & 140 & NA \\
\hline & 150 & 0.0046 & 115 & NA \\
\hline & 250 & 0.0024 & 60 & NA \\
\hline & 500 & 0.0016 & 40 & NA \\
\hline & & $0.0010-0.0012$ & $25-30$ & NA \\
\hline & & 0.0006-0.0008 & $15-20$ & NA \\
\hline & & $0.0002-0.0004$ & $5-10$ & NA \\
\hline & & $0.00004-0.00012$ & $1-3$ & NA \\
\hline
\end{tabular}

The five primary criteria pollutants include particulate matter less than $10 \mu \mathrm{m}$ in diameter (PM-10). Others include sulfur dioxide $\left(\mathrm{SO}_{2}\right)$, nitrogen dioxide $\left(\mathrm{NO}_{2}\right)$, carbon monoxide (CO), and particulate lead. A class of compounds known as volatile organic compounds (VOCs) constitutes another major primary criteria pollutant. This class of compounds is important in reactions that form the secondary criteria pollutant ozone. VOCs include all compounds with carbon 
components and with appreciable vapor pressures such as propylene, methane, hydrocarbons, aldehydes, ketones, and chlorinated solvents, with the exception usually of compounds like carbon dioxide. VOCs are regulatory and their definitions vary in different states.

\section{Air Filtration}

Filters divide the flow into smaller parts where they can collect particles. The two types of filters used in air pollution control are surface filters and depth filters. Both surface and depth filters may be used for particle collection. Surface filters are adapted to collect most of the particles in a heavily laden gas stream. Depth filters are used for final cleanup of air or gas.

\section{Surface Filters}

Although surface filters are sometimes used for air pollution control, they are not common, as constructing a filter of this type with holes small enough to collect required particles is a difficult job. Drilling holes of $0.1 \mu \mathrm{m}$ diameter or of constructing fabric with threads separated by $0.1 \mu \mathrm{m}$ is not an easy job. Ceramic filters and matted filters meet the challenge successfully. The resulting filters are however very effective in determining the chemical identity and size distribution of air pollution particles, but are too expensive and delicate for use as industrial cleaners. This kind of filter does not include bags for baghouses. Baghouse filters are woven.

In practice, industrial filters rarely have holes smaller than the smallest particles that they are designed to capture. To overcome this, fine particles are caught at the sides of the holes of a filter, tending to bridge over the holes and make them smaller. As the number of collected particles increases, the cake formed becomes the filter. The original filter medium (usually cloth) no longer acts as the filter, but supports the cake. The cake will have average pore sizes smaller than the diameter of particles in the gas stream and will act as a sieve in which to collect particles on the front surface of the expanding cake.

Fabric filters are designed to remove particulate matter (PM) from a waste gas stream by passing the gas through a porous fabric. For boiler operations, the enclosed structure and supports for the large fabric filters are known as baghouses. They are capable of achieving efficiencies of 99 percent. There are two main baghouse designs: shake-deflate and pulse-jet. 
Shake-Deflate Design. This design includes a large number of cylindrical cloth bags closed at the top and hanging from a support. The lower ends of the bags are slipped over and clamped to cylindrical sleeves that project upward from a plate at the bottom. The dirty gas flows into the space below the plate and moves up inside the bags. As the gas flows outward through the bags, it leaves solids behind. The clean gas continues on into the space surrounding the bags and is sometimes ducted to further processing. This procedure takes place under relatively low gas velocity to assure that the bag fabric does not undergo violent movement. This results in maximum bag life. To remove the cake, the baghouse is taken out of the gas stream, and the bags are shaken by the support to loosen the cake. In addition, sometimes a weak flow of gas in the reverse direction may be used to help dislodge the cake. This causes the bags to deflate and the cake to fall into a hopper at the bottom of the baghouse. Since the baghouse cannot be used to filter gas during the cleaning phase, several baghouses may be used in parallel. Figure 2 schematically shows a shaker baghouse (Cooper, p 191).

Pulse-Jet Design. In the pulse-jet design, the flow during filtration is inward through the bags. These bags are similar to those in the shake-deflate design except that they are open at the top. To prevent collapse, internal wire cages support the bags. The dust cake is removed by applying a pulsed jet of compressed air into the bag, causing the bag to expand suddenly. When the bag reaches its maximum expansion, inertial forces remove the dust. Figure 3 shows the pulse-jet design baghouse (Cooper, p 200).

\section{Filter Media Parameters}

The filter medium used in a filtration system has a direct impact on the particulate removal efficiency, the liability to bag failure and the static pressure drop across the system. Filter performance depends on the selection of the appropriate filter media. The air-to-cloth ratio is a fixed parameter unless modifications are made in the baghouse. The ratio is the result obtained by dividing the volumetric flowrate of the gas ( $\mathrm{cu} f \mathrm{ft} / \mathrm{min}$, where $1 \mathrm{cu} \mathrm{ft}=0.028 \mathrm{~m}^{3}$ ) by the surface area of filter medium. The pressure drop across a filter provides an indication of energy consumption and the need for bag cleaning or replacement. The most important factor for minimizing operating costs is the medium selected for bag construction. This includes compatibility of the selected fiber with the gaseous environment and the physical configuration of the fiber and resulting fabric as it affects filtration capabilities. Filter media are categorized based on the characteristics of the media. The five categories of filter media include woven, felted, membrane, sintered metal fiber, and ceramic honeycomb. 


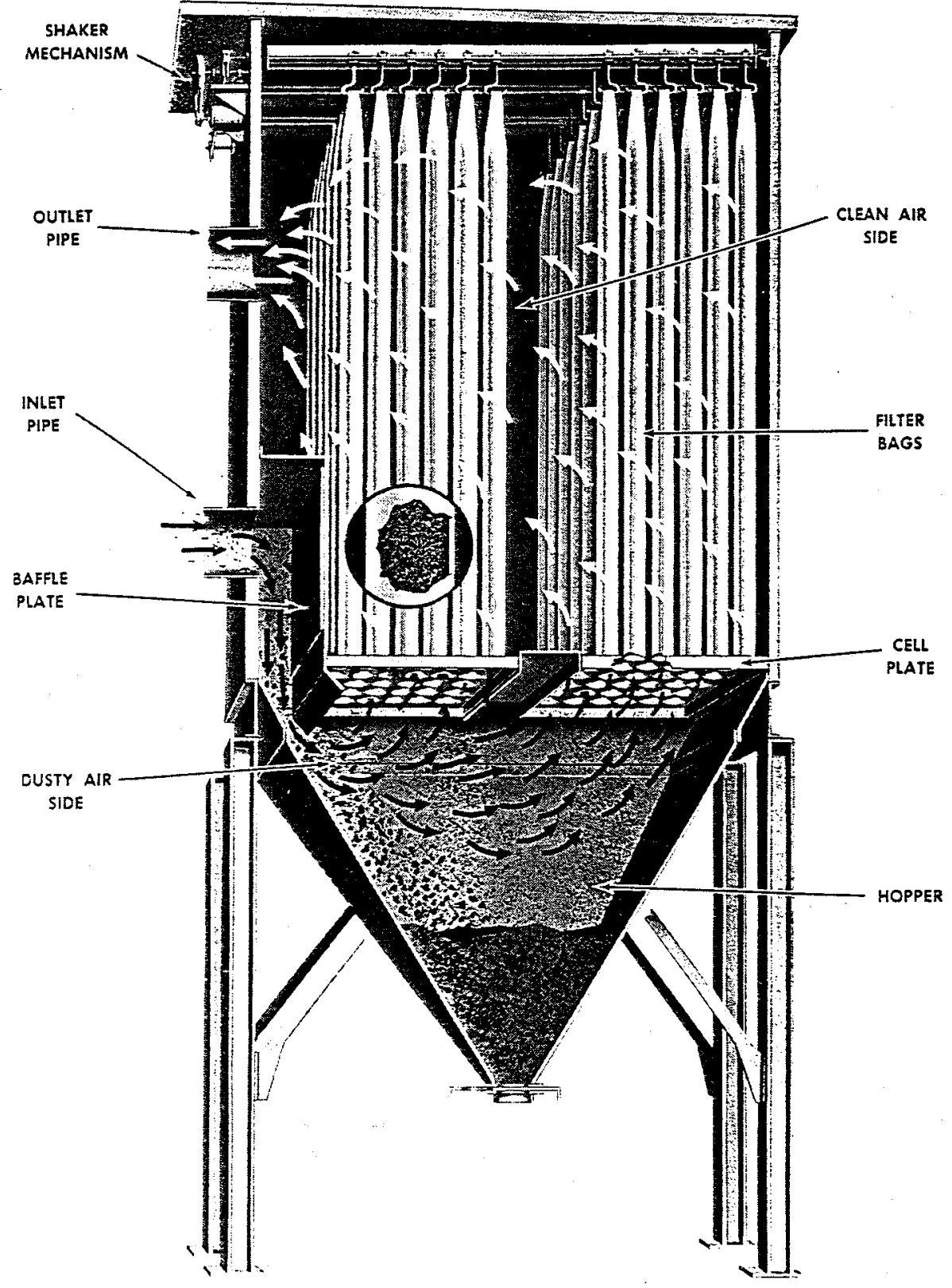

Figure 2. Typical industrial baghouse (shaker design).

Reprinted by permission of Waveland press, Inc. from Cooper-alley, AIR POLLUTION CONTROL (Prospect Heights, IL: Waveland Press, Inc. 1994). All rights reserved. 


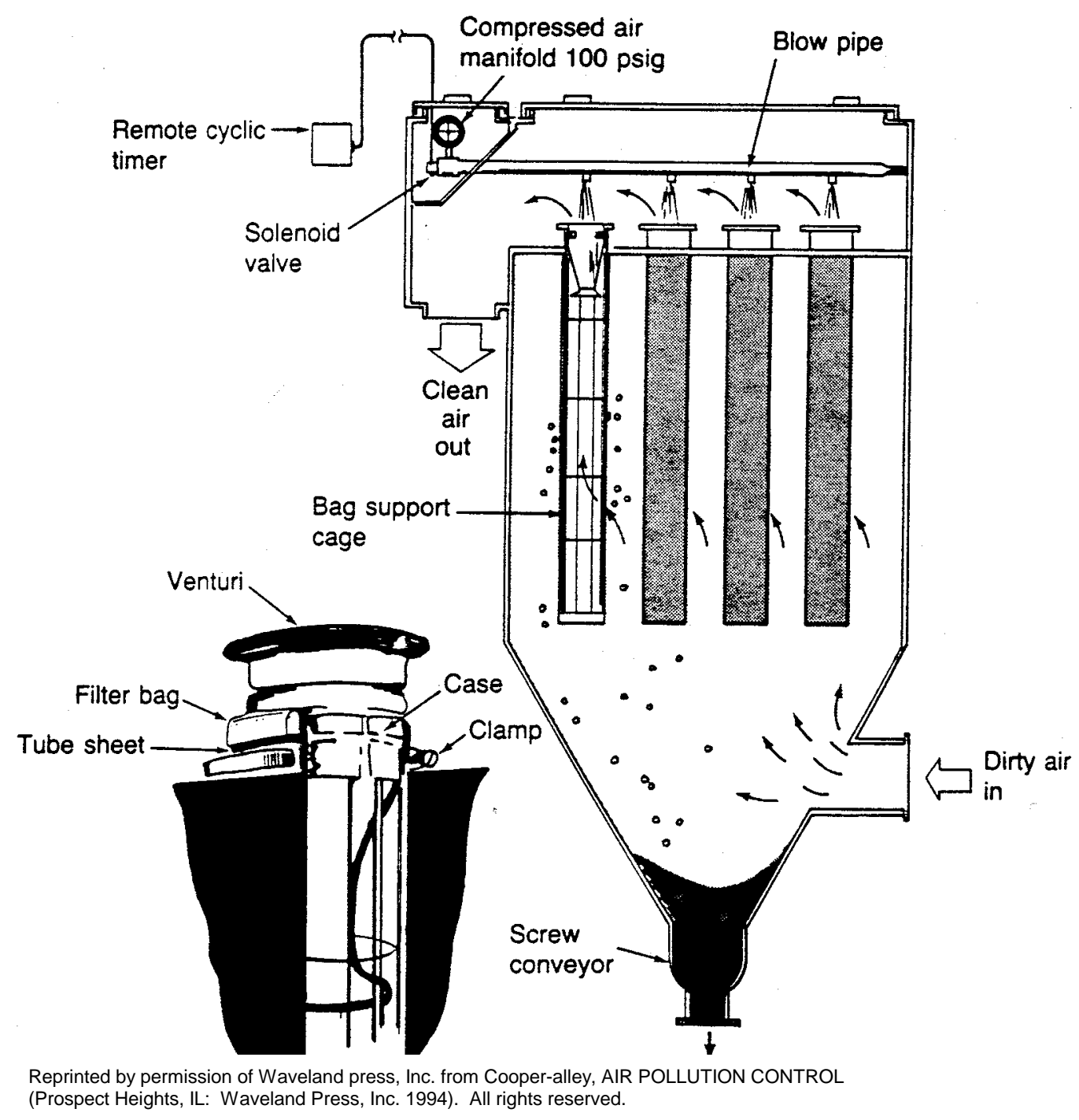

Figure 3. Typical industrial baghouse (pulse-jet design).

Woven media consists of interlaced yarns. The yarns in the vertical (warp) direction give strength to the fabric, while those in the horizontal (fill) direction determine the filtering characteristics of the fabric. The warp and fill yarns' characteristics are partially responsible for determining the porosity of the dust cake that accumulates on the surface. The three main weave patterns used in woven fabrics for baghouses are plain, twill, and sateen. The weave patterns also influence the porosity of the dust cake that accumulates on the fabric surface. Between the yarns are pores that may be greater than $50 \mu \mathrm{m}$ in size. Some of the pore area is often blocked by fibers that protrude from the yarns. However, small particles may still pass through the pores until particles are caught on the sides of the yarns and fill in the openings to form a dust cake. 
The dust cake and not the woven fabric perform most of the filtration work. Woven bags may be constructed of cotton, polyolefins, polypropylene, acrylics, nylon, polyarimide, polyimides, fiberglass, or metals. Filter media weight varies from $9 \mathrm{oz} / \mathrm{sq} \mathrm{yd}$ to $13.5 \mathrm{oz} / \mathrm{sq} \mathrm{yd}$, depending on the yarn and weave characteristics. Usually, the heavier weight filter media have a longer service life. Woven bags may be used on reverse air, shaker, and pulse jet systems.

Felted media filters consist of randomly oriented fibers that are attached to a very open weave called the scrim. The thickness of the filter depends on the number of layers of fibers attached to the scrim. Usually, felted filter media are much thicker than woven media filters, and felted media weights vary from 14 $\mathrm{oz} / \mathrm{sq}$ yd to more than $26 \mathrm{oz} / \mathrm{sq} \mathrm{yd}$. The dust cake is responsible for the capture of particles that accumulate on the surface of felted filter media. These filters are used primarily in pulse-jet systems as the materials cannot be adequately cleaned in reverse air systems.

Membrane media filters are composed of a Teflon ${ }^{\circledR}$ membrane that is laminated to either a woven or felted support fabric. The membrane is on the filtering side, and particles are collected due to the sieving action of pores in the medium less than $5 \mu \mathrm{m}$ in size. Membrane filter media are used in pulse-jet, reverse air, and shaker type systems.

Typical particle sizes: Particles collected from industrial processes vary in size from 0.1 to more than $100 \mu \mathrm{m}$. Particles larger than $5 \mu \mathrm{m}$ usually can be collected efficiently in all air pollution control systems. For particles in the 5 to $0.5 \mu \mathrm{m}$ size range, the capability of sophisticated particulate control systems is moderate-to-high. In general, all control systems have a minimum efficiency point in the 0.1 to $0.5 \mu \mathrm{m}$ size range. The relatively high efficiency of filtration systems, including the size range from 0.1 to $0.5 \mu \mathrm{m}$, is one of the main advantages of filtration systems.

Typical temperature ranges for filter media: The different filter materials behavior differently with respect to their tolerance to high temperatures. The capability of filter media to withstand high temperatures is a function of the media's dimensional stability and protective coating, and also the quantity of the dust cake. The dust absorbs some of the heat and slightly extends the time period that the fabric is exposed to the elevated temperature. Most bags can withstand temperature surges up to the values shown in Table 3 for about 30 minutes. However, more extreme temperature surges may cause damage. For longer filter media life, the normal operating temperatures should be kept below the continuous temperature values shown in Table 3. For example, the life of 
Nomex bags operating at $375 \circ \mathrm{F}$ can be seven years or more, whereas Nomex bags operating at $400 \circ \mathrm{F}$ may fail in 1 to 2 years. To avoid high temperature damage to filter media, a gas cooling system installed upstream of the baghouse is an option. The most common gas cooling systems include evaporative coolers, dilution air systems, and radiant cooling tubes.

Air-to-Cloth $(\mathrm{A} / \mathrm{C})$ ratios: The gross $\mathrm{A} / \mathrm{C}$ ratio is calculated based on the total quantity of filter media ("Cloth") used in a baghouse, and the net A/C ratio uses the reduced filter media area in service when one or more of the baghouse components are off-line. There is a limit to the maximum net $A / C$ ratio that can be employed in a filtration system. The emissions of particulate from the system remain low until the $A / C$ ratio reaches a threshold level. Above the threshold level, the emissions increase asymptotically. A general summary of commonly used A/C ratios is included in Table 4, and the data should be used only as a general guide. One of the limits of using tabulated $A / C$ ratios is that they are based on the assumption that gas is equally distributed across the entire baghouse. The A/C ratio appropriate for a given application depends on particle size distribution, fabric media characteristics, the particulate loadings (the concentration of the particulate matter in the inlet gas stream) and the gas stream conditions. Low values of $\mathrm{A} / \mathrm{C}$ ratios are appropriate when the particle size distribution includes a significant fraction of submicrometer particulate matter. Table 5 summarizes the factors influencing the $A / C$ ratios.

Table 3. High temperature capability.

\begin{tabular}{|l|l|c|c|}
\hline Name & $\begin{array}{c}\text { Common or } \\
\text { Trade Name }\end{array}$ & $\begin{array}{c}\text { Max. Temperature, }{ }^{\circ} \mathbf{F} \\
\text { Continuous }\end{array}$ & $\begin{array}{c}\text { Max. Temperature, }{ }^{\circ} \mathbf{F} \\
\text { Surges }\end{array}$ \\
\hline Natural Fiber, Cellulose & Cotton & 180 & 225 \\
\hline Polyolefin & Polyolefin & 190 & 200 \\
\hline Polypropylene & Polypropylene & 200 & 225 \\
\hline Polyamide & Nylon & 200 & 225 \\
\hline Acrylic & Orlon & 240 & 260 \\
\hline Polyester & Dacron & 275 & 325 \\
\hline Aromatic Polyamide & Nomex & 400 & 425 \\
\hline Phenyl Sulfide & Ryton & 400 & 425 \\
\hline Polyimide & P-84 & 400 & 425 \\
\hline Fiberglass & Fiberglass & 500 & 550 \\
\hline $\begin{array}{l}\text { Fluocarbon } \\
\text { Source: Table B-1, Section B4-1 Filtration Systems Course at web site: http://www- } \\
\text { epin.ies.ncsu.edu/olfabric/course/module_b/s_b4-1.htm. }\end{array}$ \\
\hline
\end{tabular}

Filter media cost: Filter media vary in cost, which has a significant impact on the overall cost of a filtration system. Table 6 shows the difference in costs of filter media using conventional silicon-graphite coated fiberglass as an index of 1.0. Other factors that should be included in the cost of filters are the 
achievable $A / C$ ratio and the service life of the filter bag. The cost analyses should be based on the overall annualized cost of the filtration system and not just on the cost of the filter media.

Table 4. General summary of air-to-cloth ratios in various industrial categories.

\begin{tabular}{|l|c|c|}
\hline Industry & $\begin{array}{c}\text { Reverse Air } \\
\text { (Woven Fabrics) }\end{array}$ & $\begin{array}{c}\text { Pulse Jet } \\
\text { (Felted Fabrics) }\end{array}$ \\
\hline Basic Oxygen Furnaces & $1.5-2.0$ & $6-8$ \\
\hline Brick Manufacturing & $1.5-2.0$ & $9-10$ \\
\hline Coal-Fired Boilers & $1.0-1.5$ & $3-5$ \\
\hline Electric Arcs & $1.5-2.0$ & $6-8$ \\
\hline Feed Mills & - & $10-15$ \\
\hline Gray Iron Foundries & $1.5-2.0$ & $7-8$ \\
\hline Lime Kilns & $1.5-2.0$ & $8-9$ \\
\hline Municipal Incinerators & $1.0-2.0$ & $2.5-4.0$ \\
\hline Phosphate Fertilizer & $1.8-2.0$ & $8-9$ \\
\hline Portland Cement & $1.2-1.5$ & $7-10$ \\
\hline $\begin{array}{l}\text { Source: EPA 450.3-76-014. } \\
\text { Table taken from Section A5-2 Filtration Systems Course http://www- } \\
\text { epin.ies.ncsu.edu/olfabric/course/module_a/s_a5-2.htm. }\end{array}$ \\
\hline
\end{tabular}


Table 5. Factors influencing the air-to-cloth ratios.

\begin{tabular}{|l|l|}
\hline Factor & Air-to-Cloth Ratio Changes from Typical Industrial Values \\
\hline $\begin{array}{l}\text { Submicrometer particulate } \\
\text { concentrations }\end{array}$ & $\begin{array}{l}\text { Decreased air-to-cloth ratio is needed due to the potential for } \\
\text { particle seepage and bag blinding at high air-to-cloth ratio } \\
\text { conditions. }\end{array}$ \\
\hline Limited fan static pressure capacity & $\begin{array}{l}\text { Decreased air-to-cloth ratio is needed to minimize static pressure } \\
\text { concentration is high on a routine or intermittent basis. }\end{array}$ \\
\hline Off-line cleaning & $\begin{array}{l}\text { Slightly increased air-to-cloth ratio is possible in pulse jet systems } \\
\text { due to the enhanced cleaning capability of off-line cleaning. }\end{array}$ \\
\hline Short bag length & $\begin{array}{l}\text { Slightly increased air-to-cloth ratio is possible due to the better } \\
\text { gas flow distribution and better cleaning capability of short bags. }\end{array}$ \\
\hline Closely spaced bags & $\begin{array}{l}\text { Closely spaced pulse jet bags have high gas stream approach } \\
\text { velocities. Decreased air-to-cloth ratio is needed if on-line } \\
\text { cleaning is to be used. }\end{array}$ \\
\hline Source: http://www-epin.ies.ncsu.edu/olfabric/course/module_c/s_c3-2-1.htm \\
\hline
\end{tabular}

Table 6. Relative costs of filter media.

\begin{tabular}{|l|l|}
\hline Generic Name & Relative Cost \\
\hline Natural Fiber, Cellulose & $0.2-0.3$ \\
\hline Polyolefin & $0.2-0.5$ \\
\hline Polypropylene & $0.3-0.5$ \\
\hline Polyamide, (Nylon) & $0.3-0.5$ \\
\hline Acrylic, (Orlon) & $0.3-0.5$ \\
\hline Polyester (Dacron) & $0.3-0.5$ \\
\hline Aromatic Polyamide, (Nomex) & $0.7-0.9$ \\
\hline Polyphenylene Sulfide (Ryton) & $0.7-0.9$ \\
\hline Polyimide (P84) & $0.7-0.9$ \\
\hline Fiberglass, silicon-graphite coating & 1.0 \\
\hline Fiberglass, Teflon B coating & $1.1-1.2$ \\
\hline Fiberglass, acid resistant coating & $1.1-1.3$ \\
\hline Fluocarbon, (Teflon) & $2.0-3.0$ \\
\hline $\begin{array}{l}\text { Note: Registered trade names } \\
\text { (Table is from Section B4 Filtration System Course } \\
\text { http://www.-epin.ies.ncsu.edu/olfabric/course/module_b/s_b4-7.htm) }\end{array}$ \\
\hline
\end{tabular}

\section{Depth Filters}

This class of filter, unlike the surface filter, does not form a cake on its surface. As the gas flows through the filter, randomly oriented fibers collect the particles throughout the entire filter body. In the depth filter, the particle-laden gas flows toward a target (a cylindrical fiber in a filter) and bends around the fiber. However, the particles that are denser than the gas move by their inertia in a straight line toward the target (fiber). 


\section{Microfiltration}

Microfiltration (MF) is a process driven by pressure and helps in separating suspended particles such as bacteria, deoxyribonucleic acid (DNA), viruses, and blood cells. In the dairy industry, MF technology is applied for the removal of spores and bacteria. The MF process is used also to remove suspended solids and microorganisms from wastewater. In October 1997, the Orange County Water District (OCWD) completed 5 years of testing microfiltration as a pretreatment method for reverse osmosis (RO). OCWD showed that MF provided exceptional RO pretreatment from the results obtained from tests of the disinfected microfiltered municipal wastewater that satisfied requirements for non-potable reuse. When MF was used upstream of RO, the increased RO output was 20 percent and the interval between RO membrane cleanings increased up to a factor of 6 . In addition, the resulting decrease in energy and chemical requirements decreased operations and maintenance costs associated with RO to realize savings of $\$ 171$ per acre-foot of reclaimed water (Orange County Water District, http://www.ocwd.com/Pages/MF.HTM). Microfiltration membranes have a retention range between 0.1 and $0.5 \mu \mathrm{m}$, which is well below the physical size of Giardia Lamblia of 5 to $15 \mu \mathrm{m}$. The Surface Water Treatment Rule (SWTR) requires that all Public Water Systems using surface water or affected groundwater must remove or inactivate 99.9 percent of Giardia Lamblia.

\section{Biofiltration}

Biofiltration is a new technology that shows a lot of promise in the treatment of large volume, low concentration VOC sources.

\section{Cost Effectiveness of Selecting the Correct Filters}

The following example taken from a manufacturing operation at an Army installation shows the benefits of selecting the correct filter for the job.

Converting Water Curtain to Dry Filters. Some wet scrubbers can be modified to become dry scrubbers and to use disposable filters. The air scrubber at the installation did not contain a packed bed, and so it could be modified to take disposable filters.

The waste from the air scrubber is paint sludge, which amounted to 1,765 lb. Twenty-five percent $(441 \mathrm{lb})$ of the paint sludge was water. At $\$ 10 / \mathrm{lb}$ disposal 
cost, the total cost for 2 months was $\$ 17,650$. The cost of disposal of the water component was $\$ 4,410$.

The cost for one person to clean out the paint booth was estimated at the fully burdened labor rate of a lineworker. Cleaning costs for one person to clean out the paint booth (coat and peel operation) after each run was:

3 hours $x \$ 68.68 \times 1.7=\$ 467$

The total cost per run for production (63 days) included disposal of water in paint sludge and labor required to clean the wet scrubber:

Disposal of water in sludge $\$ 4,410$

Cost of labor

$\$ 467$

Total

$\$ 4,877$

Analysis: Equipment needed to change the wet scrubber to dry scrubber:

Filter roll (6 ft $\times 100 \mathrm{ft} \times 1 \mathrm{in}$.) (tackafide) $=\$ 200$

Frame for filters $\quad=\$ 700$

Pressure meter to measure the pressure drop across the filter $=\$ 1,500$

$=\$ 2,400$

Payback: Calculate the payback during the production run (63 days):

First Cost $/$ Savings $x 63$ days $=(\$ 2400) /(\$ 4877) x 63$ days $=31$ days 


\section{Controls-Critical Components of PCE}

\section{Control Strategies}

Having personnel perform some test (such as residual chlorine) and after seeing the results, manually adjust the chlorine flow as needed may control equipment used to control pollution on an installation. Other equipment may be part of a large automatic system such as a power plant, where airflow can be controlled by computerized control systems that also monitor the stack gases with sensors that can be read digitally. The amount of automation is usually specified by the installation when the PCE is purchased. However, a large amount of equipment still exists that was installed before the automation became popular. With the ever shrinking manpower and employee turnover, installations are turning from manually controlled equipment to automatic controls. The installation must consider the cost of being out of compliance with applicable rules and statutes from time to time in addition to the labor cost when comparing the costs of manual against automated systems.

Much of the equipment purchased for pollution control purposes comes as a package. The actions performed and the controls used are determined by the manufacturer. This causes a maintenance problem, since installation personnel must learn to operate and service equipment from a variety of manufacturers. Operator training for a variety of systems is expensive and must be repeated when the employee leaves and a new operator is assigned. Further, when equipment is replaced, the operation of the new equipment is often quite different from that of the older equipment so the operator must receive additional training.

In a centralized control system, remote sensors provide signals to a local controller, which in turn sends impulses to monitors and actuators. Each centralized control system is unique with its own input and output and processing requirements. Large complex control systems may be partitioned into two or more centralized systems, which use controllers that must communicate continuously. These semi-distributed control systems are expensive to develop, costly to install, and difficult to expand. Their designers 
find that most of their engineering time is spent implementing and testing communications systems rather than developing the actual control systems themselves.

A number of benefits accrue when implementing intelligent distributed control systems. These systems:

1. Lower starting costs by allowing the same communications system design to be used for many different applications

2. Facilitate graceful growth by easing expansion and reconfiguration

3. Reduce installation costs by sharing or eliminating wiring

4. Enable previously disparate products and systems to inter-operate.

Because of the requirements to reduce costs in the private sector, a number of companies have produced solutions that meet distributed control system requirements. Supervisory control and data acquisition (SCADA) originally described a monitor and control process wherein all intelligence resided in a central computer (the SCADA manager). The human operators would manage the system by observing the data as presented on the computer screen. Communication between the computer and the field units occurred on dedicated wireline circuits, one per field unit, under full control of the central processor. The field units were polled to request or send data.

A number of companies manufacture SCADA systems usually composed of discrete modules that handle the individual tasks. The modules are programmable. Either the user or the manufacturer does the programming. In an unusual approach, Echelon, Inc. manufactures a line of products called LonWorks. The devices behind these products are called the Neuron Chip, which contains three identical 8-bit processors that are placed at the sensor location. The chip itself is manufactured by Motorola Semiconductor. The processors divide up tasks of data acquisition, control, and communication. Each Neuron Chip in a network is separately addressable and the wiring is similar to a LAN (local area network). Since only one wire is needed for many sensors to be connected to a central facility, wiring costs are minimized. Where direct wiring is not practical, a radio transceiver module operating in the 49 $\mathrm{MHz}$ band is available. Another example of a SCADA system is MOSCAD, manufactured by Motorola. Like the system produced by Echelon, it includes remote processing systems that communicate with the central controller. At each location, programmable modules handle data acquisition from sensors and communications with the network. Unlike Echelon, the Motorola system communicates with the field units using the Transport Control Protocol/I nternet 
Protocol (TCP/IP), the protocol of the Internet. It would seem that if everyone used the TCP/IP protocols, the equipment from various manufacturers would be interoperable. However, the information sent within a TCP/IP packet is still controlled by the each manufacturer and standards still need to be formulated.

USACERL has a small business innovative research (SBIR) contract with Team Controls (Dallas, TX). In this contract, Team Controls is developing a set of modules that will interface with the Programmable Logic Controllers (PLC) used by manufacturers of packaged energy control systems and environmental pollution control systems. These PLCs are made by a number of manufacturers, and each uses a proprietary communication protocol. The modules interface with these protocols and convert them to the TCP/IP protocol for use in communicating with the central office. This means that the control software only has to be developed once and the communication interface has to be devel oped only once per manufacturer.

Private industry also recognizes the need to set up common protocols. The Machinery Information Open System Alliance (MIMOSA) is a nonprofit organization composed of about 35 companies, including 12 of the 16 premier suppliers of machinery condition monitoring equipment and systems representing approximately 50 percent of total worldwide product sales. These companies include industrial equipment end-users, condition monitoring vendors of periodic and permanent data collection systems/services, machinery manufacturers, machinery insurers, test and measurement hardware/software vendors, digital control system (DCS) vendors, computerized maintenance management system (CMMS) vendors, and system integrators who are interested in promoting open, network-able computerized machinery information systems. A major focus of the alliance is to provide recommendations and conventions to unify machinery data taken from digital control systems, condition monitoring systems, computerized maintenance management systems, and operational logs to provide companies with the ability to create comprehensive machine information management systems (Mitchell 1996).

Environmental pollution control systems are usually spread out over a large area on Army installations. Communications with a central office such as the Directorate of Public Works (DPW) need to be installed. Often, telephone lines can be used to transmit the data in digital form. On some installations, the telephone lines are not reliable. However, in those installations where phone lines are not currently run to a pollution control facility, adding phone lines is expensive (about $\$ 40 \mathrm{~K}$ per mile). Communications can be accomplished by radio 
link. In the past, single frequency licensed transmitters could be used. However, obtaining a frequency in the bands allocated for the military takes months and must also be coordinated with the installation communications center to avoid conflict with existing links.

In a recent ruling on wireless LAN efforts, the Federal Communications Commission has authorized unlicensed wireless high-speed data transmission devices. The ruling frees 300 megahertz of spectrum in the 5 gigaHertz $(\mathrm{GHz})$ range for unlicensed National Information Infrastructure devices. Users could benefit from the ability to create local networks without wiring their buildings or neighborhoods. On the other hand, users of unlicensed spectrum must be willing to accept whatever levels of interference are present. Users who require no interference or extremely low rates of error would probably prefer to use traditional wireline LANs or the more "robust" licensed wireless networks provided by telecommunications companies. Designers should check real property records to see if wiring was installed in the past and may be available for use.

In these new bands, wireless network connections at speeds as fast as 20 megabits per second could be constructed that would cover areas as large as 6 miles in diameter. To allay concerns about interference, the FCC adopted different technical standards for the three bands it authorized. In the lowest band, from 5.15 to $5.25 \mathrm{GHz}$, broadcast power is limited to 200 milliWatts, meaning that computers, printers, or servers in one building could effectively communicate. In the second band, from 5.25 to $5.35 \mathrm{GHz}$, devices could broadcast with 1 watt of power, allowing effective communications within an installation cantonment area. In the 5.725 to $5.825 \mathrm{GHz}$ bands, devices could broadcast with 4 watts of power, allowing effective communications within a 6-mile radius, depending on local terrain and the number of users.

\section{Life Cycle Cost of Control Systems}

Technology is advancing at a rapid rate. This is especially true for computerized systems. The major advancement is the phenomenal reduction in cost of computing power. In the past 10 years, the speed of desktop computing systems has increased a thousand fold, while component prices have dropped by a similar factor. The cost of automation for a particular function at an installation is similarly dropping. On the other hand, the cost of labor is rising. Thus, it is becoming more economical to automate a system than to continue current manual methods. 
In a centralized control type of installation, cost can be reduced in the following ways:

1. Reduced operator-training time. The operator consoles present data to the operator in an installation-specific way rather than equipment specific.

2. A more active control strategy can be used. An example of this is to monitor the electricity used by the pollution control equipment. Electricity costs are often priced by time of day as well as peak demand capability. By ensuring that motor turn on is staggered throughout an installation, peak demand can be reduced. Also shifting pumping operations to the evening hours when rates are lowest can result in substantial savings in energy costs.

3. If the central control is not proprietary, then when replacing or upgrading equipment, the installation can get a variety of bids rather than having to sole source the purchase simply to be compatible with the proprietary central control.

4. Additional sensors can be installed to monitor the health of the equipment. As bearings in motors wear out, a vibration sensor attached to the motor can detect the change. As the motor approaches the point where maintenance is required (such as replacement), the maintenance can be scheduled to minimize costs. If one waits for the motor to fail completely, then maintenance must be done immediately. If failure occurs late at night or on a weekend, the costs will be significantly higher.

\section{Costs of Repair}

Electronic equipment used to control pollution abatement equipment is not much different than that used by the information management (IM) personnel. Centralized control implies the presence of networks and computers. These networks and computers can be maintained by the I $M$ staff so it is not necessary to maintain separate support staffs. On the other hand, if the controls inside a particular piece of equipment require repair, someone who is familiar with that piece of equipment must do the repair, often the manufacturer's support personnel. 


\section{Motors-Critical Components of PCE}

\section{Electric Motors}

A common component of most pollution control equipment is the motor drive. The motor drive consists of the electric power source, motor controls, electric motor, and mechanical transmission system. At the heart of the drive is the electric motor, which converts electrical energy to mechanical energy. Its proper selection and implementation are critical for reliable operation. This chapter focuses on induction motor selection and implementation issues.

The general-purpose induction machine is used in well over 90 percent of all motor-driven pollution control equipment. The discussion that follows targets motors in the range of 1 to 200 horsepower and power source voltages below 600 volts, although most of the issues mentioned will also apply to motors outside these ranges. The motor market has been evolving over the past 5 years with respect to operating efficiency. This can be attributed largely to the Energy Policy Act of 1992 (EPACT), which requires that most general-purpose, threephase, squirrel-cage induction motors in the range of 1 to 200 horsepower meet the minimum efficiency standards (Table 7) by 24 October 1997. Only singlespeed, T-Frame, foot-mounted, National Electrical Manufacturers Association (NEMA) Design A and B motors with speeds of 1200, 1800, and 3600 revolutions-per-minute will be affected. The following motors are not covered by EPACT:

1. Most non-NEMA design motors

2. Definite-purpose and special-purpose motors

3. NEMA Design C and D motors

4. Multi-speed motors

5. Rebuilt or repaired motors. 
Table 7. Nominal motor efficiency levels prescribed by EPACT 1992.

\begin{tabular}{|c|l|l|l|l|l|l|}
\hline & \multicolumn{3}{|c|}{ Open Motors } & \multicolumn{3}{c|}{ Closed Motors } \\
\hline Horsepower & 6 poles & 4 poles & 2 poles & 6 poles & 4 poles & 2 poles \\
\hline 1 & 80.0 & 82.5 & & 80.0 & 82.5 & 75.5 \\
\hline 1.5 & 84.0 & 84.0 & 82.5 & 85.5 & 84.0 & 82.5 \\
\hline 2 & 85.5 & 84.0 & 84.0 & 86.5 & 84.0 & 84.0 \\
\hline 3 & 86.5 & 86.5 & 84.0 & 87.5 & 87.5 & 85.5 \\
\hline 5 & 87.5 & 87.5 & 85.5 & 87.5 & 87.5 & 87.5 \\
\hline 7.5 & 88.5 & 88.5 & 87.5 & 89.5 & 89.5 & 88.5 \\
\hline 10 & 90.2 & 89.5 & 88.5 & 89.5 & 89.5 & 89.5 \\
\hline 15 & 90.2 & 91.0 & 89.5 & 90.2 & 91.0 & 90.2 \\
\hline 20 & 91.0 & 91.0 & 90.2 & 90.2 & 91.0 & 90.2 \\
\hline 25 & 91.7 & 91.7 & 91.0 & 91.7 & 92.4 & 91.0 \\
\hline 30 & 92.4 & 92.4 & 91.0 & 91.7 & 92.4 & 91.0 \\
\hline 40 & 93.0 & 93.0 & 91.7 & 93.0 & 93.0 & 91.7 \\
\hline 50 & 93.0 & 93.0 & 92.4 & 93.0 & 93.0 & 92.4 \\
\hline 60 & 93.6 & 93.6 & 93.0 & 93.6 & 93.6 & 93.0 \\
\hline 75 & 93.6 & 94.1 & 93.0 & 93.6 & 94.1 & 93.0 \\
\hline 100 & 94.1 & 94.1 & 93.0 & 94.1 & 94.5 & 93.6 \\
\hline 125 & 94.1 & 94.5 & 93.6 & 94.1 & 94.5 & 94.5 \\
\hline 150 & 94.5 & 95.0 & 93.6 & 95.0 & 95.0 & 94.5 \\
\hline 200 & 94.5 & 95.0 & 94.5 & 95.0 & 95.0 & 95.0 \\
\hline & & & & & & \\
\hline
\end{tabular}

\section{Motor Selection and Application Issues}

\section{Motor Enclosure and Ambient Conditions}

Choosing a proper enclosure is critical to successful motor operation. The National Electrical Manufacturers Association has classified several enclosure types according to environmental protection and methods of cooling. Several of the available types include the Drip-proof enclosure, Totally Enclosed FanCooled enclosure, Explosion-Proof enclosure, and Dust-I gnition-Proof enclosure (NEMA Std MG1).

Drip-Proof Enclosure. The drip-proof machine has ventilation openings that allow passage of external air over the windings of the machine, and is constructed to give adequate protection from dripping liquid or solid particles that strike or enter the enclosure at angles less than 15 degrees downward from vertical. This enclosure type provides minimal protection from the elements.

Totally Enclosed Fan Cooled Enclosure. A totally enclosed fan-cooled machine is a totally enclosed machine with an external shaft-mounted fan that provides external cooling air. 
Explosion-Proof Enclosure. Explosion-proof machines are designed and constructed to withstand an explosion of a specified gas or vapor in accordance with National Electrical Code for Class I Hazardous Locations (ANSI/NFPA 70).

Dust-Ignition-Proof Enclosure. Dust-ignition-proof machines are designed and constructed to keep out ignitable amounts of dust or amounts that might affect machine performance or ratings, and that will not permit arcs, sparks, or heat occurring inside the enclosure to cause ignition of exterior accumulations of dust on or in the vicinity of the enclosure. This enclosure type is to be used in Class II Hazardous locations as required by National Electrical Code (ANSI/NFPA 70).

Ambient Conditions. The temperature and air quality that the motor is likely to experience must also be identified so that an appropriate motor can be selected.

Temperature and Motor Insulation Classifications. The standard ambient temperature rating is $40{ }^{\circ} \mathrm{C}$ for general-purpose induction machines. Accelerated deterioration of insulation should be expected if the ambient temperature rating is exceeded in regular operation. Also, it should be understood that the $40{ }^{\circ} \mathrm{C}$ rating only applies for altitudes below $3300 \mathrm{ft}$.

It is important to understand how NEMA classifies motor insulation systems. The permitted temperature rise of electric motor windings is subdivided into insulation classes and temperature limits. Motor insulation systems are defined into major classes, for example, Class A, B, F and $\mathrm{H}$, according to the thermal endurance of the system for temperature rating purposes. Table 8 lists these classes and their allowable temperature rises by resistance for ambient temperatures of not over $40{ }^{\circ} \mathrm{C}$ and altitudes of $3300 \mathrm{ft}$ or less (where s.f. represents motor service factor - discussed in a later section). Insulation classes $\mathrm{B}$ and $\mathrm{F}$ are most common in general-purpose motors. Table 9 gives more information and applies for motors in an ambient temperature up to $40{ }^{\circ} \mathrm{C}$ and an altitude of less than 1000 meters above sea level. The difference between the "Maximum Temperature of the Winding" and the "Temperature Limit" arises because there will be hot spots in the winding. The "Resistance Method" which measures only the Mean Temperature of the whole winding does not measure the hot spots. An Allowance for Hot Spots is made to ensure that no part of the winding operates at its full thermal rating (Reference Standards IEC 34-1, BS 4999, AS 1359.32, http://www.westernelectric.com.au/ Help/T_Topics/tmp_insl.htm). If a motor is built with Class F insulation and designed for Class B rise, this "Thermal Reserve" increases the life of the motor, especially if the motor does not operate at less than full load and is not in continuous ambient temperature of $40^{\circ} \mathrm{F}$. 
Table 8. NEMA temperature rise requirements for the different insulation classes (fan-cooled motors).

\begin{tabular}{|c|cc|}
\hline & \multicolumn{2}{|c|}{ Temperature Rise, ${ }^{\circ} \mathbf{C}$} \\
\hline Insulation Class & $\mathbf{1 . 0}$ s.f. & $\mathbf{1 . 1 5}$ s.f. \\
A & 60 & 70 \\
B & 80 & 90 \\
F & 105 & 115 \\
G & 125 & - \\
\hline
\end{tabular}

Table 9. Insulation class and temperature limits.

\begin{tabular}{|c|c|c|c|c|c|c|}
\hline Insulation Class & $\mathbf{A}$ & $\mathbf{E}$ & B & $\mathbf{F}$ & F with B Rise & $\mathbf{H}$ \\
\hline Temperature Rise & 105 & 120 & 130 & 155 & 155 & 180 \\
\hline Maximum Temp of the Winding & 100 & 115 & 120 & 140 & 140 & 165 \\
\hline Ambient Temperature & 40 & 40 & 40 & 40 & 40 & 40 \\
\hline Allowance for Hot Spots & 5 & 5 & 10 & $\begin{array}{r}15 \\
(10) \\
\end{array}$ & 15 & 15 \\
\hline Maximum Temp Rise of Windings & 60 & 75 & 80 & $\begin{array}{r}100 \\
(105)\end{array}$ & 80 & 125 \\
\hline Thermal Reserve & 0 & 0 & 0 & 0 & 20 & 0 \\
\hline
\end{tabular}

Air Quality. Keeping the motor clean and dry is very important for lengthening life. The presence of moisture, chemicals and/or other air-borne particles should be identified so that an appropriate enclosure can be selected.

\section{Energy-Efficient Versus Standard-Efficient Motors}

Energy-efficient motors are often constructed with:

1. I mproved electrical steel, reduced core lamination thickness, and longer core stack for reducing iron power losses

2. Larger effective rotor and stator slot sizes for reduced conducting losses

3. Larger air-gaps for reducing stray load losses

4. Smaller cooling fans for reducing windage losses.

Other design aspects remain unchanged with respect to standard-efficient designs, including the same frame and rotor construction, and the same insulation system, bearings, and lubricants. Regardless of whether a motor user is faced with a new design or a retrofit situation, there are many issues that must be considered when selecting and applying these machines. This section discusses issues involving rotational speed, starting current, power factor, and torque.

Rotational Speed. One very important issue to consider involves the increase in shaft speed that often results when retrofitting a motor with one of higher 
efficiency. The speed that a motor develops for a given load varies with motor design, but tends to increase with motor efficiency. This speed increase results from the use of lower resistance rotor designs, which are used for reducing conductor power loss ( $I^{2} R$ loss). The increase in shaft speed produces higher horsepower output, where output is equal to the shaft speed times torque. For a fan or pump application, more power will be delivered to the fluid; that is, the result is increased fluid flow. Unfortunately, for many applications this extra flow will be mechanically throttled to meet system demands. A significant amount of energy can be wasted from mechanical throttling, possibly even negating the energy savings anticipated from increased motor efficiency.

To illustrate how an increase in shaft speed can impact motor power output, consider the torque-speed characteristics of a standard-efficient motor (SEM) and an energy-efficient motor (EEM), where both motors are of the three-phase, four-pole, squirrel-cage design (Figure 4). Also shown is a load torque-speed curve, representative of centrifugal fans and pumps. Each motor will operate at the point where its torque-speed characteristic intersects the load curve. As evident from inspection of the two intersection points, the EEM will operate at a higher speed (1770 rpm) than the standard motor (1730 rpm).

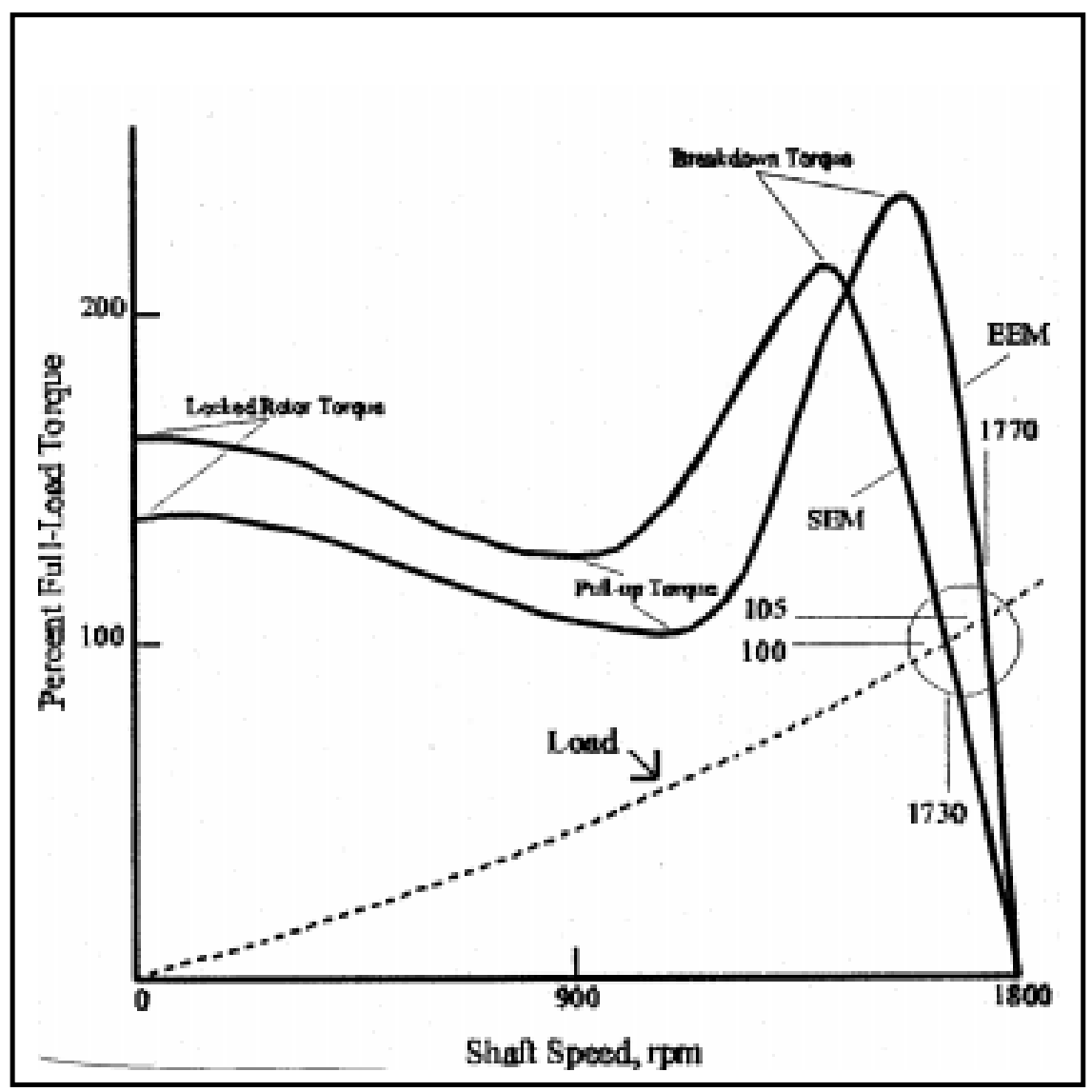

Figure 4. Torque-speed characteristics for a standard and energy motor showing the effect of increased speed on power output. 
Since the load torque varies as the square of speed, the horsepower output (torque $x$ speed) for the two cases differs as the cube of speed. Consequently, the EEM will deliver 7 percent more power (i.e., [1770/1730] $]^{3} \times 100$ ) than the standard motor. For fan and pump systems, the power increase corresponds to increased fluid flow, which, if mechanically throttled, lowers system efficiency.

It is therefore important to incorporate the shaft speed phenomenon into the motor selection criteria for continuously run applications. A technique that can be used for calculating an effective efficiency, which accounts for shaft speed changes, will be presented in the section discussing the motor rewind versus replacement issue.

This is not to imply that the speed issue will affect all motor-driven applications. There are many industrial motor applications that do not operate continuously. For example, some fan, pump, and compressor applications are cycled on and off to meet system demands. In these cases, the increase in horsepower output that is likely to result from use of a higher efficient motor will amount to performing approximately the same amount of work as before, only more quickly. In other words, the system demands that a specific amount of fluid be delivered to satisfy the load, and the higher efficient motor will tend to deliver the required fluid in less time. Consequently, inefficient mechanical flow throttling will not be an issue for these applications. However, it should be noted that slight differences in system operating efficiency may still occur depending on where, on the fan, pump, or compressor curve the new system operates.

Starting Current. The National Electrical Manufacturers Association sets limits on the locked rotor current that a general-purpose Design B motor can draw during full-voltage start-up, typically six to seven times full-load current. These requirements hold for both standard motors and energy-efficient motors. However, on application of full voltage to the motor, a fast transient current results within the first electrical half-cycle (8 milliseconds). This electrical transient can peak at greater than 13 times the full-load current, depending on the motor design and switching angle, and has been known to cause nuisance tripping of motor protective circuitry. For a given switching angle, the transient current peak increases with decreasing stator and rotor resistance. In energyefficient motor designs it is common practice to minimize stator and rotor $I^{2} R$ losses by decreasing the resistance of the stator windings and rotor cage, resulting in higher starting currents than standard motor designs. Nuisance tripping of protective circuitry has been a problem in some retrofit cases, requiring replacement or adjustment of protective devices. Prior to installation, it is difficult to predict whether starting current will pose a problem, but it 
should be recognized that the phenomenon could affect the economics of the retrofit.

Power Factor and Torque. In addition to changes in shaft speed and starting current that can occur when replacing a motor, power factor, and torque differences should also be examined. For example, consider the torque speed characteristics of a standard motor and energy efficient motor shown in Figure 4. Of particular interest are the locked-rotor torque (starting torque) and pullup torque (minimum acceleration torque), which can be lower in the energy efficient motor designs. The differences are mentioned here to make the motor user aware that acceleration times may be affected when a motor is replaced. Of particular concern is when the difference between the pull-up torque and the load curve is reduced as a result of the retrofit, causing longer acceleration times. In certain instances, the resulting acceleration times can become unacceptable, potentially even tripping overload protection devices. The torque differences, however, are generally not an issue for most centrifugal fan and pump loads, and energy efficient designs must still meet NEMA's minimum torque requirements, as specified in MG1-12.38.1.

Power factor should always be identified on the candidate replacement motor. NEMA Standard MG 1 defines some basic design and dimensional parameters of motors, and the parameters for a particular motor are coded onto the motor nameplate. The following minimum information must be included on all nameplates of single-phase and polyphase induction motorsnameplate:

- Manufacture's type and frame designation

- Horsepower output

- Time rating (See MG 1-10.36)

- Maximum ambient temperature for which motor is designed (See Note of MG 1-12.43)

- Insulation system designation

- RPM at rated load

- Frequency

- Number of phases

- Rated load current

- Voltage

- Code letter for locked rotor kVA (See MG 1-10.37)

- Design letter for medium motors (See MG 1-1.16) 
- NEMA nominal efficiency when required by MG 1-12.55

- Service factor if other than 1.0

- For motors equipped with thermal protectors, the words "thermally protected" if the motor provides all the protection described in MG 1-12.52 (See MG 1-1.71 and MG 1-1.72)

- For motors rated above $1 \mathrm{hp}$ equipped with over-temperature devices or systems, the words OVER TEMP. PROT.-. "A type number as described in MG 1-12.53 inserted in the blank would identify the protection type (White paper: What Do All Those Things on an AC Motor Nameplate Mean?, http://www.reliance.com/prodserv/motgen/b7095_1.htm).

(NOTE: For further information on nameplates, refer to NEMA Standard MG1.)

If the nameplate power factor is much less than the existing motor, it may affect the economics of the retrofit. It is common for a plant to be penalized for low power factor. Some energy efficient motor manufacturers increase the air-gap of their motors to reduce stray load losses and increase efficiency. However, the trade off can be a motor design with lower power factor. When possible, a replacement motor should be chosen with power factor equal to or greater than the existing motor.

\section{Power Source Variations}

This section will discuss several details, which must be considered, on the electrical side of the motor concerning variations in supply voltage.

Low Voltage Levels and Reduced Voltage Starters. General-purpose induction motors are typically rated to provide proper operation for voltage levels equal to rated voltage minus 10 percent. For low voltages, the motor develops less torque for any given operating speed, and therefore will deliver fewer horsepower. This can be a problem if the motor is unable to deliver the required horsepower to meet load demands. The voltage seen at terminals of the motor will depend heavily on the power source impedance. As current is pulled through the source impedance, voltage drops. The worst case voltage drop will occur when a motor is started directly off the power line, since a motor draws between six and seven times rated current at start up. For this reason, when specifying a motor for a particular plant and application, it is important to know what terminal voltage the motor will likely see. This will involve making a measurement or estimate of the power source impedance. 
Many variable torque applications require minimal torque at start-up, and consequently, are often started using what is commonly referred to as a reducedvoltage starter. The design approach is to avoid the potential problems caused by the large inrush currents that occur when induction motors are started with rated voltage applied. A common approach has been to use an autotransformer configuration to supply a lower than rated voltage to the motor at start-up. As the motor comes up to speed, the voltage is then raised to the rated level. Another technology that is gaining popularity, often called a "soft starter," uses electronic power switches to reduce the voltage to the motor during start up. This technology is typically much smaller than the transformer alternative, and can be much more cost effective. Regardless of the reduce-voltage technology used, the result is that less current is drawn by the motor-driven system during start-up, and consequently, low-voltage fluctuations in the industrial plant can be minimized. Using reduced-voltage starters can be beneficial for locations with a high power source impedance, and that are sensitive to low vol tage levels.

High Voltage Levels. High voltages, greater than 10 percent of rated voltage, can also cause difficulties. High voltages will cause the motor to develop higher torque than anticipated, which could result in an overloaded motor. Furthermore, the motor iron core loss will increase and/or the motor can be driven into magnetic saturation, potentially causing the motor to overheat. Unfortunately, the overload current relays may not detect a problem. This is because, for a high voltage situation, the resulting current levels may still below trip level settings, even though overload conditions exist. If verified that the motor will see an overvoltage, the trip level on the overload current relays may have to be lowered to adequately protect the motor. Temperature sensors on the motor can also help detect higher than normal operating temperatures.

Voltage Unbalance. The amount of voltage unbalance that will be seen by the motor should also be measured. Taking the largest of the three measured lineto-line voltages, dividing this number by the arithmetic average of the three line-to-line voltages, and then multiplying the result by 100 calculate percent voltage unbalance. It is desired that the unbalance be less than 1 percent. If it is determined that the unbalance is higher than this, then the motor may have to be derated according to the derating curve shown in Figure 5 . This curve is a reproduction of the curve presented in NEMA's MG1 standard. A small voltage unbalance can translate to a current unbalance of greater than 10 time the voltage value. Consequently, voltage unbalance can cause the motor to overheat. Industrial plants exhibiting significant voltage unbalance should consider redistributing the single phase loads evenly among the three available line-toneutral power source vol tages to correct the problem. 


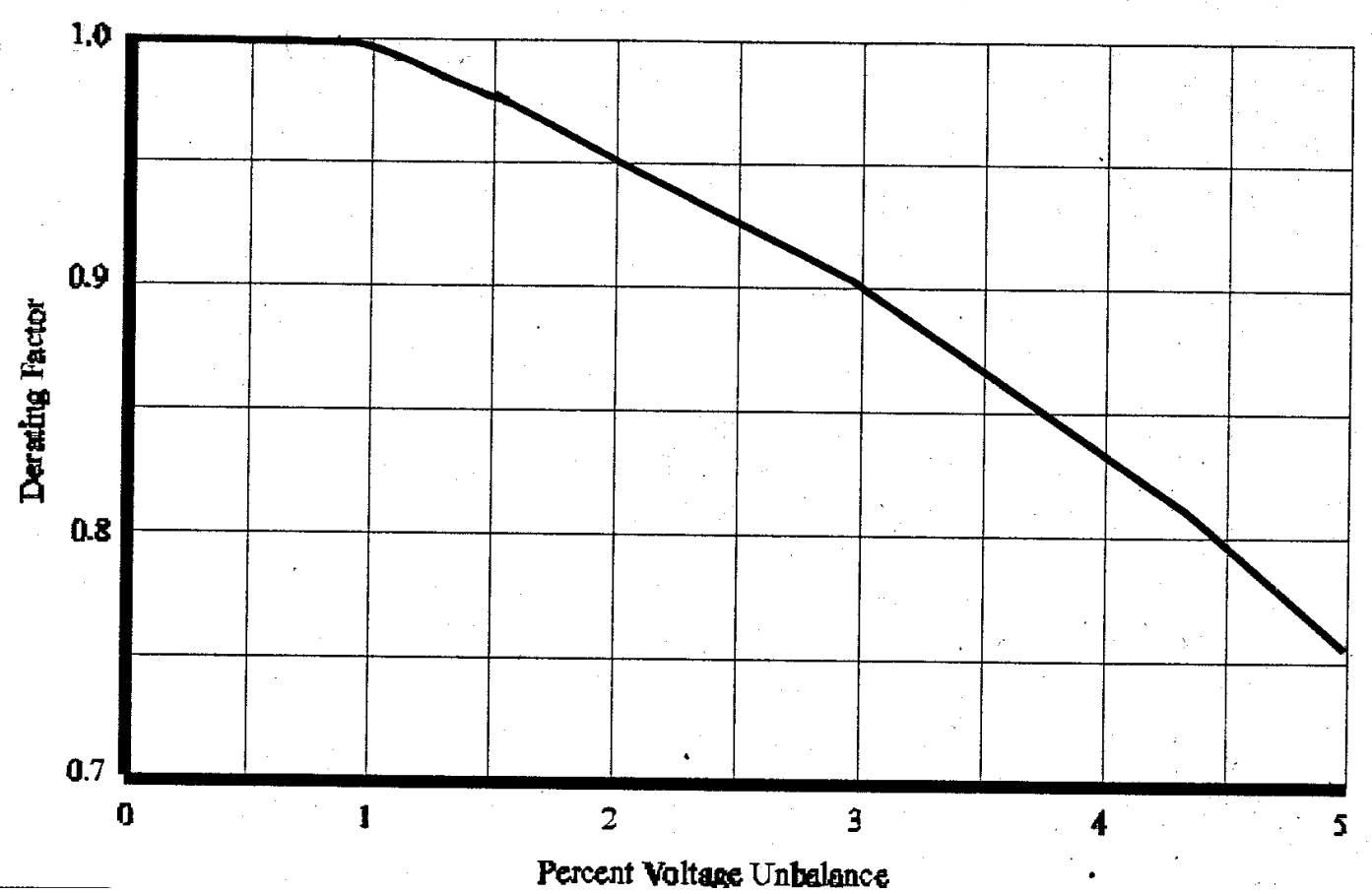

Figure 5. Motor derating factors due to unbalanced supply voltage.

Reprinted from NEMA Std. MG1, Motors and Generators, 1993 by permission of the National Electrical Manufacturers Association.

\section{Motor Sizing}

\section{Torque and Horsepower Requirements}

General-purpose NEMA motors are required to meet certain torque levels in accordance with NEMA MG1-12.38-12.40. Minimum values of locked rotor torque, breakdown torque (maximum torque), and pull-up torque is specified. The point at where these torque values occur on the motor torque-speed characteristic is illustrated in Figure 4. The minimum values are expressed as a percentage of rated torque, and vary with respect to horsepower rating and synchronous speed rating. Rated torque is calculated using rated horsepower and speed as follows:

$$
\text { Torque }(f t-l b)=5252 \times \frac{\text { Horsepower }}{\text { rpm }}
$$

Also, induction motors are typically designed for operation in the range between 50 percent and 100 percent of rated horsepower, with maximum operating efficiency occurring at around 75 percent. It is therefore vary important to identify the torque and horsepower requirements of the driven equipment, so an appropriate motor is selected. 


\section{Service Factor}

As defined in NEMA MG1-1.43, service factor is a multiplier which, when applied to the rated horsepower, indicates a permissible horsepower loading that may be continuously carried with rated nameplate voltage, frequency, and ambient temperature present. It is worth mentioning that, although it represents a continuous rating, a motor operated above any service factor greater than 1 will have a reduced life expectancy compared to when it is operated at its rated nameplate horsepower. This is because of the increase in operating temperatures that results. Furthermore, the nameplate efficiency, power factor, and speed are defined only for operation at rated load, and therefore, these values may be different when operating above rated conditions.

\section{Continuous Versus Short-Time Rating}

A continuous rating defines the load that can be carried for an indefinitely long period of time. A motor can also be specified with a short-time rating, which is a motor designed to stay below rated nameplate temperature when operated at rated load and when operated for periods below the short-time rating. A shorttime rating might be specified for intermittent loads; however, the frequency at which these loads occur must also be considered so that the motor has adequate time to cool between stopping and starting.

\section{Motor Mounting and Alignment}

Much can be written in the technical literature on the importance of providing a proper motor mounting base, using an appropriate shaft coupling, and providing sufficient shaft alignment. However, only a few comments will be made here. The choice of mounting base influences the amount of vibration and misalignment that a motor will experience. A base should be used that reduces the possibility of problems from mechanical resonance and minimizes misalignment due to differing thermal expansion rates. It is also important that the base be flat such that the mounting points on the motor structure are in the same plane. It is therefore common practice, when possible, to use a single concrete or structural steel base for mounting both the motor and the driven equipment.

Recommendations on alignment accuracy differ slightly in the technical literature. However, it is generally accepted that both parallel and angular alignment should be below 0.002 in., unless alignment information from the 
coupling manufacturer is available and indicates otherwise (Hodowanec, 70-77 $\&$ Nailen).

\section{Motor Failures}

Although the induction motor success can be attributed to its ruggedness, it has specific operating ratings, which if exceeded, will cause premature motor failure. Bearing failure and stator insulation failure will be discussed in this section. The most important parameter that influences motor life is operating temperature. The operating temperature of a motor must be limited for several reasons including:

1. Lubricants and insulation deteriorate chemically at a rate that doubles for each 8 to $12{ }^{\circ} \mathrm{C}$ increase in temperature (Alger). A widely accepted "rule of thumb" is that motor insulation life is reduced by one-half for every $10^{\circ} \mathrm{C}$ rise in insulation temperature.

2. Iron, copper, aluminum, and other materials have different thermal expansion rates, which give rise to mechanical stresses that cause progressive deterioration. The resistivity of copper and aluminum varies linearly with temperature.

\section{Bearing Life}

Bearings are used to support and control the motion of the motor rotor. For the motors considered in this report, either ball or roller bearings are typically used, which are classified as "antifriction bearings." It is important to understand that all bearings will wear; however, proper application and care will help maximize useful life. Motor operating temperature, speed and load will all affect bearing life. Consequently, these factors need to be considered when establishing proper bearing maintenance routines. In other words, each motor will demand lubrication at different intervals depending on the motor design, speed, load factor, and operating hours. Grease is typically used as the lubricant. Over or under greasing will degrade bearing life, so understanding each motor's operating characteristics, as well as the manufacturer's lubricating recommendations are important when developing maintenance routines. 
Based on methods developed by the Anti-Friction Bearing Manufacturers Association, statistical life prediction data can be obtained in the data books provided by the bearing manufacturer. Life prediction values are provided in two ways:

1. The minimum life of one out of several bearings in a group is the time that 90 percent of the group will operate before displaying signs of deterioration. This life prediction is called the L10 or B-10 life. An L10 bearing life of either 1 or 2 years, for continuous operation, is common.

2. The average life is the average time before failure for each bearing in the statistical group. The average life is taken as five times the minimum life. Therefore, an L10 life of 1 or 2 years corresponds to an average life of 5 or 10 years, respectively.

\section{Insulation Life}

Motor el ectrical insulation is designed to give many years of trouble-free service when properly cared for. Many motor designers claim that insulation can last upward of 20 years with a properly applied, maintained, and constructed motor. Keeping a motor clean and dry, within temperature ratings during operation, and protected from electrical and mechanical disturbances are critical for maximizing insulation life. This corresponds to selecting the proper motor size and design for the environment and loading conditions expected, choosing appropriate motor protective circuitry, and using the proper mechanical transmission system.

\section{Cost Analyses of Motor Breakdown: Replace Versus Rewind}

Several "rules of thumb" have been mentioned in the technical literature concerning the issue of whether to rewind or replace a failed motor. Some of these rules include: (1) replace all failed motors which were rewound prior to 1980, (2) if the rewind cost more than 65 percent of the replacement cost, replace the motor, and (3) replace failed motors below 50 horsepower. Many of these soft guidelines have resulted from the assumption that the replacement motor will likely be of a much higher efficiency than the rewound motor. With the push to produce higher efficient motors, as from the Energy Policy Act of 1992, and considering the typical motor efficiencies found in an industrial plant, this may appear to be a reasonable assumption. Unfortunately, motor efficiency is not the only criteria that should be considered. Efficiency, shaft speed, power factor, starting current, and torque requirements should all be taken into account when 
developing firm guidelines or policies regarding the rewind/replace issue. With the exception of the first rule, which resulted because of the poor winding burnout practices commonly used prior to 1980, most of the "rules of thumb" should not be relied upon.

Shaft Speed. The higher shaft speed that is typically developed in higher efficiency motors was discussed earlier, and, for many applications, should be factored into the formula used for projecting energy savings. One approach for addressing the speed issue is to derate the full-load efficiency of the candidate motor in relation to its stamped full-load shaft speed. For centrifugal fan and pump loads, the derating formula is developed as follows.

The power delivered by the two motors can be expressed as:

$$
\begin{aligned}
P_{o}^{\text {old }} & =K^{*} S P E E D_{\text {old }}^{3} \\
P_{o}^{\text {new }} & =K^{*} S P E E D_{\text {new }}^{3} \\
& =P_{o}^{\text {old }} *\left(\frac{S P E E D_{\text {new }}}{S P E E D_{\text {old }}}\right)^{3}
\end{aligned}
$$

[Eq 1]

where:

$$
\begin{aligned}
& P_{o}^{\text {old }}=\text { the output power delivered by the existing (old) motor } \\
& P_{o}^{\text {new }}=\text { the output power delivered by the new motor } \\
& K=\text { a proportionality constant } \\
& S P E E D=\text { the operating shaft speed } \text {. }
\end{aligned}
$$

The derated (effective) efficiency of the new motor can then be expressed as:

$$
\begin{aligned}
\eta_{\text {new_derated }} & =\frac{P_{o}^{\text {old }}}{P_{\text {in }}^{\text {new }}} \times 100 \\
& =\frac{P_{o}^{\text {old }}}{\left(\frac{P_{o}^{\text {old }}\left(\frac{S P E E D_{\text {new }}}{S P E E D_{\text {old }}}\right)^{3}}{\eta_{\text {new }}}\right)} \times 100 \\
& =\frac{\eta_{\text {new }}}{\left(\frac{S P E E D_{\text {new }}}{S P E E D_{\text {old }}}\right)^{3}} \times 100
\end{aligned}
$$


where:

$$
\begin{array}{ll}
P_{\text {in }}^{\text {new }} & =\text { the input power to the new motor } \\
\eta_{\text {new }} & =\text { the nameplate efficiency of the new motor } \\
\eta_{\text {new_derated }}= & \text { the derated efficiency which accounts for the speed difference } \\
& \text { between the new and existing motor. }
\end{array}
$$

For continuously operated motor applications, the derated efficiency should be used instead of the nameplate value stamped on the new motor. In other words, this derated value is used in the "Savings" equation [Eq 3] (the $\eta_{\text {new }}$ term) instead of the nameplate efficiency of the new motor, but only for continuously operated motors. For loads which cycle on and off, a compressor for example, $\eta_{\text {new }}$ should be set to equal the nameplate efficiency of the new motor, since speed is not an issue. $\eta_{\text {new }}$ is defined as the effective motor efficiency in the savings calculation. To clarify the issue, replace $\eta_{\text {new }}$ with $\eta_{\text {nev_dataded }}$ but then make a note when defining the term which indicates that $\eta_{\text {nev_drated }}$ is equal to $\eta_{\text {nev-namelate }}$ for cyclically run motors. $\eta_{\text {old }}$ is defined as the nameplate efficiency of the old motor (the motor to be replaced). This value is found on the motor nameplate.

It is important to understand that the assumption behind the above formulation is that all of the extra power delivered, as a result of the increase in shaft speed, is wasted across the mechanical throttling device used in the system. In other words, the assumption is that the output power delivered by the new motor will not change significantly as the system throttles the unneeded extra flow. For inefficient throttling techniques such as dampers, valves, and recirculation loops, or if the systems fails to throttle at all, this assumption is reasonable. The equation can also be used for systems using inlet vanes, but the results will not be as accurate when typical operation is around design conditions, since inlet vanes tend to provide fairly efficient flow control for this region of operation. The savings associated with replacing, rather than rewinding, a failed motor can be estimated using:

$$
\text { Savings }=0.746 \times H P \times \text { Load } \times \text { Hours } \times \text { Cost } \times\left(\frac{1}{\eta_{\text {old }}}-\frac{1}{\eta_{\text {new }}}\right)
$$

where:

$$
\begin{array}{ll}
\text { Savings } & =\text { annual savings in dollars } \\
H P & =\text { motor nameplate horsepower } \\
\text { Load } & =\text { average motor load as a fraction of nameplate horsepower } \\
\text { Hours } & =\text { number of operating hours per year } \\
\text { Cost } & =\text { cost of electricity in dollars per } \mathrm{kWh}
\end{array}
$$


$\eta_{\text {old }}=$ full-load nameplate efficiency of old motor ${ }^{*}$

$\eta_{\text {new }}=$ effective motor efficiency of the candidate replacement motor.

Tables 10, 11, and 12 illustrate the paybacks, which can occur from replacing, rather than repairing, electric motors for various horsepower and speeds. Payback is equal to zero when the cost to rewind is greater than the cost to replace. The efficiencies used for the more efficient (replacement) motors were selected from the Department of Energy's MotorMaster + motor database (U.S. Department of Energy DOE/CE-0384). The values were chosen mid-range of the motor efficiencies available from the various manufacturers, where the efficiency values prescribed in EPACT were used as the bottom of the range. These values were used as the effective efficiencies of the replacement motors when calculating the annual energy savings. The cost of the replacement motors were determined by taking typical list prices for TEFC and ODP motors at the given efficiencies and horsepower, and applying a discount of 30 percent. The rewind costs used are from (Campbell, pp 45-50) and include bearing replacement. An electricity cost of $\$ 0.06 / \mathrm{kWh}$ was also used. These tables are presented here as a guideline, and to give the motor user a feel for the paybacks that can be realized when replacing with higher efficiency motors. These numbers should be adjusted using values that best reflect the particulars of each industrial plant.

Table 10. Repair or replace data, $1200 \mathrm{rpm}$ motors.

\begin{tabular}{|c|c|l|l|l|l|l|}
\hline Horsepower & $\begin{array}{l}\text { Existing Motor } \\
\text { Efficiency }\end{array}$ & $\begin{array}{l}\text { Replacement } \\
\text { Motor } \\
\text { Efficiency }\end{array}$ & $\begin{array}{l}\text { Annual } \\
\text { Energy } \\
\text { Savings (\$) }\end{array}$ & $\begin{array}{l}\text { New Motor } \\
\text { Cost }\end{array}$ & $\begin{array}{l}\text { Repair } \\
\text { Cost }^{1}\end{array}$ & $\begin{array}{l}\text { Simple } \\
\text { Payback } \\
\text { Years }\end{array}$ \\
\hline 1 & 74.000 & 84.000 & 22 & 500 & 344 & 7.09 \\
\hline 1.5 & 78.000 & 84.000 & 18 & 300 & 366 & 0.00 \\
\hline 2 & 78.000 & 87.500 & 37 & 380 & 377 & 0.08 \\
\hline 3 & 81.500 & 88.500 & 39 & 500 & 451 & 1.26 \\
\hline 5 & 82.500 & 89.000 & 59 & 508 & 502 & 0.10 \\
\hline 7.5 & 84.000 & 90.500 & 86 & 660 & 614 & 0.53 \\
\hline 10 & 87.500 & 92.000 & 75 & 980 & 667 & 4.17 \\
\hline 15 & 88.000 & 92.500 & 111 & 1260 & 808 & 4.06 \\
\hline 20 & 89.000 & 92.500 & 114 & 1550 & 875 & 5.91 \\
\hline 25 & 89.000 & 93.500 & 182 & 1609 & 1045 & 3.11 \\
\hline
\end{tabular}

\footnotetext{
*An estimate of the full-load efficiency may have to be used in cases where the old motor has been previously rewound and/or no nameplate value exists. An efficiency loss of 1 to 2 percentage points is typically assumed each time a motor is rewound, where the trend is toward one percent for larger machines.
} 


\begin{tabular}{|r|l|l|l|l|l|l|}
\hline 30 & 90.000 & 94.000 & 190 & 1852 & 1117 & 3.86 \\
\hline 40 & 91.000 & 94.500 & 219 & 2514 & 1435 & 4.94 \\
\hline 50 & 92.000 & 94.500 & 193 & 2884 & 1581 & 6.75 \\
\hline 60 & 92.000 & 95.000 & 277 & 3383 & 1878 & 5.44 \\
\hline 75 & 92.500 & 95.000 & 287 & 3979 & 2093 & 6.58 \\
\hline 100 & 92.500 & 95.500 & 456 & 5440 & 2634 & 6.15 \\
\hline 125 & 93.000 & 95.500 & 472 & 6675 & 2928 & 7.93 \\
\hline 150 & 94.000 & 96.000 & 446 & 7465 & 3747 & 8.33 \\
\hline 200 & 94.000 & 96.000 & 595 & 9451 & 3907 & 9.31 \\
\hline
\end{tabular}

Table 11. Repair or replace data, $1800 \mathrm{rpm}$ motors.

\begin{tabular}{|c|c|l|l|l|l|l|}
\hline Horsepower & $\begin{array}{l}\text { Existing Motor } \\
\text { Efficiency }\end{array}$ & $\begin{array}{l}\text { Replacement } \\
\text { Motor } \\
\text { Efficiency }\end{array}$ & $\begin{array}{l}\text { Annual } \\
\text { Energy } \\
\text { Savings (\$) }\end{array}$ & $\begin{array}{l}\text { New Motor } \\
\text { Cost }\end{array}$ & $\begin{array}{l}\text { Repair } \\
\text { Cost }^{1}\end{array}$ & $\begin{array}{l}\text { Simple } \\
\text { Payback } \\
\text { Years }\end{array}$ \\
\hline 1 & 76.000 & 84.000 & 17 & 300 & 320 & 0.00 \\
\hline 1.5 & 78.000 & 85.000 & 21 & 300 & 328 & 0.00 \\
\hline 2 & 80.000 & 85.500 & 22 & 320 & 340 & 0.00 \\
\hline 3 & 83.500 & 88.000 & 25 & 256 & 364 & 0.00 \\
\hline 5 & 85.000 & 89.500 & 40 & 370 & 383 & 0.00 \\
\hline 7.5 & 86.000 & 91.000 & 64 & 500 & 462 & 0.59 \\
\hline 10 & 86.500 & 91.500 & 85 & 740 & 511 & 2.69 \\
\hline 15 & 87.500 & 93.000 & 136 & 900 & 635 & 1.95 \\
\hline 20 & 89.000 & 93.000 & 130 & 1050 & 696 & 2.73 \\
\hline 25 & 89.500 & 93.500 & 160 & 953 & 185 & 4.79 \\
\hline 30 & 89.500 & 93.500 & 193 & 1106 & 906 & 1.04 \\
\hline 40 & 91.000 & 95.000 & 249 & 1468 & 1124 & 1.38 \\
\hline 50 & 91.500 & 95.000 & 270 & 1801 & 1271 & 1.96 \\
\hline 60 & 92.000 & 95.000 & 277 & 2587 & 1505 & 3.91 \\
\hline 75 & 93.000 & 95.500 & 283 & 3275 & 1668 & 5.67 \\
\hline 100 & 93.000 & 96.000 & 451 & 4049 & 2089 & 4.34 \\
\hline 125 & 93.000 & 96.000 & 564 & 5333 & 2527 & 4.98 \\
\hline 150 & 93.500 & 96.000 & 561 & 6195 & 2857 & 5.95 \\
\hline 200 & 93.500 & 96.000 & 748 & 7511 & 3416 & 5.47 \\
\hline
\end{tabular}

Table 12. Repair or replace data, $3600 \mathrm{rpm}$ motors.

\begin{tabular}{|c|c|c|c|c|c|c|}
\hline Horsepower & $\begin{array}{c}\text { Existing Motor } \\
\text { Efficiency }\end{array}$ & $\begin{array}{c}\text { Replacement } \\
\text { Motor } \\
\text { Efficiency }\end{array}$ & $\begin{array}{c}\text { Annual } \\
\text { Energy } \\
\text { Savings (\$) }\end{array}$ & $\begin{array}{c}\text { New Motor } \\
\text { Cost }\end{array}$ & $\begin{array}{c}\text { Simple } \\
\text { Repair } \\
\text { Cost }^{1}\end{array}$ & $\begin{array}{c}\text { Payback } \\
\text { Years }\end{array}$ \\
\hline 1 & 70.000 & 80.000 & 24 & 270 & & \\
\hline 1.5 & 78.000 & 85.000 & 21 & 400 & 332 & 3.24 \\
\hline 2 & 78.000 & 86.000 & 32 & 460 & 343 & 3.66 \\
\hline 3 & 80.000 & 88.000 & 46 & 460 & 370 & 1.96 \\
\hline 5 & 82.500 & 89.000 & 59 & 560 & 399 & 2.73 \\
\hline 7.5 & 84.000 & 90.000 & 80 & 780 & 468 & 3.90 \\
\hline 10 & 85.000 & 90.000 & 88 & 800 & 518 & 3.21 \\
\hline 15 & 87.000 & 91.500 & 114 & 1050 & 640 & 3.60 \\
\hline 20 & 89.000 & 92.500 & 114 & 1260 & 710 & 4.82 \\
\hline 25 & 89.000 & 92.500 & 143 & 997 & 838 & 1.11 \\
\hline 30 & 89.500 & 93.000 & 169 & 1163 & 921 & 1.43 \\
\hline 40 & 90.000 & 94.000 & 254 & 1532 & 1158 & 1.47 \\
\hline
\end{tabular}




\begin{tabular}{|r|l|l|l|l|l|l|}
\hline 50 & 91.000 & 94.000 & 235 & 1980 & 1284 & 2.96 \\
\hline 60 & 91.000 & 94.000 & 283 & 2609 & 1539 & 3.79 \\
\hline 75 & 91.000 & 94.500 & 410 & 3273 & 1768 & 3.67 \\
\hline 100 & 91.000 & 95.000 & 621 & 4386 & 2206 & 3.51 \\
\hline 125 & 91.500 & 95.000 & 676 & 5737 & 2699 & 4.50 \\
\hline 150 & 92.000 & 95.000 & 691 & 6885 & 3033 & 5.57 \\
\hline 200 & 93.000 & 95.500 & 756 & 8973 & 3723 & 6.94 \\
\hline
\end{tabular}




\section{Sensors - Critical Components of PCE}

In looking for new technology sensors, researchers accessed the Internet and searched for web sites relating to sensor research and companies that manufacture sensors. The following is not an exhaustive list of available sensors, but it is an overview of some of the technologies that the sensor industry has adopted in its effort to detect pollutants in air and water, resulting from industrial processes. Where applicable, addresses to web sites are included to allow pollution control equipment design personnel to obtain more information on commercially available sensors.

Sensors are instruments containing a sensing element that can be either integrated within or in close contact with a transducer for signal conversion. The sensor system produces a continuous electronic signal that is directly proportional to the concentration of an analyte. Optical, electrochemical, or acoustic transducers convert the chemical recognition event into a processable signal. New technology used in sensors may involve intelligent materials, micro-fabrication, micromachinery, and exotic technologies. Micromachining, integrated circuit technologies, and microsensor technology (MST) can impact areas beyond sensors and actuators and even beyond electronics and engineering (Sensors \& Actuators, J ournal A- vol $56 \& 41 / 42$ ). MST and micromachining procedures for thin film silicon have a profound effect on the effectiveness and efficiency of the sensor and its data-processing system.

With MST, you can integrate many measurements into a single package, place the micro chip(s) in more strategic places, and achieve a new level of real-time integrated measurement fine-tuning. For example, it is predicted that, once the micro gyroscope is "stabilized" (fully developed), it will be integrated with an accelerometer function to give us a micro inertial measurement unit (IMU) with vibrational analyses and possibly new unanticipated applications. Vibration transducers are used in industry and whenever there is a need for precise vibration and acceleration measurements. Some of the applications of a commercially available vibration transducer include vibration monitoring of fans, heavy rotating machinery, pipelines, and dynamic balancing equipment. This vibration transducer offers: 
- Rugged construction

- High output signal

- 8 to $700 \mathrm{~Hz}$ dynamic range, and is

- Self-generating.

A commercially available transducer designed for vibration monitoring of ground-based turbines has:

- High accuracy and sensitivity

- Reliable performance from -65 to $+700^{\circ} \mathrm{F}$

- Omni-directional mounting

- Low impedance

- Noise free

- High output signal of $135 \mathrm{mV} / \mathrm{in}$./sec. is provided from very low frequency (15 $\mathrm{Hz}$ ) and low drive $(0.1 \mathrm{ips}$ and below) to high frequency $(2000 \mathrm{~Hz})$ and high drive levels (70 mils).

Miniature, self-generating velocity transducers suitable for both military and commercial applications are available with the following attributes:

- Small, lightweight (2 oz).

- Reliable performance through temperature range of -65 to $+700^{\circ} \mathrm{F}$

- Operating frequency range $45 \mathrm{~Hz}$ to $1500 \mathrm{~Hz}$.

A breakthrough in velocity-output vibration transducer design uses a special advanced-technology ceramic bearing system that extends service life. These sensors operate in the -65 to $+700^{\circ} \mathrm{F}$ temperature range and have sensitivities available from 60 to $135 \mathrm{mV} / \mathrm{in}$./sec. The wide dynamic operating range is from 30 to $1500 \mathrm{~Hz}$, acceleration from $1 \mathrm{~g}$ to $50 \mathrm{~g}$ peak (CEC Vibration Products).

\section{Microsensor Technology (MST)}

Microsensor Technology (MST) devices may use traditional readout systems and still incorporate sensor and sensor data processing functions placed on a single chip. Current research into micro sensors and micro systems technology involves chemoresistive silicon sensors, gas sensitive diodes, microcalorimeters, bulk and acoustic wave devices. Some microsensors offer many advantages over traditional sensors including the following (http://g3.net/vatell/amp6.html): 
- Minimized effects on measured variables - thin film construction and high thermal conductivity of the sensor substrate produce a resistance small enough to change the temperature drop in the direction of heat flow a fraction of $1^{\circ} \mathrm{C}$

- Rapid response time $-t_{c}=6 \mu \mathrm{s}$ for changes in heat flux and temperature

- Ability to withstand high surface temperatures - operates in surface temperatures up to $850^{\circ} \mathrm{C}$

- Individual calibration and heat flux corrections for temperature - each sensor is calibrated individually, including temperature correction coefficients

- Ability to measure both heat flux and temperature - one micro sensor could meet all of your energy measurement needs

- Sensitivity to conduction, convection, and radiation - the unique construction of the sensor allows detection of heat transfer in all 3 modes

- Low electrical noise - from balanced sensor construction.

\section{Fiber Optic Sensors}

Fiber optic sensors have proven especially promising and have won limited U.S. Environmental Protection Agency (USEPA) approval. This approach permits real-time in-situ environmental monitoring of pollutants without sample collection and at relatively low cost. Fiber optic sensors possess several advantages that electrical sensors do not, including, high bandwidth, small size, light weight, corrosion resistance, geometrical flexibility and an inherent immunity to electromagnetic interference (EMI). A fiber optic sensor controls the effect(s) that a selected environmental property has on light that is being sent through the optical fiber. By measuring changes in the light coming out of the optical fiber sensor, the property of the environment causing the changes in the light can also be measured.

Fiber optic sensors are well suited for monitoring, measuring, and characterizing chemicals and conditions in remote environments. One fiber optic based method is known as remote fiber spectroscopy (RFS). In RFS, light is transmitted to the sample region via the fiber optic and it performs a direct spectroscopic measurement. This analysis encompasses many spectroscopic methods including Raman, surface-enhanced Raman, absorption, reflectance, and fluorescence spectroscopies that have been adapted for use with optical fibers. Another fiber-based method uses chemically specific optrodes in which 
transmitted light probes an immediate material that is attached to the terminal end of the fiber. This material interacts with the analyte to produce an optical signal. Remote detection with optical fibers is of value for monitoring in situ contaminants that are volatile and difficult to sample accurately, particularly in groundwater.

\section{Chemical Fiber Optic Sensors}

Chemical fiber optic sensors can provide contaminant measurements that are needed for the characterization and monitoring of numerous analytes during environmental remediation activities. They have been applied to the characterization of analytes in contaminated soils, groundwater, storage tanks, and mixed waste. These sensors also monitor analytes in contaminated soils, surface water, groundwater, and effluent waste during processing. Some of the benefits of these sensors are their easy placement in monitoring of vadose zone wells or soil, rapid analysis (within hours), and their ability to measure contamination in situ and real-time that saves time and money.

\section{FiberChem Sensor}

FiberChem Sensor developed by Pacific Northwest Laboratory is an in-situ sensor that targets VOCs in groundwater and the vadose zone. Measurement results are available in seconds (vapor zone) or minutes (groundwater). It provides continuous real-time monitoring and sensitivities in the ppm to ppt (thousand) range. Because of its remote, in-situ monitoring capability, it is safer than conventional sampling and worker and public exposure are reduced. Over a 2-year period, maintenance is minimal. If component failure occurs, parts are replaceable, and the unit has a self-checking routine to describe a problem. The sensor is easy to use, portable, and programmable, and a worker can be trained to use the sensor within a four-hour period.

\section{Fiber Optic Infrared Sensors.}

Coupling fiber optic chemical sensors with Fourier transform infrared (FTIR) spectroscopy allows the sensor to be adapted for remote sensing applications. This category of sensor gives a fast response and is used where conventional infrared detectors cannot be used, such as with targets that are not easy to access. These sensors have small spot sizes and have particular values in high- 
energy fields, in environments with high humidity or containing smoke, or in vacuum applications. This means that the instrument can take measurements in harsh environments without exposing the instrument to those potentially damaging environments. The choice of the fiber dictates the spectral range over which the sensor operates effectively. Silica core fibers are a popular choice and are effective in the near-IR range of 0.5 to approximately 2.5 micron. A sensor using a silica core fiber should detect chemical species that absorb in this range.

Omega Engineering, Inc. produces a series of fiber optic infrared temperature sensors that include the following characteristics ( $N$ ote: Fourier transform may be used with other types of sensors.):

- Temperature ranges to $1825^{\circ} \mathrm{C}\left(3320^{\circ} \mathrm{F}\right)$

- $\pm 1.0 \%$ accuracy

- Fast 50 msec response time

- Small spot sizes down to 0.020 in. at 6 in.

- $1 \mathrm{mV} /$ degree output standard

- Unaffected by electrical noise

- Emissivity adjustment for high accuracy measurements

- Spectral filtering for use in dirty atmospheres

- Usable in 10-7 Torr vacuum

- Optional backlighting for precise sighting.

See Table 13 for additional information on Omega Engineering, Inc. fiber optic infrared sensors.

\section{Fiber Optic Spectrochemical Sensors.}

These sensors characterize contaminant distribution in the subsurface environment for cost-effective sampling strategies by using remote or on-site field screening methods. This technology will provide an understanding of subsurface contaminant variability by providing high-density acquisition through real-time monitoring instrumentation. 
Table 13. Fiber optic infrared sensors by Omega Engineering, Inc.

\begin{tabular}{|c|c|c|c|c|c|c|}
\hline $\begin{array}{l}\text { Model No. } \\
\text { Sensor }\end{array}$ & $\begin{array}{c}\text { Base } \\
\text { Price } \\
(\$ s)\end{array}$ & $\begin{array}{l}\text { Temp. } \\
\text { Range } \\
{ }^{\circ} \mathrm{F}\end{array}$ & $\begin{array}{l}\text { Spot Size @ } \\
\text { Target Dist. }\end{array}$ & $\begin{array}{l}\text { Max. } \\
\text { Cable }\end{array}$ & $\begin{array}{l}\text { Output } \\
\text { Signal(s) }\end{array}$ & $\begin{array}{c}\text { Signal } \\
\text { Processing }\end{array}$ \\
\hline OS1562F-L1-R1-(*)-MA:G1 & 2400 & $675-2035$ & $\begin{array}{l}\text { 0.020in.@6i } \\
\text { n. }\end{array}$ & $10 \mathrm{ft}$ & $1 \mathrm{mV} /{ }^{\circ} \mathrm{F}, 4-20 \mathrm{~mA}$ & $\mathrm{~N} / \mathrm{A}$ \\
\hline OS1562F-L1-R2-1-MA:G1 & 2360 & $350-965$ & $\begin{array}{l}\text { 0.085in.@6i } \\
\text { n. }\end{array}$ & $1 \mathrm{ft}$ & $1 \mathrm{mV} /{ }^{\circ} \mathrm{F}, 4-20 \mathrm{~mA}$ & $\mathrm{~N} / \mathrm{A}$ \\
\hline OS1562F-L1-R3-(*)-MA:G1 & 2400 & $385-950$ & 0.22in.@8in. & $10 \mathrm{ft}$ & $1 \mathrm{mV} /{ }^{\circ} \mathrm{F}, 4-20 \mathrm{~mA}$ & $\mathrm{~N} / \mathrm{A}$ \\
\hline OS1562C-L1-R4-(*)-MA:G1 & 2470 & $830-1825$ & 1.0in.@26in. & $30 \mathrm{ft}$ & $1 \mathrm{mV} /{ }^{\circ} \mathrm{C}, 4-20 \mathrm{~mA}$ & $\mathrm{~N} / \mathrm{A}$ \\
\hline $\begin{array}{l}\text { OS1572F-L1-R1-(*)-MA- } \\
\text { PS:G1 }\end{array}$ & 3735 & $905-3320$ & 0.20in.@6in. & $10 \mathrm{ft}$ & $1 \mathrm{mV} /{ }^{\circ} \mathrm{F}, 4-20 \mathrm{~mA}$ & $\begin{array}{l}\text { Peak sense } \\
\text { and hold }\end{array}$ \\
\hline $\begin{array}{l}\text { OS1572F-L1-R2-1-MA- } \\
\text { SA:G1 }\end{array}$ & 3565 & $320-900$ & $\begin{array}{l}\text { 0.085in.@6i } \\
\text { n. }\end{array}$ & $1 \mathrm{ft}$ & $1 \mathrm{mV} /{ }^{\circ} \mathrm{F}, 4-20 \mathrm{~mA}$ & $\begin{array}{l}\text { Signal } \\
\text { averaging }\end{array}$ \\
\hline $\begin{array}{l}\text { OS1572F-L1-R3-(*)-MA- } \\
\text { SA:G1 }\end{array}$ & 3595 & $390-1000$ & 0.22in.@8in. & $10 \mathrm{ft}$ & $1 \mathrm{mV} /{ }^{\circ} \mathrm{F}, 4-20 \mathrm{~mA}$ & $\begin{array}{l}\text { Signal } \\
\text { averaging }\end{array}$ \\
\hline $\begin{array}{l}\text { OS1572F-L1-R4-(*)-MA- } \\
\text { SA:G1 }\end{array}$ & 3385 & $730-1550$ & 1.0in.@26in. & $30 \mathrm{ft}$ & $1 \mathrm{mV} /{ }^{\circ} \mathrm{C}, 4-20 \mathrm{~mA}$ & $\begin{array}{l}\text { Peak sense } \\
\text { and hold }\end{array}$ \\
\hline Cable & $10 / \mathrm{ft}$ & & & & & \\
\hline Power Supply & Price & \multicolumn{5}{|c|}{ Desccription } \\
\hline PSS-D15B:G1 & 114 & \multicolumn{5}{|c|}{$\begin{array}{l} \pm 15 \mathrm{Vdc} \text { or } 30 \mathrm{~V} \text { regulated power supply, } \\
\pm 100 \mathrm{~mA}, 0.02 \% \text { line and load, } 115 \mathrm{Vac} \text { input }\end{array}$} \\
\hline
\end{tabular}

Pacific Northwest Laboratory is developing and testing the HaloSnif Fiber-Optic Spectrochemical sensor that detects any volatile chlorinated compound in air or gas. It is applicable to the detection of any volatile chlorine-containing compound including carbon tetrachloride, trichlorethylene, tetrachlorethylene and chlorofluorcarbons in air or gases. It has the potential to detect gas phase compounds containing bromine, mercury, fluorine, and possibly phosphorus by modifying the analytical emission wavelength monitored by the detector. It operates at subambient pressure (40 torr) and its response to chlorinated species is linear from the lower detection limit of 1 to 5 ppmv (for most compounds) in air to approximately 10,000 ppmv. Estimated total cost of the final unit is $\$ 10 \mathrm{~K}$ for the base system and approximately $\$ 250$ per sensor assembly. The operations and maintenance costs are expected to be minimal .

\section{Optical Absorption Sensor.}

A commercially available stack gas analysis method (Product Data Sheets) continuously samples and divides the stack gas sample into separate streams for $\mathrm{CO}$ and $\mathrm{NO} / \mathrm{NO}_{2}$, and for oxygen content analyses. A less complicated method has been proposed. Since the absorption spectra of several pollution gases in the ultra violet (UV) and visible spectra ranges are periodic and of a mostly 
nonoverlapping nature (at least different characteristic frequencies), it is possible to use a Fourier transform combined with an optical absorption technique to measure simultaneously multiple cases of atmospheric pollution. A method by Lief Axelsson showed high sensitivity, good accuracy, and some robustness for measuring common air pollutants $\left(\mathrm{NH}_{3}, \mathrm{NOx}\right.$, and $\left.\mathrm{SO}_{2}\right)$.

\section{Water Level Sensors.}

A commercial sensor is available that includes a datalogger for remote monitoring and recording of water level data. A reliable and accurate sensor, it is capable of recording 6000 readings and is programmable from one reading per minute to one reading per hour. The water level sensor's 9 VDC battery powers the logger and sensor for 1 year. For installation, the sensor may be placed slightly above the lowest expected water level. Select the range to cover the maximum water level change (range of 0-14 ft water level is standard), and then select the smallest range possible for the greatest accuracy. The cost of a water level sensor in the $14-\mathrm{ft}$ range with a $25-\mathrm{ft}$ cable is $\$ 795$. In the $28-\mathrm{ft}$ range, the cost is $\$ 825$ with a 50 -ft cable. Applications for the water level sensor include:

- Groundwater monitoring

- Surface water monitoring

- Sewer flow monitoring

- Stormwater studies

- River and stream flow monitoring

- Infiltration/inflow studies

- Pump tests.

For further information on these sensors access the web page at (http://www.globalw.com/waterlvl.html).

\section{Submersible Water Level Sensor.}

Another commercial sensor contains a microprocessor that continually monitors water levels in both fresh and wastewater. The ceramic sensor applies a realtime linearity and temperature correction algorithm to the output that minimizes the error connected with signal transmission. The sensor is suitable for use in dirty environments such as sewage wet wells because the large ceramic diaphragm is easy to clean. Because the signal output is industry 
standard analog, or SDI-12, installation costs are minimal. The sensors includes the following characteristics:

- Accuracy: Linearity/Hysteresis $\varangle 0.05 \%$ F.S., Temperature Drift $\varangle 0.003 \%$ F.S. per ${ }^{\circ} \mathrm{C}$

- Zero and Full Scale Set + - 0.05\% F.S.

- Range: (Standard) 5, 10, 20 meters water; (Optional) 50, 100 meters water

- Temperature Range: 0 to $+30^{\circ} \mathrm{C}$

- Response Time: (Analog) 1 second; (Serial) 5 seconds

- Output Options: 4-20 mA/3 wire and SDI-12

- Input Power: Voltage 9-15 VDC unregulated; Current $20 \mathrm{~mA}$ plus current loop

- Display: Various (specify requirement)

- Dimensions: $200 \mathrm{~mm}$ long $\times 32 \mathrm{~mm}$ diameter (7-7/8 in. $\times 1-1 / 4 \mathrm{in}$.)

For further details on this sensor, access the web site at

(http://www.envsens.com/water_quality.html).

\section{Gas Bubbler Pressure Transmitter/Sensor.}

This sensor gives high accuracy and temperature stability where the sensor is not in direct contact with the fluid. The transmitter is microprocessor controlled and measures the backpressure on a gas bubbler line. It senses the liquid head pressure over a bubble orifice. Attributes of this sensor include:

- Accuracy: Linearity/Hysteresis $\varangle 0.03 \%$ F.S., Temperature Drift $\varangle 0.003 \%$ F.S. per ${ }^{\circ} \mathrm{C}$

- Zero and Full Scale Set +- 0.05\% F.S.

- Range: (Standard) 5, 10, 20 bar; (Optional) 20, 50, 100, 200, 400 bar

- Temperature Range: -5 to $+60^{\circ} \mathrm{C}$

- Response Time: (Analog) 1 second; (Serial) 5 seconds

- Output Options: 4-20 mA/3 wire and SDI-12

- Input Power: Voltage 9-15 VDC unregulated; Current $20 \mathrm{~mA}$ plus current loop 
- Display: 8 character LCD

- Dimensions: $152 \mathrm{~mm} \times 98 \mathrm{~mm} \times 87 \mathrm{~mm}$ (6 in. $\times 3-7 / 8 \mathrm{in}$. $\times 3-7 / 16 \mathrm{in}$.)

For further details on this sensor, access the web site at (http://www.envsens.com/water quality.html).

\section{Turbidity Sensor.}

This sensor includes a miniature backscatter nephelometer_that detects turbidity and suspended solids in fluids. Its linear response to particle concentrations and turbidity levels spans three orders of magnitude, and this response range enables it to be used in applications from potable water to sediment laden rivers. Some of the sensor's characteristics include:

- Accuracy: Linearity/Hysteresis 2\% F.S., Temperature Drift $\varangle$ $\varangle 5 \%$ F.S. per ${ }^{\circ} \mathrm{C}$

- Zero and Full Scale Set +- 0.05\% F.S.

- Range: (Standard) 500, 1000, 2000 Formazine Turbidity Units (FTU)

- Temperature Range: 0 to $+30^{\circ} \mathrm{C}$

- Response Time: 1 second

- Output Options: 4-20 mA/3 wire

- Input Power: Voltage 9-15 VDC unregulated; Current $20 \mathrm{~mA}$ plus current loop

- Display: Various

- Dimensions: $200 \mathrm{~mm}$ long $\times 32 \mathrm{~mm}$ diameter (7-7/8 in. $\times 1-1 / 4$ in.)

For further details on this sensor, access the web site at (http://www.envsens.com/water quality.html).

\section{Intelligent Sensor.}

This may be defined as "one that modifies its behavior to optimize its ability to collect data from the physical world and communicate (these data) ... to a host system" (Sensors \& Actuators, B-Chemical). In other words, the intelligent sensor can be deductive but not arbitrary. Universities and some industrial laboratories have been working on smart (multi-function) sensors with 
electronic chip processing for nearly 10 years. A problem here has been standardizing the "natural" output (voltage, current, resistance, and capacitance) of the sensor - so that developers can make more coordinated progress and manufacturers can make faster adaptations. To meet its full potential, the MST smart sensor must be in an integrated network of sensing, signal-conditioning, analog-to-digital (AD) conversion, and an output interface (electrical bus). All of these functions can be collected on a single chip as an Integrated Smart Sensor (ISS). The ISS often has more than one sensor for multiple measurements, multiplexing, and signal conditioning. Concepts such as neural networks, fuzzy control, and artificial intelligence offer potential for the design and control of industrial processes. Neural network based control systems are capable of learning complex process control and can adapt to changes in process dynamics. The combination of learning algorithms and optimal control systems can be integrated into existing manufacturing systems to provide intelligent control solutions to environmental compliance challenges.

Chemical sensor arrays have been built to give distinctive signatures for substances such as fuels and combustible gases that are of interest to the military and industry. The quick and efficient pattern recognition techniques are applied to analyze the sensor array data and the need for complex chemical calculations is eliminated. The sensor array also can be constructed as an integrated device with many active areas. In addition, a pattern recognition algorithm can be implemented as an application-specific integrated circuit.

\section{Site Characterization and Analysis Penetrometer System (SCAPS).}

Tri-Service and U.S. Environmental Center combined traditional cone penetrometer technology with contaminant sensors and samplers to provide a quick and inexpensive method to profile contaminants at hazardous waste sites and provide their geophysical properties (http://www.scaps.com).

\section{Gas Sensor Array for the Detection of Hazardous Compounds.}

A project funded by the German federal ministry of education, science, research and technology (grant no. 01RG9314) devel oped a sensor array for the detection of hazardous airborne compounds. The system is calibrated by clean air and calibration gas and has an enrichment device for the detection of low sample concentrations. In addition, with the combination of pattern recognition (for example, Kohonen Feature Map neural network), unknown gas species can be 
detected, or mixtures identified and quantified. The sensor apparatus consists of 10 semiconductor gas sensors and a photo ionization detector for detecting organic compounds. The inclusion of two electrochemical cells enables the system to detect two inorganic compounds: phosgene and hydrocyanic acid. By using their cross sensitivities, the system is suitable for identifying other inorganic compounds. Table 14 describes some of the research and development at the Department of Measurement Engineering, Technical University of Hamburg-Harburg of new measuring methods in environmental analysis on gas chromatography couple to mass spectrometers and on sensor arrays.

For further information, access the web page at:

http://www.tu-harburg.de/et1/umwelt/torsten/sensor.html ).

Table 14. Research and development on new measuring methods.

\begin{tabular}{|c|c|}
\hline Research Topics & Available Information \\
\hline $\begin{array}{l}\text { Mobile GC/MS } \\
\text { Field analysis }\end{array}$ & $\begin{array}{l}\text { Fast GC/MS-Analysis of Hazardous Organics in Fires and Chemical } \\
\text { Accidents } \\
\text { Fast GC/MS-Analysis of Industrial Emissions with an Automatic } \\
\text { Particle Sampling Probe } \\
\text { Fast on-site analysis of contaminated soils. SFB } 188 \text { (TUHH-DFG) } \\
\text { Submersible MI/GC/MS }\end{array}$ \\
\hline Sample Preparation & $\begin{array}{l}\text { Sample and sample preparation for a mobile GC/MS system } \\
\text { Sample Preparation for Semivolatile Organic Compounds with a } \\
\text { "Silicoat-Tube" } \\
\text { Automatic solvent vaporizer for rapid and reproducible enrichment } \\
\text { "Silicoat filter" thermal desorption GC/MS for field screening of PCBs in } \\
\text { air }\end{array}$ \\
\hline $\begin{array}{l}\text { MIMS } \\
\text { Membrane Introduction } \\
\text { MS }\end{array}$ & $\begin{array}{l}\text { Automatic Process Gas Monitoring with a Mass Spectrometer } \\
\text { Process Monitoring of Biotechnological Fermentations by GC/MS } \\
\text { Development of an on-site system for the detection of gases and } \\
\text { organic compounds in water } \\
\text { Mass-spectrometric "on-line" analysis of gaseous and solved organic } \\
\text { substances in a biogas-tower reactor. SFB } 238 \text { (TUHH-DFG) }\end{array}$ \\
\hline MS-Development & $\begin{array}{l}\text { Development of a small, portable mass spectrometer for the use in } \\
\text { environmental analysis }\end{array}$ \\
\hline Remote Sensing & Remote detection of hazardous vapors using FTIR spectrometry \\
\hline Sensors & $\begin{array}{l}\text { Sensor Array with Auto-Calibration Property for the Detection of } \\
\text { Hazardous Compounds } \\
\text { Simple Calibration Gas Generator for Easy Testing of Sensors and } \\
\text { Sensor Arrays } \\
\text { Gas Detector Array with Ion Mobility Spectrometer for emergency } \\
\text { response }\end{array}$ \\
\hline
\end{tabular}




\section{Gas Chromatography (GC)}

This method of chromatography separates chemical components by a combination of three processes: partition chromatography, adsorption chromatography, and difference and boiling point (volatility in this case) of components in the gaseous state. The compound is passed through a coiled column of glass fused silica oxide-glass located inside an oven. The sample inside the column is heated until the components vaporize. Due to the characteristic sizes of different molecules, affinity with the stationary phase, and boiling point, chemical compounds are transported through the column at different times. The retention time (RT) is the period between injection of the mixture and detection by the sensor, and RT is a specific behavior for each compound. To identify and quantify the sample compound, compare its RT with standard RT. Gas chromatography systems are available commercially and one system incorporates the following attributes:

- Full electronic control of all system parameters (eliminating manual pneumatic pressure regulators and mass flow controllers)

- All system gases are controlled under electronic pressure/pneumatic control (EPC)

- The carrier gas is programmable from 0 to $80 \mathrm{psi}$

- Ramp rates are as high as 99 psi per minute

- An insulated column oven, measuring 7.25 in. x 7.25 in. x 2.5 in., equipped with a new design, high-output heating element, allows temperature programming from ambient to $400^{\circ} \mathrm{C}$, at ramp rates up to $40^{\circ} \mathrm{C}$ per minute

- An oven circulation system eliminates any temperature gradients in the column oven

- A cooling system cools the oven from $250{ }^{\circ} \mathrm{C}$ to ambient temperature in 5 minutes or less, allowing rapid recycle

- Units weigh from 40 to $60 \mathrm{lb}$ depending on the configuration of the GC

- LED display panel that shows status of all controlled zones in the GC system

- Equipped with a built-in 4-channel serially-interfaced IBM-PC compatible data system

- Price of this sensor is $\$ 4,495$ (U.S.)

For information on this and other GC sensors, access the web site at http://www.srigc.com. 


\section{Mass Spectrometry}

A commercial mass spectrometer is available that analyzes ethylene furnace gas. This instrument has allowed improved control; better ethylene yields, reduced maintenance, and near real-time analysis. The device can withstand hydrocarbon contamination and only requires cleaning every 12 months. Because the instrument samples up to 64 points, one instrument can replace several gas chromatographs and can analyze more gas components in a shorter analysis time. A commercial on-line mass spectrometer has the ability for continuous multi-point monitoring of VOCs. It will monitor a multicomponent VOC mixture in seconds, detecting even small transient leaks from valves and flanges. Another feature of this device is its ability to monitor the majority of VOCs presently used at ppb levels 10-100 times lower than that legally required. Sample line lengths can extend to $350 \mathrm{~m}$, which allows monitoring for a wide area around the plant. This instrument has had wide success in monitoring vinyl chloride monomer (VCM) and dichlorethane (EDC) during PVC production. It is able to perform an analysis of the process in less than 5 seconds per inlet (without cross-interference), whereas traditional process chromatography takes at least 2-4 minutes to monitor a single point. The system also monitors chloroform, MIBK, toluene, and acetone in ambient air and stacks. For more details, see the web site:

\section{http://halon.vggas.com/publications/on-line/iss/pg3.html).}

Mass spectrometry not only measures combustion gases (for example, $\mathrm{CO}_{2}, \mathrm{CO}$, $\mathrm{NO}_{\mathrm{x}}$ ), but simultaneously monitors unburned fuel compounds (for example benzene, toluenes, xylenes, and naphthalenes). These properties of mass spectrometry are of interest to the automobile industry that currently measure emission with infrared and electrochemical sensors. In the past, mass spectrometry has been very expensive, but Lawrence Livermore National Laboratory has been working to produce smaller and less costly mass spectrometry systems for real-time emission and engine combustion measurements

(http://www.Ilnl.gov/IpandC/opportunities93/03 ENVIRONMENT/MASS_SPEC.shtml).

Argonne National Laboratory (ANL) together with industry is investigating the potential and feasibility of passive and active millimeter-wave spectrometry technology for the constant emission monitoring of process effluents. ANL is developing systems in the frequency range or $200-300 \mathrm{GHz}$. The research is looking at both standoff monitoring of wide areas and in-situ monitoring of individual stacks (http://refining.dis.anl.gov/oit/toc/monitor.html). 


\section{Mobile GC-MS System}

This system was developed for the fast analysis of volatile and semivolatile organic compounds in air, water, and soil or on surfaces in emergency situations. It is a semi-automatic GC/MS system that performs sampling and analysis in less than 10 minutes, and the following sample collection and preparation methods are defined as follows:

1. Enrichment of gaseous samples on adsorbents.

The following adsorbents for air sampling were selected based on several hundred samples taken under realistic conditions:

- Tenax. adsorbent for sampling combustion gases with high humidity. The low breakthrough volume of water on Tenax keeps the absolute amount of water low and does not disturb the injection.

- Multi-Bed-Adsorbent Tubes. used for sampling air in case of chemical spills. They contain Tenax in combination with Carbosieve SIII.

The adsorbent tubes are stored in brass cartridges with Teflon ${ }^{\circledR}$ seals and brass swagel ok fittings on both sides. Internal standards are preloaded onto the adsorbent by injection of $5 \mu \mathrm{l}$ methanolic solution (d6-benzene, d8-toluene, d10o-xylene, d8-naphthalene; 500 ng each).

2. Volatiles in water by "Purge and Trap"

Water samples are collected in $250 \mathrm{ml}$ bottles with screw caps. For the extraction of volatiles, a special cap is used that has a glass tube with a frit and a sample cartridge fastened on top. The sample is purged by drawing ambient air through the device by means of a hand pump ( 10 strokes $=1$ I, $6 \mathrm{kB}$ ). The simple purge-and-trap method is limited to non-foaming samples without surfactants, as often used in fire fighting operations.

3. Volatiles in water by "Spray-and-Trap"

In case of water with surfactants, use the "Spray-and-Trap" apparatus. The water sample in bottle 1 is pumped to bottle 2 and sprayed by a continuous flow of spray gas towards the bottle wall. The analytes are trapped on a Tenax tube and extraction takes 4 minutes. Because foaming is prevented, this method is especially useful for the analysis of heavily contaminated water. From the field 
study, it was found that dilution of real water samples (factor 10) is often necessary to avoid overloading of the analytical system.

\section{Semivolatiles in water by liquid-liquid extraction}

To extract semivolatiles from water, pour the sample $(250 \mathrm{ml})$ into a disposable PE-bottle. Since in most cases heavily contaminated samples (> $1 \mathrm{mg} / \mathrm{L})$ are treated, compound loss at the PE-bottle walls does not measurably influence the results. Perform the extraction by shaking the sample with $5 \mathrm{ml}$-hexane, containing the internal standards. The organic phase separates on top of the water layer and is elevated by squeezing the PE-bottle. Take out a $5 \mu$ quantity of extract from the separation tube on top of the bottle and transfer it to a "silicoat" tube.

\section{Volatiles in soil by headspace analysis}

Load $10 \mathrm{ml}$ of soil into a $20 \mathrm{ml}$ PE-syringe integrated into a screw cap. Completely transfer the sample into a $100 \mathrm{ml}$ bottle and add $5 \mu \mathrm{l}$ quantities of methanolic solution of internal standards. Then close the bottle with the "headspace operation cap" and thermostatted at $80^{\circ} \mathrm{C}$ for $5 \mathrm{~min}$. After opening a venting screw, the headspace gas is purged to the Tenax trap by applying 1 stroke $(100 \mathrm{ml})$ from the hand gas pump.

\section{Semivolatiles in soil by ultrasonic extraction}

Take $2 \mathrm{ml}$ of soil sample with a $5 \mathrm{ml} \mathrm{PE}$-syringe fastened to the screw cap of a test tube. For transportation to the GC/MS, screw the cap onto the test tube. Before extraction, completely push the sample into the tube and add $10 \mathrm{ml}$ of acetone containing the internal standards (d8-naphthalene, d10-anthracene; 500 ng each). After $5 \mathrm{~min}$ of ultrasonic treatment, pipette $5 \mu \mathrm{l}$ of extract into a "silicoat" tube and analyze.

\section{Surface contaminants analysis}

The setup for analysis of surface contaminants consists of several different devices. For liquids and solid substances, integrate different sample collection "pins" into the test tubes lids. Small amounts of released substances are taken up with the pins and carefully stripped off on a "silicoat" tube. The substances are then thermally desorbed. To sample a compound layer, wipe the surface with a strip of silicone-coated spun glass. The strips are transferred into a glass tube and thermally desorbed. 
Install the analytical equipment in a portable instrument case, constructed for analyzing under rough environmental conditions. Glass bottles are plastic coated on the outside to provide protection against mechanical damage. Mount the "Spray-and-Trap" apparatus in an extra housing. The GC/MS system, including batteries for two-hour operation and a data transmission system, is mounted on a stretcher and weighs $120 \mathrm{~kg}$. The complete instrumentation can be transported by van or helicopter. This information was obtained from the website:

http://www.tu-harburg.de/et1/umwelt/alfred/sample.html.

\section{Detection of Flawed Sensors.}

Expert Microsystems, Orangevale, CA, and Argonne National Laboratory have developed a sophisticated mathematical model to determine when electronic sensors give false readings. I nitially, the software was developed for NASA, but eventually industries and utilities will benefit also. When a sensor produces an unusual reading, it may signify that the process being monitored is degrading or that an environmental condition or faulty sensor is creating a false signal. The prototype computer software package (Dynamic Sensor Validation System [DSVS]) is based on the patented Multivariate State Estimation Technique System developed by Argonne. The objective of DSVS is to compare the accuracy of previous sensor readings with current readings and calculate the probability that current readings are accurate

(http://www.anl.gov/OPA/news98/news980206.html). 


\section{Guidelines for Selecting PCE Subsystems}

\section{Introduction}

Before selecting PCE, it is essential to fully understand the industrial environment in which the equipment will be employed. Hostile gases, toxic fumes, oil and grime, and extreme temperatures can damage and destroy sensors and the monitoring processes involved.

\section{Selecting PCE to Meet Future Requirements}

- Define project scope Calculate how much exhaust and at what temperature the exhaust is emitted. Know the State and Federal EPA compliance requirements.

- Stay current with the commercially available PCE that applies to your processes.

- Pilot test. If uncertainty exists regarding the suitability of a specific technology in regard to your process, test it on-site with a small test unit (American Dyestuff Reporter, 21).

\section{PCE Implementation Checklist}

The operation and maintenance of pollution monitoring and control equipment must start on the designer's desk. Equipment that is designed for easy maintenance can save thousands of dollars during the life of the equipment. It is important to have a complete package so that there are few add-ons to the completed equipment installation. Add-ons usually require further maintenance thereby causing unnecessary time delays in repair. Appendix B outlines general guidelines for those persons involved in purchasing or designing pollution control equipment systems. 


\section{Estimation}

As the laws become more stringent, the cost of pollution control equipment increases and the technology used in the past to control pollution is now inefficient. The higher cost of PCE is partly due to the increasing difficulty of capturing the additional submicron particulate. In the past as problems were identified, technology was applied to correct the problems. This "end-of-pipe" treatment proved to be inefficient as well as costly. A more holistic approach is now sought, whereby waste materials do not reach the end of the process and then require disposal or storage.

Military manufacturing plants must budget not only for the pollution control equipment itself, but also for its operation and maintenance. It is important that accurate cost estimates from commercial vendors be made available to establish expenditure priorities. Factors affecting equipment costs include DOD policies, local and Federal government regulations, and national economic conditions. Cost estimates can be classified by the degree of accuracy required. The levels of accuracy in estimating equipment costs are (Cooper, $p$ 90):

1. Order of magnitude estimate for conceptual planning (accuracy $\pm 50 \%$ ).

2. Preliminary estimate for the initial go or no goes decision on a project (accuracy $\pm 25 \%$ ).

3. Final detailed engineering estimate for preparation of budget requests (accuracy $\pm 5 \%$ ).

Usually cost data are several months to several years out of date and must be adjusted for inflation. To update equipment cost, a cost index may be used, for example, the Consumer Price Index (CPI), which provides a measure of inflation each year. Process equipment costs can be correlated with size or capacity as shown in the following relationship:

$$
\cos t_{\mathrm{B}}=\cos t_{\mathrm{A}}\left(\frac{\text { capacity }_{\mathrm{B}}}{\text { capacity }_{\mathrm{A}}}\right)^{b}=\cos t_{\mathrm{A}}\left(\frac{\text { size }_{\mathrm{B}}}{\text { size }_{\mathrm{A}}}\right)^{b^{\prime}}
$$

[Eq 4]

where:

capacity $_{\mathrm{B}}=$ equipment throughput, in standard units of cfm, gpm, etc. 
size $_{\mathrm{B}}=$ equipment size, in standard units of sq ft, cu ft, etc.

$b, b^{\prime}=$ constants (the exponents vary from 0.5 to 0.8 and average between 0.6 and 0.7 for many types of equipment).

There are two ways of approaching the implementation of pollution control equipment into an industrial process:

1. An end of the pipe design

2. An entire process design.

Before purchasing pollution control equipment, determine which of these methods of design you will be adopting. Collect data from pre-existing process controls to give the proposed new pollution control system a chance of being entirely self-correcting, rather than an end-of-process go-no-go indicator. Making the system entirely self correcting offers the chance of running a plant more efficiently, thus justifying the cost of usage rather than running an end-ofpipe option in which no one wants to be involved. Remember that it may be more cost effective to redesign a process and install pollution control equipment at strategic points, than to install pollution control equipment at the end of the pipe. 


\section{Summary}

This study has provided guidelines for designing pollution control equipment (PCE) components for DOD installations. The guidelines cover only major components that are common to all PCE. Commercially available PCE that may help curb known pollution emission problems at DOD installations were identified (Appendix A). Critical components of PCE were identified and independently studied:

\section{Filters (Ch 2)}

\section{Controls (Ch 3)}

\section{Motors (Ch 4)}

4. Sensors (Ch 5).

Research results were incorporated into implementation guidelines for DOD installations to help installation personnel select the most cost effective PCE to adequately deal with the pollution emanating from Army manufacturing processes (Ch 6, Appendix B).

Decisions for selecting PCE components are installation and process specific, and it is not the intent of this study to look at installations and processes individually. The designer should study the checklist (Appendix B) carefully before making decisions about acquiring or modifying current PCE. Also, check all applicable Federal and State Regulations and available control data to understand what is required in terms of emissions. 


\section{References}

Alger, P.L., Induction Machines (Gordon and Breach, New York, 1970).

ANSI/NFPA 70, National Electrical Code, Artide 500 (1990).

Berkowitz, J oan B., J ohn T. Funkhouser, and J ames I. Stevens, Unit Operations for Treatment of Hazardous I ndustrial Wastes (Noyes Data Corporation, Park Ridge, NJ , 1978).

BHA Group of Kansas City, Missouri, USA, "Reducing Energy Costs via Air Pollution Control Equipment.," World Cement, vol 23 , No. 11 (1992), pp 37-39.

Buonicore, Anthony J., and Wayne T. Davis (eds.), Air Pollution Enginering Manual (Van Nostrand Reinhold, New York, 1992).

Butow, Raymond, "Photoelectric Sensors for Industrial Systems," Mechanical Engineering, vol 118, No. 3 (1996), pp 122-124.

Campbell, B.H., "Failed Motors: Rewind or Replace," IEEE Industry Applications, vol 3, No. 1 (J anuary/F ebruary 1997), pp 45-50.

Cheremisinoff, Nicholas P., and Paul N. Cheremisinoff, Filtration Equipment for Wastewater Treatment (Prentice Hall, Englewood Cliffs, NJ , 1993).

Cooper, C. David, and F.C. Alley, Air Pollution Control - A Design Approach, 2d ed (Waveland Press, Inc., Prospect Heights, IL, 1994).

Daugherty, J ack E., Industrial Environmental Handbook (Government Institutes, Inc., Rockville, MD, 1996).

De Nevers, Noel, Air Pollution Control Engineering (McGraw-Hill, Inc., New York, 1995).

Department of Measurement Engineering, Technical University of Hamburg-Harburg, "Sensor Array for the Detection of Hazardous Compounds,"

(http://www.tu-harburg.de/et1/umwelt/torsten/sensor.html).

DialSearch Literature Search Service, Pollution Control Cost Analysis (1996).

"Electromagnetic Measurements," IEEE Transactions on Instrumentation and Measurement, vol IM-35, No. 4, pp 456-462 (December 1996).

Environmental Equipment Consulting \& Production, Inc. Home Page.

EPA/540/F-92/008, Metals Treatment at Superfund Sites by Adsorptive Filtration, Emerging Technology Bulletin (1992). 
EPI.89/4:540/AR-93/513, EPOC Water Inc. Microfiltration Technology, Applications Analysis Report (1995).

“Glass Industry," Exhibit in print, Pollution Control Equipment (May 1994), pp 23-25.

Hodowanec, M.M., "Effects of Coupling Insulation on Motor Performance," IEEE Industry Applications, vol 3, No. 1 ( anuary/February 1997), pp 70-77.

Huisman, L. and W.E. Wood, Slow Sand Filtration (World Health Organization, Geneva, 1974).

J ohnson, J.H., and M.J. Poskin, Industrial Instrumentation for Quality Assurance, Catalog of Systems Available for Real Property Quality Assurance Applications, Technical Report (TR) FF-95/02/ADA292745 (U.S. Army Construction Engineering Research Laboratories [USACERL], November 1994).

J ohnson, J .H., and M.J. Poskin, Investigation of Sensor/ Measurement Systems for Army InstalIation QA Applications, TR FF-93/14/ADA274851 (USACERL, September 1993).

Mitchell, J ohn S., "MIMOSA - One Year Later," Sound and Vibration (September, 1996). (More information on MIMOSA is available on its internet web page at: www.hsb.com/pcm/mimosa/mimosa.html.)

Mycock, J .C., J .D. McK enna, and L. Theodore, Handbook of Air Pollution Control, Engineering and Technol ogy (Boca, Lewis, 1995).

Nailen, R.L., Managing Motors (Barks Publications, Chicago, IL, 1991).

NEMA Std MG1, Motors and Generator (1993).

O'Connor, David, “Tougher Environmental Regulation Drives New Technology for Air Pollution Control Equipment," American Dyestuff Reporter, vol 82, No. 8 (1993), pp 17-21.

O'Connor, E.T., D. Kermath, and M.R. Kemme, Environmental Sensor Technologies and Procedures for Detecting and Identifying Indoor Air Pollution, TR P-92/07/ADA251882 (USACERL, March 1992).

Patel, Ahul, and Dennis Clifford, Radium Removal from Water by Manganese Dioxide Adsorption and Diatomaceous Earth Filtration, EPA Project Summary EPI.89/2:600/S2-91/063 (1992).

Permutit-Boby Australia, "Integrated Water and Wastewater Treatment Facility for Toyota," Process Enginering, vol 20, No. 7 (1992), p 15.

Public Works, Novel Incinerator Gas Clean-U p Retrofit Passes Six-M onth Test (1989), p 83.

"Pollution Control and Water Treatment," Process and Control Engineering, vol 48, No. 8 (1993), pp $18,20,22,24,26$.

Sensors and Actuators, A (Physics) and B (Chemical) editions. A- vol 41/42 (1994), 43 (1994), 46/47 (1995), 52 (1996), 56 (1996); B- vol 20 (1994), 23 (1995), 29 (1995). 
Smith, Clyde M., and William E. Brown, "Elimination of VOC Emissions from Surface Coating Operations," Air \& Waste, vol 43 (1993), pp 1015-1019.

Sprangle, P., A. Ting, E. Esarey, R. Hubbard, and B. Hafizi, Active Remote Sensing Using UItra Broadband Radiation, NRL/MR/6790-96-7885 (Naval Research Laboratory, Washington, DC, 1996).

Up-Flow, Expanded Bed, Granular-Activated Carbon Bioreactors for Treatment of Propellant Wastewaters Fact Sheet UL 20 (USACERL, 1995).

U.S. Department of Energy DOE/CE-0384, Energy-Efficient Electric Motor Selection Handbook, Revision 3 (J anuary 1993). 


\section{Appendix A: Review of Pollution Control Equipment (PCE)}

Waste streams emitted to the environment may be in gaseous, liquid, or solid form. PCE may be used to limit the amount of emission to the environment. Effective pollution control equipment must optimize operational efficiency, increase productivity, and protect the environment by dealing with both primary and secondary emissions. The relatively high cost of pollution control equipment requires proper selection to ensure that the chosen equipment is designed to comply with regulatory emission limitations on a continual basis. Interruptions in PCE operations may be the cause of large fines to installations. Four critical components in common with most PCE are: (1) filters, (2) controls, (3) motors, and (4) sensors.

However, even though PCE is costly, it is worthwhile to look at the costs incurred by the DOD for treating and disposing of waste materials at installations. Table A1 shows Army-wide costs and Table A2 Army Materiel Command (AMC) costs derived from the Directorates of Public Works Annual Summary of Operations "Red Book," Volume III (Fiscal Year 1995).

Table A1. Army-wide totals for treating and disposing of installation waste (Red Book).

\begin{tabular}{|l|l|r|r|}
\hline Description & Unit & \multicolumn{1}{l|}{ Quantity } & \multicolumn{1}{c|}{ Total Costs (\$) } \\
\hline Wastewater plant operation & $\mathrm{K} \mathrm{gal}$ & $27,668,111$ & $21,620,224$ \\
\hline Industrial wastewater treatment facility & $\mathrm{K} \mathrm{gal}$ & $3,343,118$ & $6,854,591$ \\
\hline Industrial wastewater treatment plants & $\mathrm{K} \mathrm{gal}$ & 730,301 & $5,132,585$ \\
\hline Wastewater collection systems (include pumping) & $\mathrm{K} \mathrm{lin} \mathrm{ft}$ & 54,138 & $24,359,186$ \\
\hline Indus wastewater collection systems (include pumping) & $\mathrm{K} \mathrm{lin} \mathrm{ft}$ & 4,512 & $4,110,886$ \\
\hline Untreated industrial waste/cool wt & $\mathrm{K} \mathrm{gal}$ & $27,130,444$ & 184,320 \\
\hline Wastewater plant buildings & $\mathrm{K} \mathrm{sq} \mathrm{ft}$ & 602 & 407,600 \\
\hline Refuse handling & & $126,626,114$ & \\
\hline Incineration (collection through disposal) & tons & 106,151 & $5,590,663$ \\
\hline Landfill Army-owned (collection through disposal) & tons & 843,500 & $21,939,417$ \\
\hline Landfill other (collection through disposal) & tons & $1,009,252$ & $68,370,396$ \\
\hline Other disposal costs (collection through disposal) & tons & 267,703 & $22,536,287$ \\
\hline
\end{tabular}


Table A2. Army Materiel Command (AMC) totals for treating and disposing of installation waste (Red Book).

\begin{tabular}{|l|l|r|r|}
\hline Description & Unit & \multicolumn{1}{|l|}{ Quantity } & \multicolumn{1}{|c|}{ Total Costs (\$) } \\
\hline Wastewater plant operation & $\mathrm{K} \mathrm{gal}$ & $5,454,224$ & $3,969,732$ \\
\hline Industrial wastewater treatment facility & $\mathrm{K} \mathrm{gal}$ & $3,254,976$ & $6,432,509$ \\
\hline Industrial wastewater treatment plants & $\mathrm{K} \mathrm{gal}$ & 55,403 & $3,096,300$ \\
\hline $\begin{array}{l}\text { Wastewater collection systems (include } \\
\text { pumping) }\end{array}$ & $\mathrm{K} \mathrm{lin} \mathrm{ft}$ & 10,458 & $4,281,675$ \\
\hline $\begin{array}{l}\text { Indus wastewater collection systems (include } \\
\text { pumping) }\end{array}$ & $\mathrm{K} \mathrm{lin} \mathrm{ft}$ & 2,229 & $3,722,009$ \\
\hline Untreated industrial waste/cool wt & $\mathrm{K} \mathrm{gal}$ & $26,275,956$ & 99,351 \\
\hline Wastewater plant buildings & $\mathrm{K} \mathrm{sq} \mathrm{ft}$ & 15 & 5,932 \\
\hline Refuse handling & & & $9,387,693$ \\
\hline Incineration (collection through disposal) & tons & 41,234 & 653,076 \\
\hline $\begin{array}{l}\text { Landfill Army-owned (collection through } \\
\text { disposal) }\end{array}$ & tons & 172,419 & $2,070,985$ \\
\hline Landfill other (collection through disposal) & tons & 130,679 & $4,630,411$ \\
\hline $\begin{array}{l}\text { Other disposal costs (collection through } \\
\text { disposal) }\end{array}$ & tons & 13,854 & $1,132,750$ \\
\hline
\end{tabular}

\section{Commercial Off-the-Shelf PCE}

A literary search for commercial off-the-shelf (COTS) PCE was conducted and the search results follow. In addition, some examples of the application of PCE to solve specific industrial pollution problems are included.

\section{Pollution Control Equipment for Air/Gas/Dust}

- Electrostatic Precipitators. United McGill Corporation maintains that electrostatic precipitators provide effective, economical air pollution control for furnaces and other process equipment used in the glass industry. In addition, smaller design size than that of standard precipitators and a reported reduction of power consumption of 70 percent leads to lower costs. The most important component of the electrostatic precipitator is a patented discharge electrode that provides consistent particulate collection. In addition, a high-voltage rapping system reportedly provides effective deaning and a reduction in maintenance costs (Glass Industry, 23).

- Enviroflo Filtration Systems. Edipse Systems, Incorporated, produces two types of Enviroflo filtration systems that it daims provide high efficiency removal of airborne particulates as well as better filter life. The better filter performance is attributed to the full distribution of air flow in sealed filter chambers, higher particulate removal in the prefilter chamber, and higher cubic feet per minute ( $\mathrm{fm}$ ) delivery under loaded filter conditions. The General Capture model deals 
with overhead filtration of general air mass and the Source Capture model acts at the source. Particulate contaminants of 10,000 microns down to 0.01 micron can be filtered by using either model, according to the company (Glass Industry, 23).

- The Tenkay Air Quality Booth. Farr Company offers an air quality booth that endoses and isolates indoor air pollution by continuously washing the enclosed work area with airflows of 100 to $160 \mathrm{ft}$ per minute (fpm). The suppliers of this system affirm that it provides high efficiency removal of hazardous fumes, dust, and other particulates from the work area. Also, the filters enable users to recirculate treated air back into the plant, which reduces heating and cooling costs (Glass Industry, 23).

- The Tube J et Pulse J et Dust Collector. According to the manufacturers (Sly, Incorporated) this piece of equipment is designed to handle dust from less than $100 \mathrm{~cm}$ to more than $100,000 \mathrm{cfm}$. The system does not require tools for filter bag changes and maintains an even pressure drop by periodic on-line compressed air cleaning. The company reports that the compressed air, combined with a venturi designed to multiply its low volume air, deans the entire length of the filter bags, and also that the collector has no internal moving parts and has a 99.9 percent collection efficiency (Glass Industry, 24).

- The OXA 1000. This instrument is a zirconium oxide sensor-based process oxygen analyzer. The company explains that the equipment can provide a wet or dry analysis of process oxygen content in a flowing gas sample for such applications as continuous emissions monitoring systems for USEPA and local governmental emissions compliance. The equipment provides oxygen measurements in 0 to 25 percent linear or 0.25 to 25 percent logarithmic ranges. The key component of the unit is the Hagen zirconium oxide sensor cell, consisting of a zirconia disc coated with porous metal el ectrodes (Glass Industry, 24).

- Biddle 569001 Leak and Corona Detector. The ultrasonic leak and corona detector is for use with electrical corona sources and gas leaks. Both visual and audible outputs indicate the presence of ultrasonic signals from poor connections, faulty equipment, or radio frequency (RF) signal sources. The battery powered unit can detect a 0.002 -in. leak at $5 \mathrm{ft}$ with only $10 \mathrm{lb} / \mathrm{psi}$ pressure. The frequency range is 35 to $45 \mathrm{kHz}$ (Industrial Testing, 117).

- Low Pressure/ Differential Pressure Transmitter (Model 891.09.1968). WIKA Instrument Corporation's low/differential pressure transmitters are designed for the measurement of low and differential pressures of dean, inert, gaseous media. Applications include heating, ventilation, and air conditioning (HVAC) 
draft flow monitoring, pollution control monitoring systems, dust collection systems, and medical equipment. The transmitter uses a linear variable differential transformer (LVDT) sensor to measure very low pressures. The built-in signal conditioning circuit provides a 0 to $10 \mathrm{~V}$ DC 3-wire output signal. In addition, a 4 to $20 \mathrm{~mA}$ 2-wire output signal is available as an option (WIKA, $\mathrm{p} 1$ ). Computer-controlled factory calibration provides for excellent accuracy and long term signal stability. The durable construction is essentially maintenance free.

- Automatic Cleaning High Efficiency Particulate Absolute (HEPA) Filter System. Mac Environmental the supplier of this equipment daims that it offers efficiencies associated with static filters and the added benefit of collecting the filtered particulates in a hopper or drum to dispose of or reuse. Further, the company daims that the Miasmact filter has a life expectancy that is 10 times longer than that of traditional filters. The filter is designed also for heavy duty loads, eliminating the need for prefiltration in most cases. The supplier daims the following benefits from using this filter include a reduction in the cost of filter element replacements, less operator exposure to hazardous or toxic materials, less process variation and downtime, and lower capital, energy, and disposal costs (Glass Industry, 24).

- CPM 5000 with System Monitoring Software The manufacturer (BHA) daims that this is a state-of-the-art, multi-point dust emissions monitoring system. It is designed to provide years of troublefree service with minimal maintenance. The CPM 5000 is manufactured to provide superior monitoring compared to opacity or triboelectric systems, with many new powerful features including multi-point capability (up to 255 points), remote diagnostic capabilities, maintenance-free monitoring, and LASER or light emitting diodes (LED) light source. The patent is pending (BHA Product Spotlight, 1).

- AMAHSCO Ambient Gas Analyzer Transmitter (AGAT). This company has developed an AGAT for transmission of ambient pollution levels. AGAT uses an electrochemical gas sensing cell to generate a 4 to $20 \mathrm{~mA}$ industry standard signal for transmission of the measured values to a chart recorder, personal computer $(\mathrm{PC})$, or programmable logic controller (PLC), from which external control and/or alarming function may be instituted. AGAT contains two adjustable control level setpoints that may be used to drive relay outputs for actuation of external control functions, including ventilation control and alarm systems. Another enhancement is the development of a microprocessor controlled printed circuit board (PCB) with two programmable level control setpoints and a customized sequencing program. This addition is invaluable where time controlled actuation or deactuation of systems is needed. 
- With the provision of a $24 \mathrm{~V} \mathrm{DC}$ power supply and a liquid crystal display (LCD) and/or status indicator light emitting diodes (LED), AGAT-4 is a standalone ambient gas monitor that has four levels of control functions (Process \& Control Engineering, 26).

- Accurate 1 Bag Filter System. In the Accurate 1 bag filter system, the filtration medium is manufactured from pure blown virgin polypropylene using a new computerized technique and the Sentinel Ring from advanced elasomeric material. The combination of the chemical advantages of polypropylene and the mechanical advantages of rubber provides a thermo plastic rubber that suits a broad range of applications. Accurate 1 can be supplied with removal ratings of $1,3,5,10,25$, and $50 \mu$. Its calibration is based on the ISO 4572 single-pass-test procedure and influent and effluent analysis is carried out with a Coulter counter (Process \& Control Engineering, 22).

\section{Pollution Control Equipment for Furnace Flue Gas}

- Model 8104 Portable Flue Gas Analyzer. North American Manufacturing Company produces this self-contained unit that is designed for simple operation while sampling furnace flue gas. The equipment is suitable for low-cost emissions surveys of plants that are preparing to comply with some emissions regulations. The company states that the unit helps to tune-up a furnace quickly and accurately for optimal emissions levels before regulation tests. Its built-in memory can store up to 50 sample readings (Glass I ndustry, 23).

\section{Pollution Control Equipment for VOCs}

- Continuous Stack Gas Monitor. Land Combustion describes its continuous stack gas monitor, FGA 950, as an economical sampling system for environmental efficiency. The system simultaneously monitors NOx, $\mathrm{CO}, \mathrm{O}_{2}$ as well as temperature which is said to provide the basic parameters for environmental concerns, including NOx reduction, and efficiency monitoring in the combustion process (Glass Industry, 24).

- Thermal Recuperative And Regenerative Oxidizers. The manufacturer (Thermo Electron Wisconsin, Inc.) explains that these oxidizers are provided with varying heat exchanger efficiencies ranging from 40 to 95 percent and are available for destruction of a variety of process exhaust VOCs. The systems are provided with insulation and cladding, controls, and instrumentation for environmental reporting. In addition, secondary heat recovery is available (Glass Industry, 25). 


\section{Pollution Control Equipment for Water and Other Liquid Waste}

- Monitors. Siemens now offers two systems to monitor the quality of water in rivers and lakes. The systems continuously record the presence of pollutants in the water and in turn warn the water protection authorities in the event of violation of the specified maximum and minimum levels. The "Sherlock" monitoring system is a mobile unit for use on river banks and lake shores. The second product, the "Merlin" monitoring system, is a floating unit. Both units are battery-powered enabling them to be rapidly activated as required. The data recorded by the two systems are transmitted by radio link to a computer center (Process \& Control Engineering, 18).

- Effluent Monitoring. Watertec Engineering has designed the Aldos range of microprocessor controlled instrumentation specifically for multiplexing monitoring functions in the wastewater and effluent fields. The equipment uses microprocessor technol ogy to monitor up to three different process parameters in the one instrument. It can simultaneously monitor $\mathrm{pH}$ values, reductionoxidation (redox) potential and chlorine/chlorine dioxide or ozone levels such that all results are displayed on the one instrument. The split liquid crystal display (LCD) enables operators to monitor all three functions at any one time (Process \& Control Engineering, 18).

- Calfran International's Cold Vaporization Units. These units are used to solve plating waste treatment problems. The system operates unattended at very low temperatures such that plating solution additives do not decompose, corrosion and scaling are negligible, and there is very little maintenance and operator time required. The process is 5 to 10 times more energy efficient than atmospheric evaporators and requires no air discharge permitting. In addition, there are no chemicals to store or handle, no membranes to soil or be destroyed, and no ion exchange media to be contaminated or be regenerated.

Cold Vaporization is suitable for a wide variety of plating waste in the same machines including spent baths, rinse waters' cleaning solutions, strips, strong acids or bases, all with pretreatment. In some cases Cold Vaporization can complement existing plant installations such as treating the reject from a reverse osmosis installation or processing the ion exchange regenerant. In new installations, it is more effective to use a Cold Vaporization unit to perform all of the treatment directly, eliminating the support equipment and operator time that the other processes require (Process \& Control Engineering, p 24).

- Discflo Pumps. The company maintains that its nonimpinging, nondogging, rotary disc pumps can handle a great variety of difficult fluids that flow through wastewater systems. The pumps can process fluids ranging from heavy viscous $(100,000+$ cubic pounds per second) sludges and scums to high percentage (70+ 
percent) air-entrained froth and foam, from highly abrasive grit to low shear flocculents, and from large sol ids and stringy fibers to delicate anaerobes.

The non-clogging, non-pulsating pumps can deal with radical fluid fluctuations and are able to run on "shut off" without pump damage and contend with twophase fluids with no emulsification. In addition, the pumps offer low cost pump maintenance, repair, and downtime (Process \& Control Engineering, p 26).

- Pumps for Toxic Compounds. Kelair Pumps Australia designed the HMD magnetic drive seal-less pump that allows safe handling of compounds while they are in a toxic form without threatening the environment. The principle of operation of magnetically driven seal-less pumps implies that there is no connection between the driven pump shaft and the drive motor. The seal-less magnetic drive occupies the space normally occupied by a mechanical seal or stuffing box.

The passage of liquid to the outside environment is prevented by a rear casing or cylindrical isolation shell attached to the conventional pump volute and sealed by a flat gasket. The centrifugal impeller is supported on plain bearings inside the isolation shell which also houses the inner rotor or flux receiving ring. An outer magnet ring rotated by a suitable prime mover is outside the isolation shell. Magnetic flux passes through the air gap and isolation shell to the inner rotor which in turn follows after the outer rotor without any physical contact. The isolation or containment shell prevents leakage out of or into the pump system and is about $1.5 \mathrm{~mm}$ thick (Process \& Control Engineering, p 20).

- Horiba Continuous Monitoring System (CMS). This system available from Email Electronics provides continuous emission monitoring based on NDIR, CLD, FID, and magnetopneumatic analyzing principles. All parts in contact with samples are made from nonabsorptive corrosion-resistant Teflon ${ }^{\circledast}$ or polyvinyl chloride (PVC). The continuous monitoring emission monitoring system (CEMS) range provides continuous monitoring at 0 to 25 parts per million (ppm) full scale levels for over 29 different component combinations (Process \& Control Engineering, 26).

\section{Case Studies of PCE Applications in Industry}

\section{EEC OIL-SEP (Environmental Equipment Consulting \& Production, Inc.)}

The EEC OIL-SEP is a commercially-available system designed for handling wastewater containing pollutants, to meet effluent treatment requirements. 
The system comprises a singlestage device that is designed to separate and remove insoluble oil, solids, and entrained air from oily water. The equipment is designed for both continuous and intermittent operation and does not need the addition of chemicals or other additives. After initial start, the equipment can operate automatically.

EEC OIL-SEP combines a mechanical rotating coalescing fiber and stationary polishing pack that provide an efficient and effective means for separating oil from water. The system design also eliminates the need to change or replace filters or filtering media. The fabricated vessel consists of a series of matrix plate pack assemblies that are fitted in a vertical position to enhance solid removal. The plate assemblies are manufactured from corrugated, rigid, PVC sheets. Figure Al shows the use of corrugated sheets in the plate pack assemblies that greatly increases the contact time between the oily water and the corrugated sheets that accelerates the coalescing process (Environmental Equipment Consulting (EEC) \& Productions, Inc. H ome Page).

EEC OIL-SEP design specifications including capacity, length, width, height, and weight for various models are included in Table A3. Table A4 lists some of the standard features and Table A5 lists special features of EEC OIL-SEP.

\section{Evaporative Cooler/Precipitator}

A package of PCE was retrofitted into two, 250-ton/day (tpd) municipal incinerators by the Central Wayne County, MI, Sanitation Authority to meet tighter county air quality codes. The PCE was required to perform four functions: (1) fit into the existing incinerator systems to minimize the retrofit expense, (2) lower flue gas temperatures so that the induced draft fan, ductwork, and precipitator could handle the gases without damage, (3) condition the gases with water vapor to enhance the precipitator performance characteristics, and (4) reduce flue gas volume and subsequently the precipitator's size and cost. 


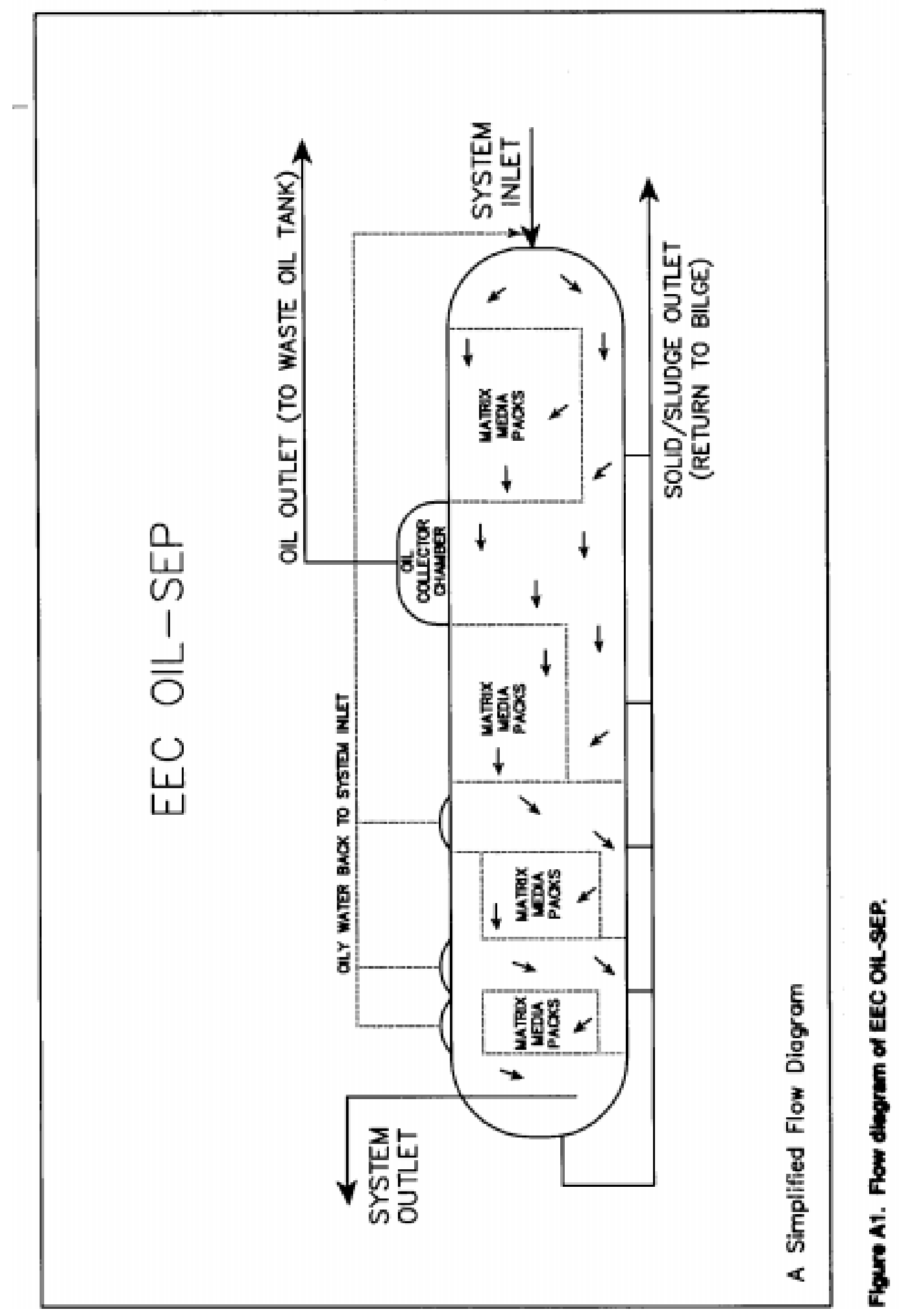


Table A3. EEC OIL-SEP design specifications.

\begin{tabular}{|l|l|l|l|l|l|l|}
\hline Model & M1000 & M2000 & M2500 & M5000 & M10000 & M11000-M200000 \\
\hline Capacity & 1 cu.m/d & 2 cu.m/d & 4 cu.m/d & 5 cu.m/d & 10cu.m/d & 仓े \\
\hline Capacity & $264 \mathrm{gpd}$ & $528 \mathrm{gpd}$ & $1056 \mathrm{gpd}$ & $1320 \mathrm{gpd}$ & $2376 \mathrm{gpd}$ & 仓े \\
\hline Length & $1270 \mathrm{~mm}$ & $1270 \mathrm{~mm}$ & $1270 \mathrm{~mm}$ & $1473 \mathrm{~mm}$ & $1473 \mathrm{~mm}$ & 仓े \\
\hline Width & $610 \mathrm{~mm}$ & $610 \mathrm{~mm}$ & $610 \mathrm{~mm}$ & $610 \mathrm{~mm}$ & $610 \mathrm{~mm}$ & Custom Made \\
\hline Height & $635 \mathrm{~mm}$ & $635 \mathrm{~mm}$ & $686 \mathrm{~mm}$ & $686 \mathrm{~mm}$ & $990 \mathrm{~mm}$ & 几 \\
\hline Weight & $125 \mathrm{~kg}$ & $134 \mathrm{~kg}$ & $159 \mathrm{~kg}$ & $170 \mathrm{~kg}$ & $241 \mathrm{~kg}$ & Л \\
\hline
\end{tabular}

Table A4. EEC OIL-SEP standard features.

\begin{tabular}{|l|}
\hline Standard Features \\
\hline No expensive, messy filters. \\
\hline $\begin{array}{l}\text { Self-cleaning, polishing pack never needs } \\
\text { replacing. }\end{array}$ \\
\hline All automatic operation. \\
\hline Compact and easy to install. \\
\hline Suction directly from bilge. \\
\hline No holding tank required. \\
\hline All separation accomplished in one stage. \\
\hline
\end{tabular}

Table A5. EEC OIL-SEP special features.

\begin{tabular}{|l|l|}
\hline Special Features & Characteristics \\
\hline Controls & $\begin{array}{l}\text { ON/OFF toggle switch Automatic operation ON/OFF toggle switchClean } \\
\text { water inlet pressure regulator and flow control regulator and oil- level } \\
\text { sensor. }\end{array}$ \\
\hline Separable oils & $\begin{array}{l}\text { Animal oils and fat, automative gasoline and oil, ballast water, bilge water, } \\
\text { bunker fuel, motor gasoline and oil, transformer oil, vegetable oil, etc. }\end{array}$ \\
\hline Separation Efficiency & Less than 15 ppm oil. Down to 1 ppm free oil. \\
\hline
\end{tabular}

The incinerators burn up the solid waste from five municipalities. The combustion process gives off 200,000 actual cubic feet per minute (ACFM) of flue gas that exits the incinerators at $1,800^{\circ} \mathrm{F}$. The flue gases then go through an expansion chamber where they are cooled slightly. From the expansion chamber, the gases enter the evaporative cooler at 1,600 ${ }^{\circ} \mathrm{F}$ and 200,000 ACF M. In the evaporative chamber, 10 nozzles inject into the gas stream 130 gal per minute (gpm) of water (in micron-sized droplets). The reaction that follows cools the gases by evaporation to $550{ }^{\circ} \mathrm{F}$ that has the effect of reducing the gas volume by 40 percent to 125,000 ACFM. The cooler gases now pass through the fourfield precipitator for particulate removal, an induced draft fan, and up and out through a stack.

The water droplets in the evaporative cooler are 200 times smaller than those from conventional nozzles, so there is quicker evaporation and cooling. The evaporation is so fast and complete that the system functions as a form of dry 
scrubbing. The evaporative cooler occupies only one-fourth of the space of a conventional evaporative cooler (Public Works, p 83).

\section{Integrated Water and Wastewater Treatment Facility for Toyota}

The Wastewater Treatment System is designed to treat five streams from the industrial complex with a combined flow rate of $1940 \mathrm{~m}^{3} /$ day. These streams are: IW-M Steady - Heavy Metal Steady Flow Stream; IW-M Periodic - Heavy Metal Periodic Flow Stream; I W-O Steady - Oily Waste Steady Flow Stream; IWO Periodic - Oily Waste Periodic Flow Stream; and Untreated - Other Factory Wastewaters. With the exception of the untreated flows, all streams are collected in individual equalization tanks.

The Periodic Flow Equalization Tanks transfer water back to respective Steady Flow Tanks and a composite of both streams is treated in separate plants. An Emergency Tank is included so that the Steady Flow Tank for IW-M or IW-O can be bypassed for maintenance. In addition, the Emergency Tank is used when the system is in a recycle mode (that is, when effluent from the final $\mathrm{pH}$ Adjustment Tank fails to meet sewer discharge limits).

The Water Treatment Plant includes two, 50 percent demineralization trains that incorporate sand filters, carbon filters, cation/anion columns, and hydrogen ion polishing (HIPOL) (Process Engineering, 15).

\section{The Mobile Zone Recirculation System}

Surface coating operations using hydrocarbon solvents are a major source of VOCs and hazardous air pollutants (HAPs). In an effort to reduce the exhaust volumes from surface coating operations, Mobile Zone Associates developed a recirculation system that can be incorporated into new construction or retrofitted to existing spray booths. The system will reduce the exhaust volumes ranging from 65 to 95 percent without affecting the production rate, quality, or worker safety. The apparatus is used in conjunction with pollution control equipment.

The apparatus consists of a recirculating system for ventilating air in a paint spray booth. In the Mobile Zone Spray Booth, fresh air enters through a doorway that constitutes about 5 to 35 percent of the total air volume used inside the booth. Figure A2 shows a schematic view of a conventional paint booth (Smith, $p$ 1018) and Figure A3 the Mobile Zone spray booth (Smith, $p$ 
1019). The balance of the air inside the booth is the recycled air that contains residual VOC contamination from previous travels through the booth.

Before fresh air can be introduced into the booth, an equal amount of VOC contaminated air must be removed through the booth exhaust stack. The exhaust stream is then ducted to VOC control equipment such as a carbon adsorption unit or regenerative, recuperative, or catalytic incinerators.

Substantial savings may be achieved when a recirculating system is used in combination with VOC control equipment. The recirculation system concentrates the VOCs into a smaller volume of air that is discharged from the recycle loop, allowing the VOC control equipment to be smaller and less expensive. In addition, the recirculation equipment provides fresh air to the painter.

A spray booth at Kolemba Industries (Gallatin, TN), a commercial job shop finisher that uses solvent-thinned coatings, was used as a test site. The conventional spray booth was modified by the addition of the recirculating system. The recirculating system was designed for a flow rate up to $24,390 \mathrm{cfm}$. After the addition of the recirculating system, the flow rate was 2,325 cfm, a reduction of 90 percent. Table A6 shows estimates of the savings attained by controlling VOC and HAP emissions by installing a recirculating system.

\section{PCE Technology in the Test Phase}

\section{Up-Flow, Expanded Bed, Granular-Activated Carbon Bioreactors for Treatment of Propellant Wastewaters}

The regulation of dinitrotoluene (DNT) in low concentrations in the outflow of wastewater treatment plants is a major problem for Army propellant producers. The U.S. Army Construction Engineering Research Laboratories (USACERL) is presently testing a combined adsorption/biodegradation treatment process to combat this problem.

The DNT (from single and multi-base propellant production) is transferred to the wastewater during wet-screening and water-dry operations. The surface of granular-activated carbon adsorbs nonpolar compounds (for example, DNT) and acts as a storage place to buffer variations in influent concentration. In addition, the surface acts as an attachment medium for bacteria. 


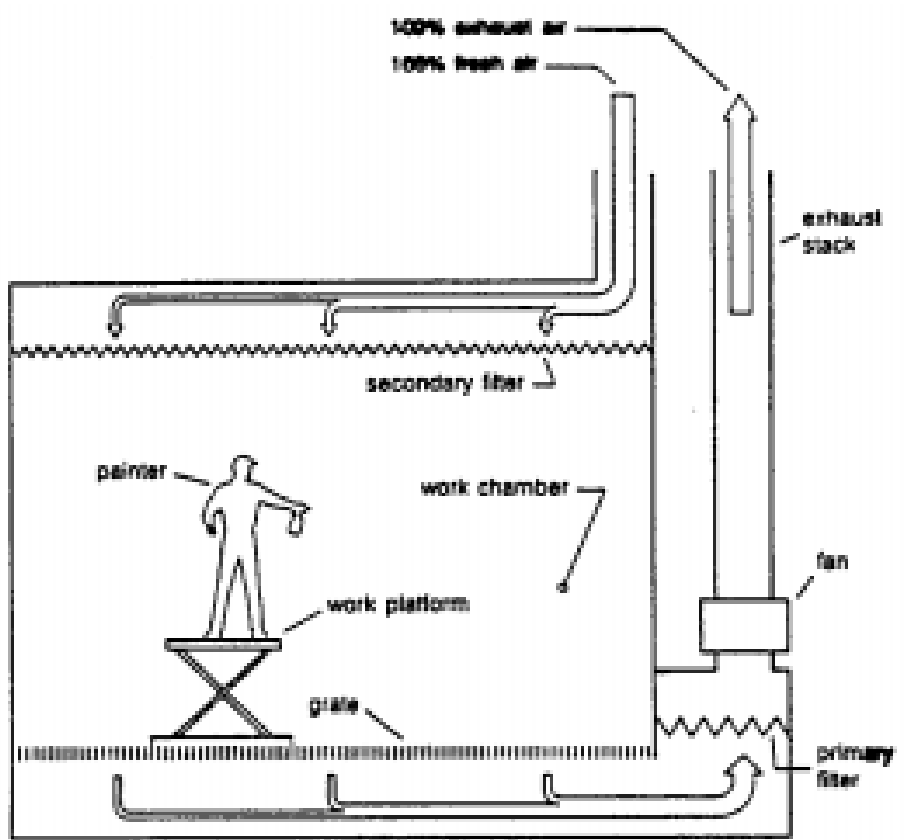

Source: Clyde M. Smith and William E. Brown, "Elimination of VOC Emissions from Surface Coating Operations" (Air \& Waste Management Association).

Figure A2. Conventional spray booth.

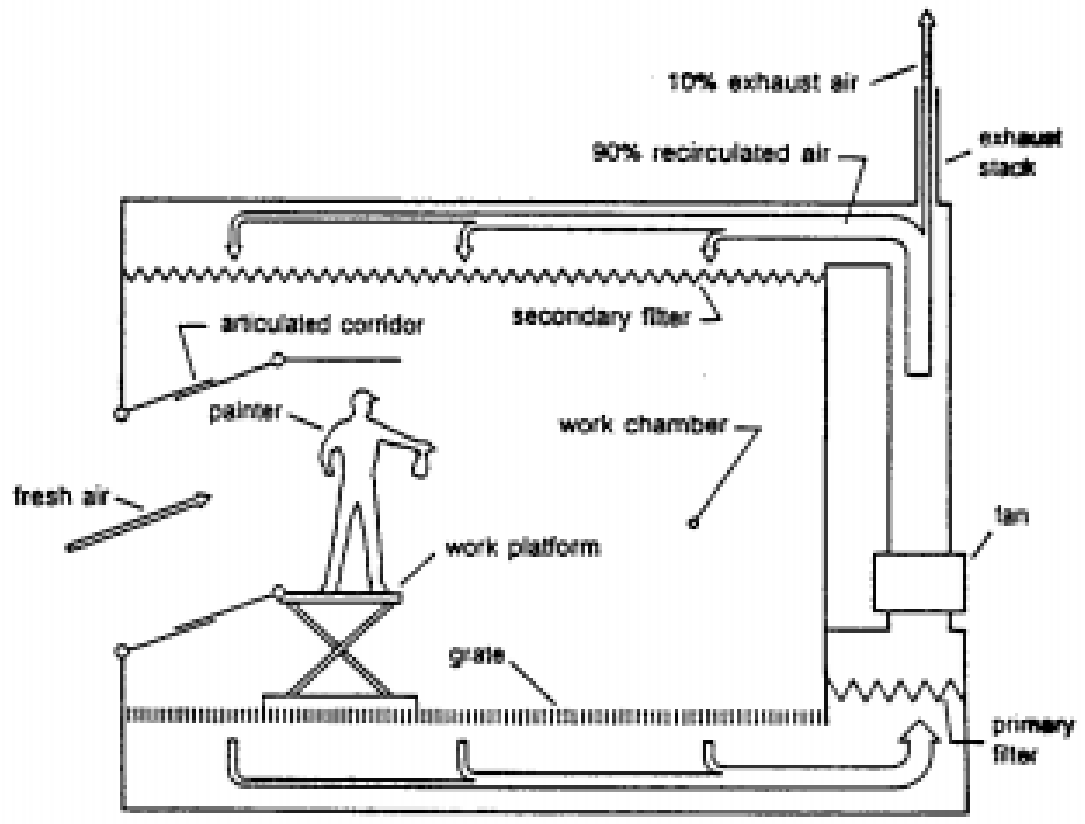

Mobile Zone Spray Booth

Source: Clyde M. Smith and William E. Brown, "Elimination of VOC Emissions from Surface Coating Operations" (Air \& Waste Management Association).

Figure A3. Mobile zone spray booth. 
Table A6. Estimates of savings by installing a recirculating system.

\begin{tabular}{|l|c|c|}
\hline Type of Costs & ${ }^{*}$ Conventional Booth & ${ }^{* \star}$ Recirculating System \\
\hline Fixed bed catalytic incinerator & $\$ 403,600$ & $\$ 108,600$ \\
\hline Installation (direct \& indirect) & 246,200 & 27,200 \\
\hline Mobile Zone Equipment & 649,800 & 50,000 \\
\hline Total capital investment & & $\$ 85,800$ \\
\hline Net Savings & & $\$ 464,000$ \\
\hline $\begin{array}{l}{ }^{*} \text { Conventional Spray Booth with an exhaust flow of 24,390 cfm which requires treatment. } \\
{ }^{* *} \text { Recirculating System with a recirculating system with an exhaust flow of 2,325 cfm which requires } \\
\text { treatment (Air \& Waste, 1015-1019). }\end{array}$
\end{tabular}

This allows the bacteria to thrive in a more uniform aqueous concentration of DNT. The treatment process uses bioreactors that are operated either anaerobically or anoxically in an up-flow, expanded bed mode. These innovations eliminate clogging problems.

USACERL transported a bioreactor to Radford Army Ammunition Plant, VA. The bioreactor successfully treated high strength wastewater directly from a water-dry operation. DNT was reduced by more than 99.9 percent, allowing the new low concentration limits to be met directly at the pretreatment step (Fact Sheet UL 20).

\section{Ultra Broadband (UB) Radiation to Identify Hazardous Air Pollutants}

A report issued by the $\mathrm{N}$ aval Research Laboratory and prepared by researchers from the Beam Physics Branch, Plasma Physics Division \& ICARUS Research gives an account of the experimentation performed on ultra broadband (UB) radiation as a source for detecting and monitoring multi species HAPs in the atmosphere.

Although conventional remote sensing has been in use for some time, the current techniques do not detect many of the HAPs in real time or on a continuous basis. The narrow tuning ranges of LASERS restrict its use to the detection of a select group of predetermined pollutants.

However, since the introduction of ultrashort supercontinuum pulses LASER technology, scientists can study nonequilibrium states of matter and take advantage of the generation of supercontinuum - the production of intense ultrashort broadband "white light" pulses. This allows a third wave-length to be added to the conventional two wave-length system and in turn gives the UB remote sensing system the capability "... of simultaneously interrogating multiple HAPs" (Sprangle, p 2). 


\section{Appendix B: Guidelines for Designing PCE}

\begin{tabular}{|c|c|c|}
\hline \multirow[b]{2}{*}{$\begin{array}{l}\text { The following guidelines are intended to assist process designers in fulfilling } \\
\text { requirements when buying or preparing a contract to purchase pollution control } \\
\text { equipment. }\end{array}$} & Ans. & Notes \\
\hline & & \\
\hline \multicolumn{3}{|l|}{ GENERAL QUESTIONS } \\
\hline \multicolumn{3}{|l|}{$\begin{array}{l}\text { Are there new regulations pending that will require pollution control } \\
\text { equipment?(Check with Environmental Division.) }\end{array}$} \\
\hline \multicolumn{3}{|l|}{$\begin{array}{l}\text { Have you reviewed the law of both the state and Federal EPA to see if you are } \\
\text { required to install pollution control equipment? (Check with Environmental } \\
\text { Division.) }\end{array}$} \\
\hline \multicolumn{3}{|l|}{$\begin{array}{l}\text { Did you negotiate with the state officials to exempt your installation of pollution } \\
\text { control equipment? }\end{array}$} \\
\hline \multicolumn{3}{|l|}{$\begin{array}{l}\text { Has your state approved predictive emissions modeling systems (PEMS) to assist } \\
\text { in the pollution control? }\end{array}$} \\
\hline \multicolumn{3}{|l|}{ Have you reviewed the requirements for Predictive Emission Modeling (PEMS)? } \\
\hline \multicolumn{3}{|l|}{ Have you compared the cost of various pollution control equipment? } \\
\hline \multicolumn{3}{|l|}{ Is there room on an existing control system to meet your requirements? } \\
\hline \multicolumn{3}{|l|}{$\begin{array}{l}\text { Do you understand present parametric monitoring and operations and maintenance } \\
\text { record keeping at your installation? }\end{array}$} \\
\hline \multicolumn{3}{|l|}{$\begin{array}{l}\text { Have you considered the cost of replacement parts for the systems you are } \\
\text { purchasing or designing? }\end{array}$} \\
\hline \multicolumn{3}{|l|}{$\begin{array}{l}\text { Did you do the economic analysis of package systems that includes the operations } \\
\text { and maintenance for at least the life of the equipment? }\end{array}$} \\
\hline \multicolumn{3}{|l|}{ Do you know the Record Keeping requirements for your state? } \\
\hline \multicolumn{3}{|l|}{ Do you know the Reporting requirements for your state? } \\
\hline \multicolumn{3}{|l|}{$\begin{array}{l}\text { Have you interviewed at least two persons at installations where the equipment is } \\
\text { installed and used? }\end{array}$} \\
\hline \multicolumn{3}{|l|}{$\begin{array}{l}\text { Have you contacted the maintenance person that will be expected to maintain the } \\
\text { equipment? (His area of expertise will help guide you in which kind of equipment } \\
\text { to purchase.) }\end{array}$} \\
\hline \multicolumn{3}{|l|}{$\begin{array}{l}\text { Have you read the Quality Assurance Procedures for Pollutant and Diluent } \\
\text { Monitors? }\end{array}$} \\
\hline $\begin{array}{l}\text { Have you reviewed 40CFR Part 75, } 40 \text { CFR Part } 60 \text {, Subpar } \\
\text { Subpart D, CFR Part } 51 \text { Appendix P for comparison? }\end{array}$ & & \\
\hline
\end{tabular}

\footnotetext{
1 Daiva E. Edgar, Gerald t. DeWitt, and Jearldine I. Northrup, The Use of Continuous Emissions Monitoring to Track, Record, and Report Criteria Pollutant Emissions, Technical Report (TR) 96/69/ADA310491 (U.S. Army Construction Engineering Research Laboratories [USACERL], June 1996).
} 


\begin{tabular}{|c|c|c|}
\hline \multirow{2}{*}{$\begin{array}{l}\text { Have you discussed the purchase with the contracting officer at your military base } \\
\text { to ensure that the engineering limitations of the proposed equipment are } \\
\text { understood? }\end{array}$} & Ans. & Notes \\
\hline & & \\
\hline \multicolumn{3}{|l|}{$\begin{array}{l}\text { Does the contracting officer understand that some equipment degrades with time } \\
\text { so that they will not accept equipment that can not show } 98 \% \text { accuracy at time of } \\
\text { purchase? }\end{array}$} \\
\hline \multicolumn{3}{|l|}{ Do you know applicability of the law to the equipment you have chosen? } \\
\hline \multicolumn{3}{|l|}{ SOLID WASTE } \\
\hline \multicolumn{3}{|l|}{$\begin{array}{l}\text { Are designing or purchasing a process involving pollution control equipment for any } \\
\text { of the following: solid waste, municipal waste, hospital waste, coating operations, } \\
\text { toxic waste, or co-generation? If so, please answer the questions }(1-15) \text { where } \\
\text { appropriate. }\end{array}$} \\
\hline $\begin{array}{l}\text { What is the minimum capture efficiency? } \\
\text { Solid waste } \\
\text { Municipal waste } \\
\text { Hospital waste } \\
\text { Coating operations } \\
\text { Toxic waste } \\
\text { Cogeneration }\end{array}$ & & \\
\hline $\begin{array}{l}\text { 2. What is the minimum combustion efficiency? } \\
\text { Solid waste } \\
\text { Municipal waste } \\
\text { Hospital waste }\end{array}$ & & \\
\hline 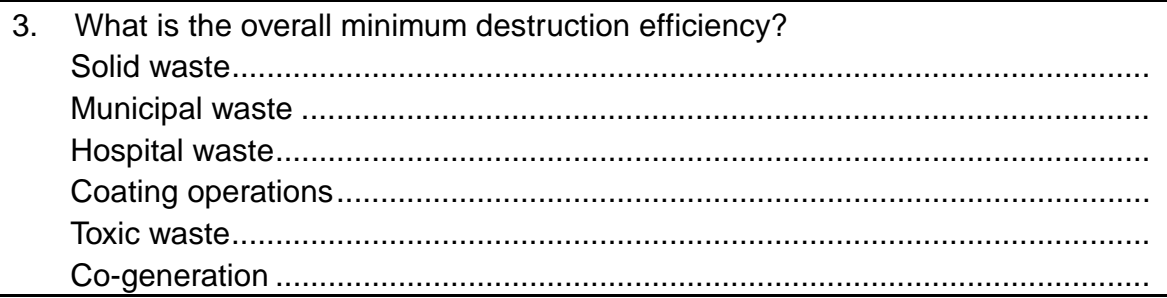 & & \\
\hline $\begin{array}{l}\text { What is the minimum temperature for acceptable destruction (only the ones } \\
\text { you will be handling)? } \\
\text { Solid waste. } \\
\text { Municipal waste }\end{array}$ & & \\
\hline $\begin{array}{l}\text { Change in pressure across catalyst } \\
\text { Solid waste } \\
\text { Municipal waste } \\
\text { Hospital waste } \\
\text { Coating operations } \\
\text { Toxic waste } \\
\text { Co-generation }\end{array}$ & & \\
\hline
\end{tabular}




\begin{tabular}{|c|c|c|}
\hline & Ans. & Notes \\
\hline $\begin{array}{l}\text { What is the minimum catalytic temperature? } \\
\text { Solid waste } \\
\text { Municipal waste } \\
\text { Cospital waste }\end{array}$ & & \\
\hline 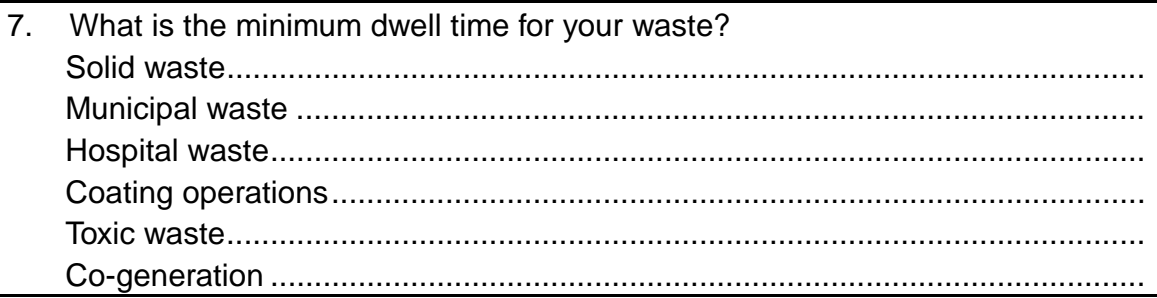 & & \\
\hline 8. Are there safety consideration when testing? & & \\
\hline 9. What is the required dioxin control? & & \\
\hline 10. What are the permit requirements? & & \\
\hline 11. Does the state have a specific list of hazardous/toxic chemicals? & & \\
\hline 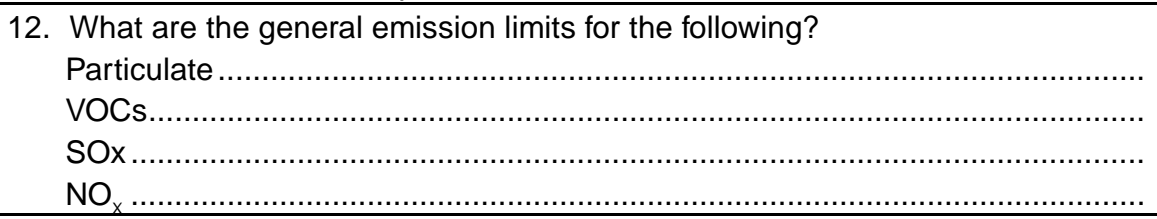 & & \\
\hline 13. Is a particulate pre-filter required on probe? & & \\
\hline 14. Is a heated sample line required on probe? & & \\
\hline 15. What are the opacity limits? & & \\
\hline Is a confirming stack test required, then consider the following questions (1-5)? & & \\
\hline 1. What kind of source is to be tested ( batch, continuous or semi-cyclic)? & & \\
\hline $\begin{array}{l}\text { 2. What is the \% of total capacity that you must operate during acceptance testing } \\
\text { process? }\end{array}$ & & \\
\hline $\begin{array}{l}\text { 3. Are there unusual requirements such as the maximum number of hours per day } \\
\text { that a test team can work? }\end{array}$ & & \\
\hline 4. Number and size of available test ports? & & \\
\hline $\begin{array}{l}\text { During the Stack test consider: } \\
\text { What are the pre-test conditions? } \ldots \ldots \ldots \ldots \ldots \ldots \ldots \\
\text { Which parts of the system require calibration? } \\
\text { Calibration gases required? } \\
\text { Is a heated sampling line required? } \\
\text { Is a detailed test protocol required? } \\
\text { Is detailed quality assurance/quality control plan required? } \\
\text { Is state required to witness test? } \\
\text { Comment on test reports? } \\
\text { Verify that system heat exchanger is not leaking, if applicable? }\end{array}$ & & \\
\hline
\end{tabular}




\begin{tabular}{|c|c|c|}
\hline & Ans. & Notes \\
\hline \multicolumn{3}{|l|}{ FILTERS } \\
\hline \multicolumn{3}{|l|}{$\begin{array}{l}\text { Are filtration systems appropriate to your needs? If you answer Yes to any of the } \\
\text { following questions (1-5), then you should consider alternative particulate control } \\
\text { systems (for example, electrostatic precipitators or high pressure drop wet } \\
\text { scrubbers) should be considered before installing a filtration system. }\end{array}$} \\
\hline $\begin{array}{l}\text { 1. Do you deal with high concentrations of combustible and/or explosive dust? } \\
\text { 2. Do you handle high concentrations of potentially explosive carbon monoxide, } \\
\text { organic vapor, or other gases? } \\
\text { 3. Do you have entrained droplets? } \\
\text { 4. Do you have high concentrations of sticky particulate? } \\
\text { 5. Do you have very high particulate loading ( }>100 \mathrm{gr} / \mathrm{ACF})\end{array}$ & & \\
\hline \multicolumn{3}{|l|}{$\begin{array}{l}\text { Did you know that if efficiencies of }>99.9 \% \text { are required, only High Efficiency } \\
\text { Particulate Absolute (HEPA) type filters are appropriate? }\end{array}$} \\
\hline \multicolumn{3}{|l|}{$\begin{array}{l}\text { Did you know that HEPAs are considerably more expensive than other types of } \\
\text { filtration systems? }\end{array}$} \\
\hline \multicolumn{3}{|l|}{$\begin{array}{l}\text { Did you know that all other types of filtration systems are capable of operating at } \\
\text { efficiencies approaching } 99.9 \% \text { ? }\end{array}$} \\
\hline \multicolumn{3}{|l|}{$\begin{array}{l}\text { Did you know that HEPAs are not appropriate for normal filtering applications, } \\
\text { especially those at gas temperatures exceeding } 250^{\circ} \mathrm{F} \text { or those with moderate-to- } \\
\text { high dust loadings? }\end{array}$} \\
\hline \multicolumn{3}{|l|}{$\begin{array}{l}\text { Did you know that HEPAs long term performance in conventional industrial } \\
\text { applications is probably worse than pulse jet, reverse air, and cartridge filters due } \\
\text { to the better cleaning capabilities of these filters? }\end{array}$} \\
\hline \multicolumn{3}{|l|}{$\begin{array}{l}\text { Are the dust loadings and gas temperatures low? Then, a cartridge filter might be } \\
\text { the lowest cost, easiest-to-maintain alternative for this application. Pulse jets may } \\
\text { also be a good choice in applications involving low dust loadings and low gas } \\
\text { temperatures. }\end{array}$} \\
\hline \multicolumn{3}{|l|}{$\begin{array}{l}\text { Did you know that cartridge units are appropriate when a large number of small } \\
\text { filtration units are needed around a manufacturing facility? }\end{array}$} \\
\hline \multicolumn{3}{|l|}{$\begin{array}{l}\text { Are the temperatures in the range of ambient to } 400^{\circ} \mathrm{F} \text { (the range that covers the } \\
\text { large majority of small-to-medium-sized industrial applications)? If so, the pulse jet } \\
\text { filtration system is the best choice. }\end{array}$} \\
\hline \multicolumn{3}{|l|}{$\begin{array}{l}\text { Did you know that the following filter media fabrics tolerate temperatures from } 180 \\
\text { to } 400^{\circ} \mathrm{F} \text { ? } \\
\text { Natural Fiber, Cellulose (Cotton) - Max. Temperature }\left(180^{\circ} \mathrm{F}\right) \text { \& Continuous Surges } \\
\left(225^{\circ} \mathrm{F}\right) \\
\text { - } \quad \text { Polyolefin - Max. Temperature }\left(190^{\circ} \mathrm{F}\right) \text { \& Continuous Surges }\left(200^{\circ} \mathrm{F}\right) \\
\text { - } \quad \text { Polypropylene - Max. Temperature }\left(200^{\circ} \mathrm{F}\right) \& \text { Continuous Surges }\left(225^{\circ} \mathrm{F}\right) \\
\text { - } \quad \text { Polyamide (Nylon) - Max. Temperature }\left(200^{\circ} \mathrm{F}\right) \& \text { Continuous Surges }\left(225^{\circ} \mathrm{F}\right) \\
\text { - } \quad \text { Acrylic (Orlon) - Max. Temperature }\left(240^{\circ} \mathrm{F}\right) \& \text { Continuous Surges }\left(260^{\circ} \mathrm{F}\right) \\
\text { - } \quad \text { Polyester (Dacron) - Max. Temperature }\left(275^{\circ} \mathrm{F}\right) \& \text { Continuous Surges }\left(325^{\circ} \mathrm{F}\right)\end{array}$} \\
\hline \multicolumn{3}{|l|}{$\begin{array}{l}\text { Are the gas temperatures primarily in the range of } 400 \text { to } 500{ }^{\circ} \mathrm{F} \text { ? If so, consider } \\
\text { the respective merits of both reverse air systems and pulse jet systems in terms of } \\
\text { annualized cost, ease of maintenance, and space requirements. The reverse air } \\
\text { may win on annualized cost, but the pulse jet excels in ease maintenance and } \\
\text { space requirements. }\end{array}$} \\
\hline $\begin{array}{l}\text { Did you know that the following filter media fabrics tolerate temperatures from } 400 \\
\text { to } 500^{\circ} \mathrm{F} \text { ? } \\
\left.\text { - Aromatic Polyamide - Max. Temperature ( } 400^{\circ} \mathrm{F}\right) \text { \& Continuous Surges }(425 \\
\left.{ }^{\circ} \mathrm{F}\right) \\
\text { - Phenyl Sulfide - Max. Temperature }\left(400^{\circ} \mathrm{F}\right) \& \text { Continuous Surges }\left(425^{\circ} \mathrm{F}\right) \\
\text { - Polyimide - Max. Temperature }\left(400^{\circ} \mathrm{F}\right) \& \text { Continuous Surges }\left(425^{\circ} \mathrm{F}\right)\end{array}$ & & \\
\hline
\end{tabular}




\begin{tabular}{|c|c|c|}
\hline \multirow{2}{*}{$\begin{array}{l}\text { Are the gas temperatures above } 500^{\circ} \mathrm{F} \text { ? If so, all of the filter media fabric capable } \\
\text { of operating at temperatures exceeding } 500^{\circ} \mathrm{F} \text { are fabricated only for pulse jet } \\
\text { filtration systems. }\end{array}$} & Ans. & Notes \\
\hline & & \\
\hline 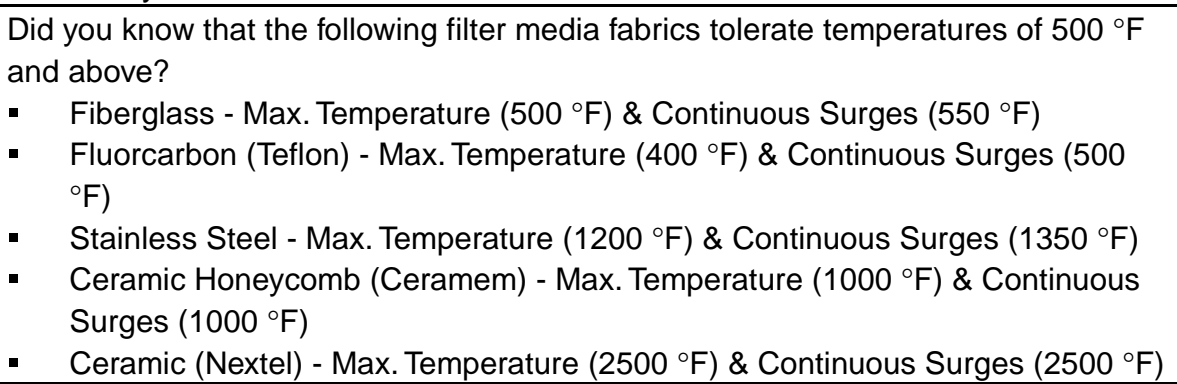 & & \\
\hline $\begin{array}{l}\text { Did you know that the ability of the filter media to withstand short term temperature } \\
\text { spikes depends on the quantity of dust cake? }\end{array}$ & & \\
\hline $\begin{array}{l}\text { Did you know that high temperature damage problems can be avoided by using gas } \\
\text { cooling systems upstream of the baghouse? }\end{array}$ & & \\
\hline $\begin{array}{l}\text { Did you know the most common types of gas cooling systems include the } \\
\text { following? Evaporative coolers, Dilution air systems, Radiant cooling tubes }\end{array}$ & & \\
\hline $\begin{array}{l}\text { Did you know that the following types of filter media have superior cake release } \\
\text { properties? (The media are listed in descending order with respect to the ability to } \\
\text { dislodge the dust cake.) Teflon, woven or felted media, Membrane filter media, } \\
\text { Sintered metal fiber media, Singed filter media }\end{array}$ & & \\
\hline $\begin{array}{l}\text { Did you know that systems should have membrane or teflon bags if they are } \\
\text { handling ammonium bisulfate (or other sticky or highly particulate matter)? }\end{array}$ & & \\
\hline $\begin{array}{l}\text { Did you know that Slow Filtration does not support aftergrowth in the distribution } \\
\text { system \& does not need the addition of chemicals, compresses air, mechanical } \\
\text { stirring, or high-pressure water for backwashing? }\end{array}$ & & \\
\hline $\begin{array}{l}\text { Did you know that sludge from biological filters is handled in a dry state \& the } \\
\text { chance of polluting adjacent watercourses in virtually impossible? }\end{array}$ & & \\
\hline $\begin{array}{l}\text { Did you know that Slow Filtration methods may necessitate the installation of } \\
\text { expensive equipment to prevent freezing? }\end{array}$ & & \\
\hline $\begin{array}{l}\text { Did you know that if the water to be treated is subject to sudden changes in quality } \\
\text { or where certain types of toxic wastes are present, the working of the biological } \\
\text { filter may be impaired? }\end{array}$ & & \\
\hline $\begin{array}{l}\text { Did you know that if your process involves the dewatering of waste sludges, the } \\
\text { vacuum filter (for example the drum vacuum filter or the rotary drum vacuum filter) } \\
\text { may be a good choice? }\end{array}$ & & \\
\hline $\begin{array}{l}\text { Did you know the Internal Rotary Drum Cocurrent Filter should be considered if } \\
\text { your process involves rapid settling slurries? }\end{array}$ & & \\
\hline $\begin{array}{l}\text { Did you know that the Nutsch (flat filtering plate) Cocurrent Filter may be a good } \\
\text { choice if frequent and uniform washings are required? }\end{array}$ & & \\
\hline $\begin{array}{l}\text { Did you know the Horizontal Rotary Cocurrent Filter may be a good option for } \\
\text { filtering quick-draining crystalline solids? }\end{array}$ & & \\
\hline $\begin{array}{l}\text { Did you know that Diaphragm Filters by combining an initial pumping and } \\
\text { subsequent squeezing cycle can reduce the process cycle time up to } 80 \% \text { ? }\end{array}$ & & \\
\hline $\begin{array}{l}\text { Did you know that after a few cycles the filter cloth of the Diaphragm Filter will need } \\
\text { cleaning? }\end{array}$ & & \\
\hline Did you know that Cross-Mode Filters may be used as thickeners? & & \\
\hline $\begin{array}{l}\text { Did you know that although Filter Presses are more effective than Vacuum Filters in } \\
\text { dewatering difficult-to-filter sludges, they have slightly higher capital and operating } \\
\text { costs? }\end{array}$ & & \\
\hline
\end{tabular}




\begin{tabular}{|c|c|c|}
\hline & Ans. & Notes \\
\hline $\begin{array}{l}\text { Did you know that Disk Filters although not as efficient in washing the cake as } \\
\text { Drum Vacuum Filters occupy less floor space? }\end{array}$ & & \\
\hline $\begin{array}{l}\text { Did you know that Filter Presses deliver can operate at both full and reduced } \\
\text { capacity and deliver relatively well washed and dried cakes? }\end{array}$ & & \\
\hline $\begin{array}{l}\text { Did you know that in the treatment of sludges and slurries, volume reduction is the } \\
\text { main function and the Rotary Vacuum or Filter Press is the best choice? }\end{array}$ & & \\
\hline $\begin{array}{l}\text { Did you know that strainers and filter baskets may be used as prefiltering or } \\
\text { prestraining devices to stop larger contaminated particles and prolong the life of the } \\
\text { system? }\end{array}$ & & \\
\hline $\begin{array}{l}\text { Did you know that cotton filter tubes are a good choice, if the moderately acid or } \\
\text { alkaline solution you are filtering is in the } \mathrm{pH} \text { range } 3 \text { to } 11 \text { ?. }\end{array}$ & & \\
\hline $\begin{array}{l}\text { Did you know that polypropylene, Dynel, and porous carbon filter tubes are good } \\
\text { choices for concentrated acid or alkaline solutions (porous stone filter tubes for } \\
\text { concentrated acid solutions)? }\end{array}$ & & \\
\hline $\begin{array}{l}\text { Did you know that polypropylene, Dynel, and porous carbon filter tubes are good } \\
\text { choices for all fluoborate solutions over the entire } \mathrm{pH} \text { range }(0 \text { to } 14) ?\end{array}$ & & \\
\hline $\begin{array}{l}\text { Did you know that polypropylene filter tubes are suitable for electropolishing and } \\
\text { other highly corrosive solutions? }\end{array}$ & & \\
\hline Did you know that filter tubes are suitable for water? & & \\
\hline 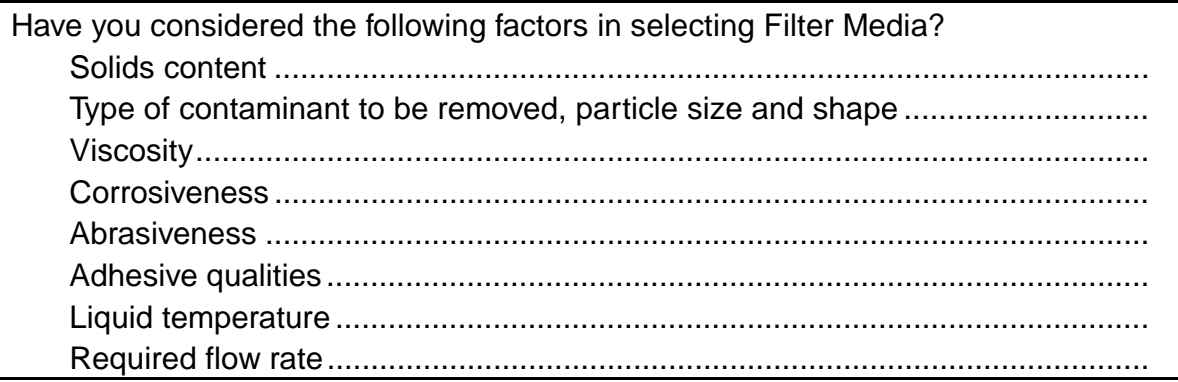 & & \\
\hline 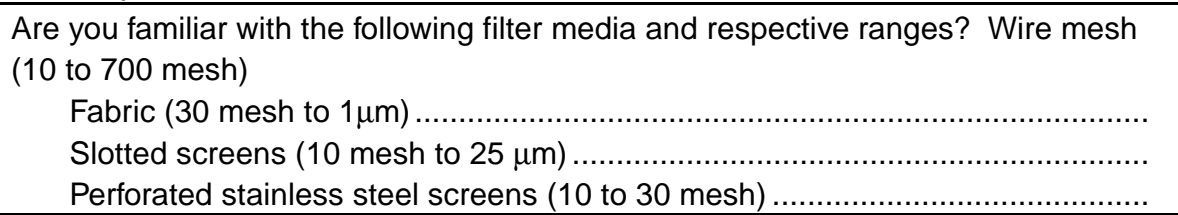 & & \\
\hline 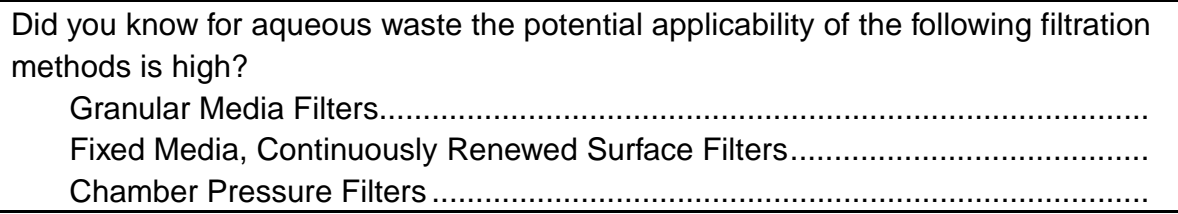 & & \\
\hline 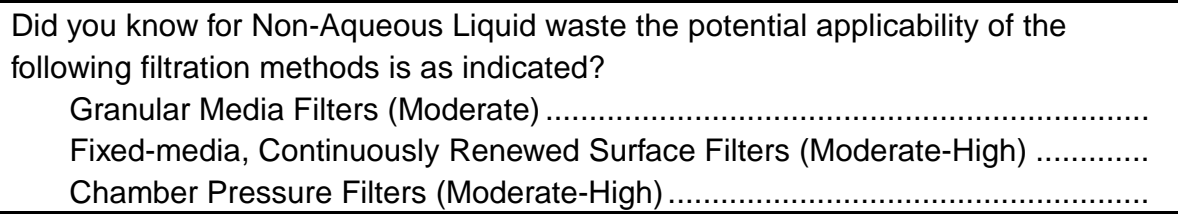 & & \\
\hline $\begin{array}{l}\text { Did you know for Slurries and Sludges the potential applicability of the following } \\
\text { filtration methods is as indicated? } \\
\qquad \text { Granular Media Filters (Low) } \\
\text { Fixed-media, Continuously Renewed Surface Filters (High) } \\
\text { Chamber Pressure Filters (High) }\end{array}$ & & \\
\hline $\begin{array}{l}\text { Did you know that although Surface Filters are very effective in determining the } \\
\text { chemical identity and size distribution of air pollution particles, they are too delicate } \\
\text { and expensive to use as industrial cleaners? }\end{array}$ & & \\
\hline
\end{tabular}




\begin{tabular}{|c|c|c|}
\hline \multirow{2}{*}{$\begin{array}{l}\text { Did you know that fabric filter performance depends on air-to-cloth ratio and } \\
\text { pressure drop? }\end{array}$} & Ans. & Notes \\
\hline & & \\
\hline \multicolumn{3}{|l|}{$\begin{array}{l}\text { Did you know that the most important factor for minimizing Baghouse operating } \\
\text { costs is the medium selected for the bag construction? }\end{array}$} \\
\hline \multicolumn{3}{|l|}{$\begin{array}{l}\text { Have you considered Microfiltration for removing particles in the range } 0.06 \text { to } 2 \\
\text { microns? }\end{array}$} \\
\hline \multicolumn{3}{|l|}{$\begin{array}{l}\text { Did you know that Ultrafiltration removes particles in the range from } 0.002 \text { to } 0.2 \\
\text { microns; however, it has high capital and operating costs? }\end{array}$} \\
\hline \multicolumn{3}{|l|}{$\begin{array}{l}\text { Did you know that Hyperfiltration is an option for removal of the finest particles } \\
\text { (0.0001 to } 0.002 \text { microns)? }\end{array}$} \\
\hline \multicolumn{3}{|l|}{$\begin{array}{l}\text { Have you considered the use of Biofiltration for the treatment of large volume, low } \\
\text { concentration volatile organic compounds (VOC) sources? }\end{array}$} \\
\hline \multicolumn{3}{|l|}{$\begin{array}{l}\text { Did you know that some wet scrubbers can be modified to change them to dry } \\
\text { scrubbers using disposable filters? }\end{array}$} \\
\hline $\begin{array}{l}\text { Have you considered the following? (Table provided by AMETEK - Plymouth } \\
\text { Products Division) } \\
\text { Pleated cellulose polyester cartridges } \\
\text { - } \quad \text { Provide twice the surface area } \\
\text { - Have approx. } 8 \mathrm{ft}^{2}\left(0.74 \mathrm{~m}^{2}\right) \text { filtration area (twice that of standard cartridges) } \\
\text { - } \quad \text { Give high flow rates, low pressure drops \& high dirt-holding capacities } \\
\text { - } \quad \text { Media are fused to end caps and core and the seam is welded to ensure no } \\
\text { bypass } \\
\text { Ratings from } 1 \text { to } 10 \text { micron. }\end{array}$ & & \\
\hline \multicolumn{3}{|l|}{$\begin{array}{l}\text { Select Housings That: } \\
\text { - } \quad \text { Solve problems in high capacity applications } \\
\text { - } \quad \text { Are the highest flow/highest capacity housings available } \\
\text { - } \quad \text { Have flow rates are up to } 50 \mathrm{gpm} \\
\text { Have double- and triple-systems for added capacity or multimedia filtration }\end{array}$} \\
\hline \multicolumn{3}{|l|}{$\begin{array}{l}\text { Radial flow carbon cartridges } \\
\text { - They reduce organics and particulates } \\
\text { - Series RFC is designed to remove organic \& particulate contamination from } \\
\text { plating acid, alkaline \& hydrocarbon solutions } \\
\text { They reduce chlorine gases, organics such as oil mist, water vapor, and fine } \\
\text { particulate from gases }\end{array}$} \\
\hline \multicolumn{3}{|l|}{$\begin{array}{l}\text { Mixed bed cartridges } \\
\text { - } \quad \text { They deionize water to } 16 \text { megohms } \\
\text { - } \quad \text { Cartridges use FDA-grade resin \& post production processing to minimize total } \\
\text { organic carbon level } \\
\text { - Units are applicable to pharmaceuticals, medical laboratory, cosmetics, \& } \\
\text { electronic manufacturing } \\
\text { To attain maximum performance, install after a reverse osmosis or distillation } \\
\text { system }\end{array}$} \\
\hline $\begin{array}{l}\text { Pleated polypropylene cartridges } \\
\text { - } \quad \text { They produce high throughput } \\
\text { - } \quad \text { They feature large surface areas } \\
\text { - } \quad \text { They are excellent in situations that require high flow rates, extremely low } \\
\text { pressure drops \& high dirt holding capacities } \\
\text { Available in a variety of lengths, with ratings from } 0.2 \text { to } 40 \text { microns }\end{array}$ & & \\
\hline
\end{tabular}




\begin{tabular}{|c|c|c|c|}
\hline \multicolumn{2}{|l|}{ Bag filters and housings } & Ans. & Notes \\
\hline \multicolumn{2}{|c|}{$\begin{array}{l}\text { - They are corrosive resistant } \\
\text { - } \quad \text { They are less costly than metal housings } \\
\text { - } \quad \text { Thermally welded seams prevent filter bypass } \\
\text { - } \quad \text { Telted bags have higher loading capacities for less frequent change-outs } \\
\text { - } \quad \text { solvents, oils, acids \& alkalies } \\
\text { - Housings are available in } 1 \mathrm{in} \text {. and } 1-1 / 2 \text { in. inlet/outlet } \\
\text { - Bags are available from } 1 \text { to } 200 \text { micron filtration }\end{array}$} & & \\
\hline \multicolumn{2}{|c|}{$\begin{array}{l}\text { Did you know that typical applications of cartridge filters include? } \\
\text { - } \quad \text { Remove undispersed solidsRemove precipitated solids } \\
\text { - } \quad \text { Protect catalyst beds } \\
\text { - } \quad \text { Remove oversize particles from slurries } \\
\text { - } \quad \text { Protect instruments } \\
\text { - } \quad \text { Clean electrolytic solutionsFilter waste oil for reuse } \\
\text { - } \quad \text { Keep spray nozzles open } \\
\text { - } \quad \text { Filter recirculating waterRemove particles from coatings } \\
\text { - } \quad \text { Filter cooling-tower water } \\
\text { - } \quad \text { Filter condensate } \\
\text { - } \quad \text { Filter scrubber water } \\
\text { - } \quad \text { Filter boiler feed water } \\
\text { - } \quad \text { Filter pump seal water } \\
\text { - Protect reverse osmosis systems } \\
\end{array}$} & & \\
\hline \multicolumn{2}{|c|}{$\begin{array}{l}\text { Did you know some of the following chemical industry applications of cartridge } \\
\text { filters? } \\
\text { - Acetic acidCalcium carbonate } \\
\text { - BrineEthylene glycol } \\
\text { - Herbicides } \\
\text { - Hydrochloric acid } \\
\text { - } \text { Latexes } \\
\text { - Resins } \\
\text { - Polymers } \\
\text { - } \text { Sulfuric acid } \\
\text { - } \text { Cooling-tower water } \\
\end{array}$} & & \\
\hline \multicolumn{2}{|c|}{ Did you check your filtrate and suggested filter from the list below? } & & \\
\hline $\begin{array}{l}\text { Filtrate } \\
\mathrm{Cu}, \mathrm{Fe}, \mathrm{Pb}, \mathrm{Sn}\end{array}$ & $\begin{array}{l}\text { Suggested FilterFluoborates } \\
\text { Polypropylene (PP) or Dynel/PP }\end{array}$ & & \\
\hline \multicolumn{2}{|l|}{ Nonfluoborates } & & \\
\hline $\begin{array}{l}\mathrm{Cu}, \mathrm{Sn}, \mathrm{Zn}:<6 \text { oz/gal H} \mathrm{SO}_{4} \\
\mathrm{Cu}, \mathrm{Sn}, \mathrm{Zn}:>6 \text { oz/gal H} \mathrm{SO}_{4}\end{array}$ & $\begin{array}{l}\text { PP or cotton/PP } \\
\text { PP or Dynel/PP }\end{array}$ & & \\
\hline $\mathrm{Cr}$ & $\mathrm{PP}$ or Dynel/PP & & \\
\hline $\begin{array}{l}\mathrm{Au}, \mathrm{In}, \mathrm{Rh}, \mathrm{Pd} \\
\mathrm{FeCl}(190 \mathrm{~F})\end{array}$ & $\begin{array}{l}\text { PP or Dynel/PP } \\
\text { PP/rigid (RPP) or porous stone }\end{array}$ & & \\
\hline $\mathrm{Ni}$ (Woods) & PP or Dynel/PP & & \\
\hline $\mathrm{Ni}$ (Watts type \& bright) & $\mathrm{PP}$ or cotton/PP & & \\
\hline $\mathrm{Ni}$ (high-chloride) & PP or cotton/PP & & \\
\hline $\mathrm{Ni}$ (sulfamate) & PP or cotton/PP & & \\
\hline Electrotype $\mathrm{Cu}$ and $\mathrm{Ni}$ & PP or cotton/PP & & \\
\hline
\end{tabular}




\begin{tabular}{|c|c|c|c|}
\hline & & Ans. & Notes \\
\hline \multicolumn{2}{|l|}{ Cyanide } & & \\
\hline Sn (stannate) & Cotton/stainless steel (SS) & & \\
\hline Brass, Cd, Cu, $\mathrm{Zn}^{\mathrm{a}}$ & Cotton SS, PP or Dynel/PP & & \\
\hline $\mathrm{Au}, \mathrm{In}, \mathrm{Pt}, \mathrm{Ag}$ & Cotton/SS, PP/PP & & \\
\hline \multicolumn{2}{|l|}{ Pyrophosphate } & & \\
\hline $\mathrm{Cu}, \mathrm{Fe}, \mathrm{Sn}$, etc. & Cotton/SS or PP & & \\
\hline \multicolumn{2}{|l|}{ Electroless } & & \\
\hline Ni plating: $<140^{\circ} \mathrm{F}$ & Cotton/SS or PP & & \\
\hline Ni plating: $>140^{\circ} \mathrm{F}$ & PP/RPP, cotton /SS & & \\
\hline $\mathrm{Cu}:<140^{\circ} \mathrm{F}$ & $\mathrm{PP} / \mathrm{PP}$ & & \\
\hline $\mathrm{Cu}:>140^{\circ} \mathrm{F}$ & $\mathrm{PP} / \mathrm{RPP}$ & & \\
\hline \multicolumn{2}{|l|}{ Acids } & & \\
\hline Acetic: dilute & Cotton/SS, PP/PP & & \\
\hline Acetic: concentrated & PP or Dynel/PP & & \\
\hline Boric & Cotton/SS, PP/PP & & \\
\hline \multicolumn{2}{|l|}{ Chromic, hydrochloric, nitric, } & & \\
\hline phosphoric, sulfuric & PP or Dynel/PP, porous stone ${ }^{b}$ & & \\
\hline Hydrofluoric, fluoboric & PP or Dynel/PP & & \\
\hline \multicolumn{2}{|l|}{ Alkalies } & & \\
\hline $\mathrm{NaOH}$ or $\mathrm{KOH}$ & $\mathrm{PP} / \mathrm{PP}$ & & \\
\hline $\mathrm{NH}_{4} \mathrm{OH}$ : dilute & Cotton SS, PP/PP & & \\
\hline $\mathrm{NH}_{4} \mathrm{OH}$ : concentrated & PP or Dynel/PP & & \\
\hline Misc. ChemicalsBiological solutions & Cotton/SS, PP/PP, porous stone ${ }^{b}$ & & \\
\hline Electropolishing solutions & Porous stone, PP/PP & & \\
\hline Pharmaceutical solutions & Cotton/SS, PP/PP, porous stone & & \\
\hline Photographic solutions & Cotton/SS, PP/PP & & \\
\hline Radioactive solutions & Cotton/SS, porous stone ${ }^{b}$ & & \\
\hline Ultrasonic cleaning solutions & Cotton special B compound/SS & & \\
\hline Nickel acetate $\left(190^{\circ} \mathrm{F}\right)$ & Cotton/SS & & \\
\hline Food products & Cotton/SS, PP/PP & & \\
\hline \multicolumn{2}{|l|}{ Organic Liquids } & & \\
\hline $\mathrm{CCl}_{4}$ & Cotton/steel or SS & & \\
\hline Dichloroethylene & Cotton/steel or SS & & \\
\hline Hydraulic fluids & Cotton/steel or SS & & \\
\hline Lacquers & Cotton/steel or SS & & \\
\hline Per- and trichloroethylene & Cotton/steel or SS & & \\
\hline Solvents & Cotton/steel or SS & & \\
\hline \multicolumn{2}{|l|}{ Petroleum Products } & & \\
\hline \multicolumn{2}{|l|}{ Fuel oil, diesel, kerosene, } & & \\
\hline When operated as high-speed & ${ }^{b}$ Porous stone is recommended for all & & \\
\hline baths at high temperatures & acids except hydrofluoric and fluoboric. & & \\
\hline $\begin{array}{l}\left(>140^{\circ} \mathrm{F}\right) \text { or with high alkali } \\
\text { content, use PP or Dynel/PP. }\end{array}$ & & & \\
\hline
\end{tabular}




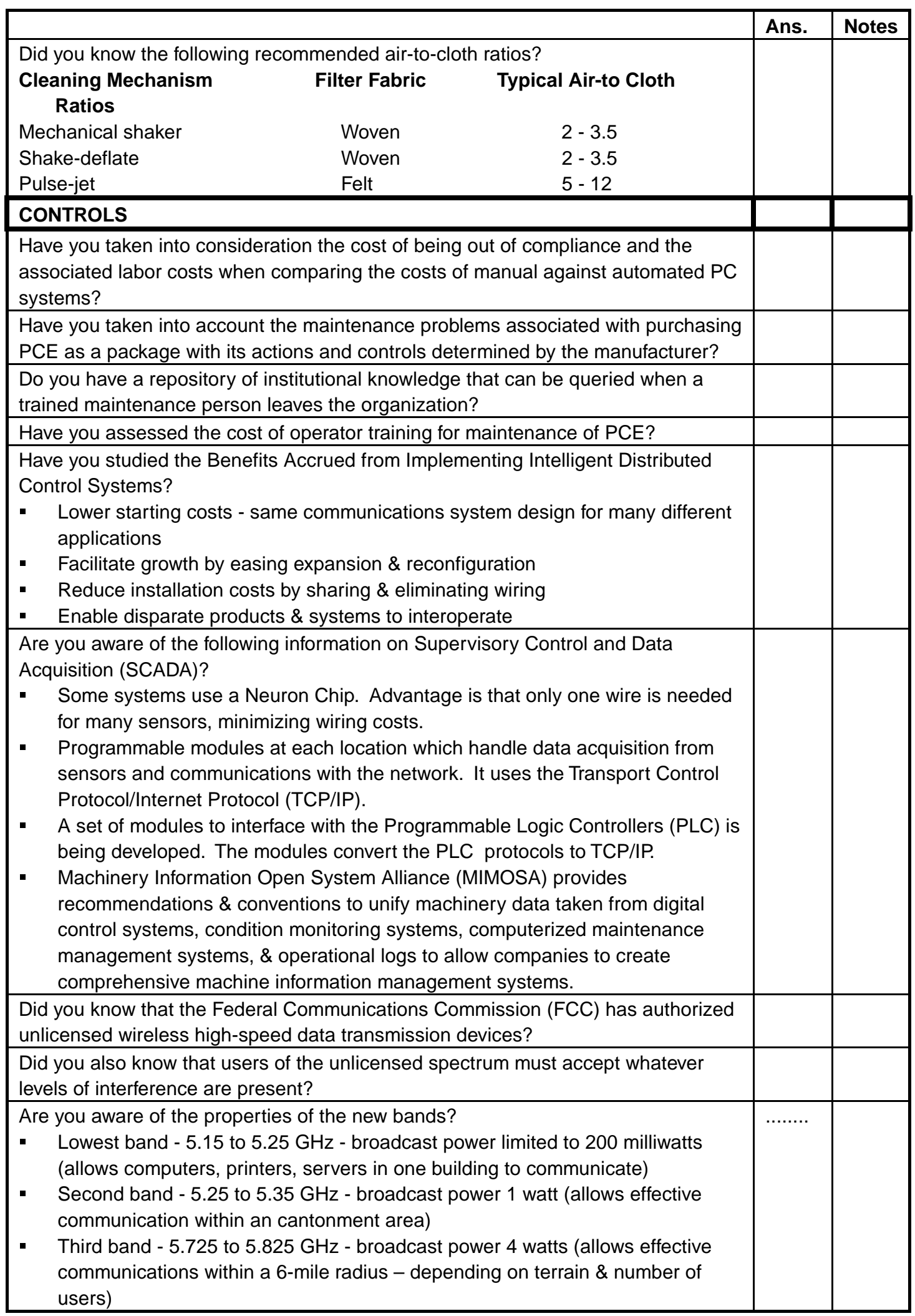




\begin{tabular}{|c|c|c|}
\hline & Ans. & Notes \\
\hline $\begin{array}{l}\text { Are you aware of the reduction of costs in centralized control type of installation? } \\
\text { - } \quad \text { Reduced operator training time } \\
\text { - } \quad \text { More active control strategy can be usedlf central control is not propriety, } \\
\text { installation does not have to sole source purchase } \\
\text { - } \quad \text { Additional sensors can be installed to monitor health of equipment }\end{array}$ & & \\
\hline \multicolumn{3}{|l|}{ MOTORS } \\
\hline \multicolumn{3}{|l|}{$\begin{array}{l}\text { Do most of your general-purpose, three-phase, squirrel-cage induction motors in } \\
\text { the range of } 1 \text { to } 200 \text { horsepower meet the minimum efficiency standards as } \\
\text { required by the Energy Policy Act of } 1992 \text { (EPACT)? }\end{array}$} \\
\hline $\begin{array}{l}\text { Did you know that the following motors are not convered by EPACT? } \\
\text { - } \quad \text { Most non-NEMA design motors } \\
\text { - } \quad \text { Definite-purpose \& special-purpose motors } \\
\text { - } \quad \text { NEMA Design C \& D motors } \\
\text { - } \quad \text { Multi-speed motors } \\
\text { - } \quad \text { Rebuilt or repaired motors }\end{array}$ & $\ldots \ldots$ & \\
\hline $\begin{array}{l}\text { Are you familiar with the types of enclosures that ensure successful motor } \\
\text { operation? } \\
\text { - } \quad \text { Dipproof Enclosure - provides minimal protection from the elements } \\
\text { - } \quad \text { Totally Enclosed Fan Cooled Enclosure - totally encloses machine \& provides } \\
\text { external cooling air } \\
\text { - Explosion-Proof Enclosure - designed \& constructed to withstand an explosion } \\
\text { of a specified gas or vapor in accordance with National Electrical Code for } \\
\text { Class I Hazardous Locations (ANSI/NFPA 70) } \\
\text { Dust-Ignition-Proof Enclosure - designed \& constructed to keep out ignitable } \\
\text { amounts of dust which might affect performance or ratings, \& not permit arcs, } \\
\text { sparks or heat to occur inside the enclosure. }\end{array}$ & $\ldots \ldots$ & \\
\hline \multicolumn{3}{|l|}{$\begin{array}{l}\text { Did you know that to select the appropriate motor, identify the temperature \& air } \\
\text { quality which the motor is likely to experience? (For altitudes below } 3300 \mathrm{ft} \text {, the } \\
\text { standard ambient temperature rating is } 40^{\circ} \mathrm{C} \text {.) }\end{array}$} \\
\hline \multicolumn{3}{|l|}{ Did you know that to prolong life of the motor, keep it clean \& dry? } \\
\hline $\begin{array}{l}\text { Did you know the following facts about energy-efficient motors? } \\
\text { - } \quad \text { Improved electrical steel, reduced lamination thickness, longer core stack for } \\
\text { reducing iron power losses } \\
\text { - } \quad \text { Larger effective rotor \& stator slot sizes for reduced conducting losses } \\
\text { - } \quad \text { Larger air-gaps for reducing stray load losses } \\
\text { - } \quad \text { Smaller cooling fans for reduced windage losses }\end{array}$ & & \\
\hline $\begin{array}{l}\text { Have you considered the following important factors to consider in motor retrofit? } \\
\text { - Rotational Speed - retrofitting a motor with one of higher efficiency will } \\
\text { increase motor efficiency but may waste a significant amount of energy from } \\
\text { mechanical throttling } \\
\text { - Starting Current - prior to installation, it is difficult to predict whether starting } \\
\text { current will create a problem, but is a recognized phenomenon that can affect } \\
\text { the economics of the retrofit } \\
\text { - Power Factor \& Torque - a replacement motor should be chosen with power } \\
\text { factor equal to or greater than the existing motor. }\end{array}$ & & \\
\hline
\end{tabular}


Do you know the following information regarding Power Source Variations?

- Low Voltage Levels - know what terminal voltage the motor is likely to encounter to avoid the problem of a motor being unable to deliver the required horse power to meet load demands

- Reduced Voltage Starters - these can be beneficial for locations that have a high power source impedance and are sensitive to low voltage levels

- High Voltage Levels - high voltages cause the motor to develop higher torque than anticipated, sometimes resulting in motor overload. To guard against this, lower the trip level on the overload current relays.

- Voltage Unbalance - the unbalance should be less than 1 percent. If the unbalance is determined to be higher than this, the motor may have to be derated (according to NEMA's MG1 derating curve)

Do you know the following facts about Motor Sizing?

- Torque \& Horsepower Requirements - to select an appropriate motor, identify the torque \& horsepower requirements of the driven equipment (generalpurpose motors must meet certain torque levels in accordance with NEMA MG1-12.38-12.40)

- Continuous Rating - defines the load that can be carried for an idefinitely long period. A motor that is operated above any service factor greater than 1 will have a reduced life expectancy.

- Short-Time Rating - refers to a motor designed to stay below rated nameplate temperature when operated at rated load for periods below the short-time rating.

Did you realize how important is the provision of proper motor mounting base?

(The correct provision of the mounting base can prevent motor vibration and misalignment.)

Why must the operating temperature of a motor be limited?

1. Lubricants \& insulations deterirate chemically at a rate that doubles for each 8 to $12{ }^{\circ} \mathrm{C}$ increase in temperature.

2. Iron, copper, aluminum \& other materials have different thermal expansion rates which give rise to mechanical stresses that cause progressive deterioration.

3. The resistivity of copper \& aluminum varies linearly with temperature.

Are you aware of Bearing Life Prediction Values?

1. $\mathrm{L}_{10}$ or $\mathrm{B}-10 \mathrm{Life}$ - bearing minimum of 1 or 2 years for continuous operation is common.

2. Average Life - this is the average time before failure for each bearing in the statistical group. (Average life is taken as 5 times the minimum life. $A n L_{10}$ life of 1 or 2 years corresponds to an average life of 5 or 10 years, respectively.)

Do you have information on Prolonging Insulation Life?

- Keep the motor clean \& dry

- Keep motor within temperature ratings during operations

- Keep motor protected from electrical \& mechanical distrubances

- Select the proper motor size \& design for the environment \& expected loading conditions

- Choose appropriate motor protective circuitry

- Use the proper mechanical transmission system 


\begin{tabular}{|c|c|c|}
\hline & Ans. & Notes \\
\hline SENSORS & & \\
\hline $\begin{array}{l}\text { Do you know some of the advantages of MST? } \\
\text { - } \quad \text { Minimize effects on measured variables } \\
\text { - } \quad \text { Rapid response time } \\
\text { - } \quad \text { Individand high surface temperatures } \\
\text { - } \quad \text { Measures both heat flux and temperature } \\
\text { - } \quad \text { Sensitive to conduction, convection, and radiation } \\
\text { - } \quad \text { Low electrical noise }\end{array}$ & & \\
\hline $\begin{array}{l}\text { Facts about Fiber Optic Sensors: } \\
\text { - } \quad \text { Fiber optic sensors - real-time, in-situ environmental monitoring of pollutants } \\
\text { - } \quad \text { without sample collection } \\
\text { - } \quad \text { High bandwidth } \\
\text { - } \quad \text { Small size } \\
\text { - } \quad \text { Light weight } \\
\text { - } \quad \text { Corrosion resistance } \\
\text { - } \quad \text { Inherent immunity to electromagnetic interference (EMI) } \\
\text { - } \quad \text { Suited for monitoring, measuring, and characterizing chemicals and } \\
\text { - } \quad \text { conditions in remote environments } \\
\text { - } \quad \text { Monitor in-situ volatile and difficult to sample contaminants in groundwater }\end{array}$ & & \\
\hline$\bullet$ & & \\
\hline $\begin{array}{l}\text { Facts about Optic Infrared Sensors } \\
\text { - Remote sensing applications } \\
\text { - } \quad \text { Fast response } \\
\text { - Used on difficult to reach targets } \\
\text { - Small spots } \\
\text { - } \quad \text { Particularly valuable in high energy fields, in environments with high humidity } \\
\text { - Choice of fiber dictates the spectral ranges over which the sensor operates } \\
\text { effectively }\end{array}$ & & \\
\hline
\end{tabular}


Gas chromatography systems are available commercially and one system

incorporates the following attributes:

- $\quad$ Full electronic control of all system parameters (eliminating manual pneumatic pressure regulators and mass flow controllers)

- All system gases are controlled under electronic pressure/pneumatic control (EPC)

- $\quad$ The carrier gas is programmable from 0 to 80 psi

- $\quad$ Ramp rates are as high as 99 psi per minute

- An insulated column oven, measuring 7.25 in. x 7.25 in. x 2.5 in., equipped with a new design, high-output heating element, allows temperatureprogramming from ambient to $400{ }^{\circ} \mathrm{C}$, at ramp rates up to $40^{\circ} \mathrm{C}$ per minute

- An oven circulation system eliminates any temperature gradients in the column oven

- A cooling system cools the oven from $250{ }^{\circ} \mathrm{C}$ to ambient temperature in 5 minutes or less, allowing rapid recycle

- Units weigh from 40 to $60 \mathrm{lb}$ depending on the configuration of the GC

- $\quad$ LED display panel that shows status of all controlled zones in the GC system

- $\quad$ Equipped with a built-in 4-channel serially-interfaced IBM-PC compatible data system

- $\quad$ Price of this sensor is $\$ 4,495$ (US)

- For information on this and other GC sensors, access the web site at http://www.srigc.com.

Some applications for water level sensors include:

- Groundwater monitoring

- $\quad$ Surface water monitoring

- Sewer flow monitoring

- Stormwater studies

- $\quad$ River and stream flow monitoring

- Infiltration/inflow studies

- $\quad$ Pump tests.

Mass spectrometry is able to:

- Analyze of ethylene furnace gas

- Continuous multi-point monitoring of VOCs

- Monitor of vinyl chloride monomer (VCM) and dichlorethane (EDC)

- Monitor chloroform, MIBK, toluene, and acetone in ambient air and stacks.

- Measures combustion gases (carbon dioxide, carbon monoxide and nitrogen oxides) while simultaneously monitors unburned fuel compounds (benzene, toluenes, zylenes, naphthalenes)

When selecting a transducer designed for vibration monitoring of ground-based turbines look for these attributes:

- High accuracy and sensitivity

- Reliable performance from -65 to $+700^{\circ} \mathrm{F}$

- Omni-directional mounting

- Low impedance

- $\quad$ Noise free

- High output signal of $135 \mathrm{mV} / \mathrm{in}$./sec. provided from very low frequency $(15 \mathrm{~Hz})$ and low drive $(0.1 \mathrm{ips}$ and below) to high frequency $(2000 \mathrm{~Hz})$ and high drive levels (70 mils). 


\section{CERL DISTRIBUTION}

Chief of Engineers

ATTN: CEHEC-IM-LH (2)

ATTN: CEHEC-IM-LP (2)

ATTN: CECC-R

ATTN: CERD-L

ATTN: CERD-M

HQ Industrial Operations Command

Rock Island Arsenal, IL (2)

Defense Tech Info Center 22304

ATTN: DTIC-O (2) 